Inert Electrodes Program

\title{
Final Report on the PNL Program to Develop an Alumina Sensor
}

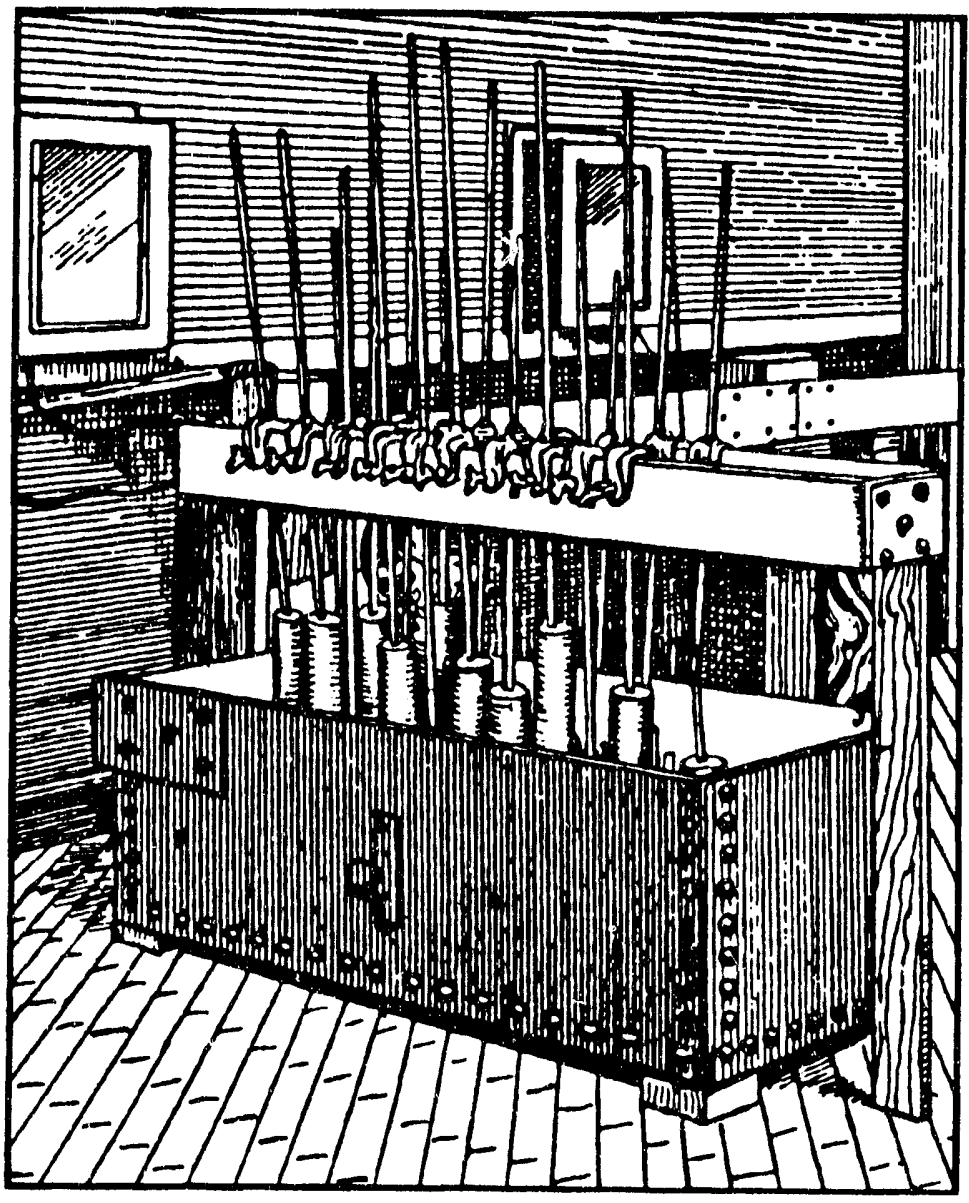

October 1992

Work Supported by the U.S. Department of Energy under Contract DE-AC06-76RLO 1830

Pacific Northwest Laboratory

Operated for the U.S. Department of Energy

by Battelle Memorial Institute 


\title{
DISCLAIMER
}

This report was prepared as an account of work sponsored by an agency of the United States Government. Neither the United States Government nor any agency thereof, nor Battelle Memorial Institute, nor any of their employees, makes any warranty, expressed or implied, or assumes any legal liability or responsibility for the accuracy, completeness, or usefulness of any information, apparatus, product, or process disclosed, or represents that its use would not infringe privately owned rights. Reference herein to any specific commercial product, process, or service by tracie name, trademark, manufacturer, or otherwise does not necessarily constitute or imply its endorsement, recommendation, or favoring by the United States Government or any agency thereof, or Battelle Memorial Institute. The views and opinions of authors expressed herein do not necessarily state or reflect those of the United States Government or any agency thereof.

\author{
PACIFIC NORTHWEST LABORATORY \\ operated by \\ BATTELLE MEMORIAL INSTITUTE \\ for the \\ UNITED STATES DEPARTMENT OF ENERGY \\ under Contract DE-AC06-76RLO 1830
}

Printed in the United States of America

Available to DOE and DOE contractors from the

Office of Scientific and Technical Information, P.O. Box 62, Oak Ridge, TN 37831, prices available from (615) 576-8401. FTS 62.6-8401.

Available to the public from the National Technical Information Service,

U.S. Department of Commerce, 5285 Port Royal Rd., Springfield, VA 22161. 
Sensors Development Program

FINAL REPORT ON THE PNL PROGRAM TO DEVELOP AN ALUMINA SENSOR

C. F. Windisch Jr.

B. B. Brenden

O. H. Koski

R. E. Williford

October 1992

Prepared for

The U.S. Department of Energy

under Contract DE-AC06-76RLO 1830

Pacific Northwest Laboratory

Richland, WA 99352

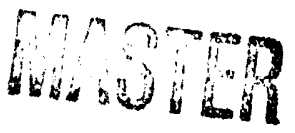




\section{Acknowledgments}

The authors wish to acknowledge the contributions of N. C. Davis, L. G. Morgan, N. D. Stice, and D. M. Strachan, Pacific Northwest Laboratory (PNL); the assistance with signal analysis by C. L. Nikias, University of Southern California, Los Angeles, California; the editorial review by $\mathrm{D}$. K. Hilliard; and the programmatic support provided by $\mathrm{M}$. J. McMonigle and the Office of Industrial Processes (OIP), U.S. Department of Energy (DOE), Washington, D.C., and the DOE Richland Field Office. The author is also grateful to the personnel at Reynolds Metals Company, Sheffield, Alabama, who assisted in performing the prototype anode test in March 1989 and the pilot cell test in August 1991. 


\section{Summary}

An alumina conceritration sensor was required to ensure safe operating conditions for cermet inert anodes that were under development at the Pacific Northwest Laboratory (PNL) ${ }^{(\mathbf{a})}$ for the electrolytic production of aluminum metal. The Sensors Development Program at PNL was conducted in response to this need for an alumina sensor. In all, eight different approaches to developing an alumina sensor were evaluated as part of this program. Each approach sought to correlate alumina concentration either to some spectral, physical, or electrical property of the molten electrolytic, or alternatively, to some operational characteristic of the reduction cell such as the integrity of the cermet anodes or the electrical noise generated by them during cell operation. The studies on electrical noise were performed using a large number of digital signal analysis (DSA) methods.

There were two primary requirements for success for an alumina sensor to be used in conjunction with cermet anodes: 1) adequate sensitivity to alumina concentration at concentrations close to saturation, and 2) ease of use in an industrial setting. After numerous laboratory experiments as well as field studies in some cases, it was concluded that none of the approaches sufficiently satisfied the two criteria to serve as the basis for an alumina sensor. If further work is to continue in this area, it is recommended that the research focus on alternative DSA approaches, primarily because DSA methods would be so easy to use in an industrial environment. Due to the lack of correlation using DS $;$ in the present work, however, it is recommended that alternative strategies for data collection and analysis be used in any further development activities.

(a) Operated for the U.S. Department of Energy by Battelle Memorial Institute under Contract DE-AC06-76RLO 1830. 


\section{Contents}

Acknowledgments $\ldots \ldots \ldots \ldots \ldots \ldots \ldots \ldots \ldots \ldots \ldots \ldots \ldots$ iii

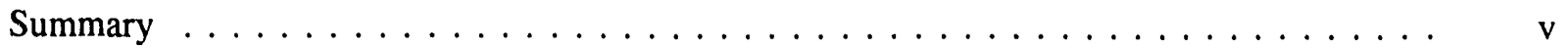

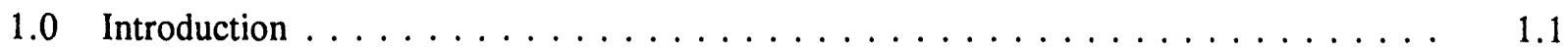

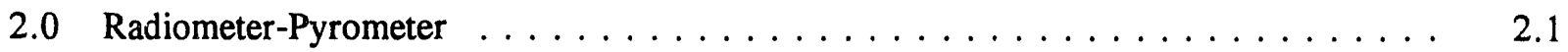

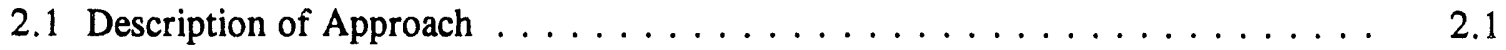

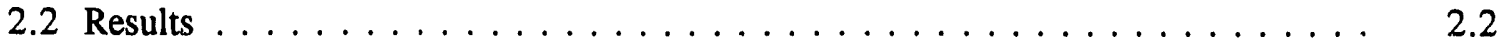

2.3 Summary of Conclusions $\ldots \ldots \ldots \ldots \ldots \ldots \ldots \ldots$

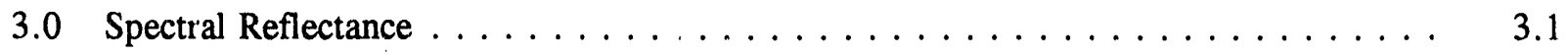

3.1 Description of Approach $\ldots \ldots \ldots \ldots \ldots \ldots \ldots \ldots \ldots \ldots \ldots \ldots$

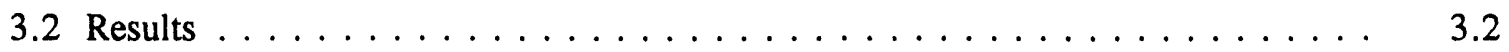

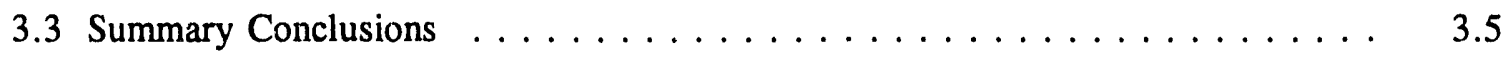

4.0 Infrared Imaging $\ldots \ldots \ldots \ldots \ldots \ldots \ldots \ldots \ldots \ldots \ldots \ldots \ldots \ldots \ldots$

4.1 Description of Approach $\ldots \ldots \ldots \ldots \ldots \ldots \ldots \ldots \ldots \ldots \ldots \ldots$

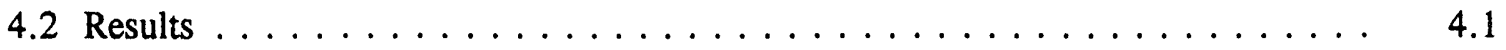

4.3 Summary of Conclusions $\ldots \ldots \ldots \ldots \ldots \ldots \ldots \ldots \ldots$

5.0 Bath Vapor Analysis $\ldots \ldots \ldots \ldots \ldots \ldots \ldots \ldots \ldots \ldots \ldots \ldots \ldots \ldots \ldots$

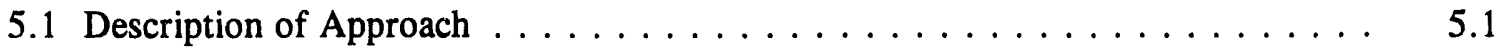

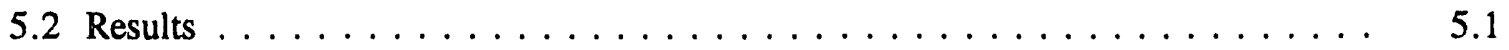

5.3 Summary of Conclusions $\ldots \ldots \ldots \ldots \ldots \ldots \ldots \ldots \ldots \ldots$

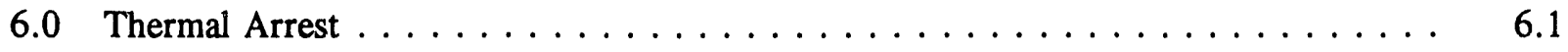

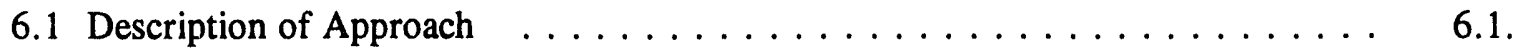

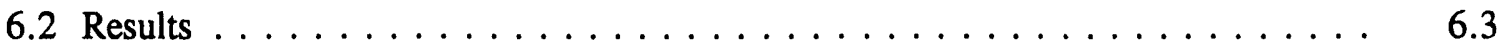


6.3 Summary of Conclusions $\ldots \ldots \ldots \ldots \ldots \ldots$

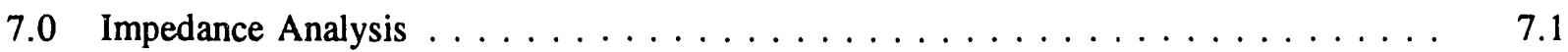

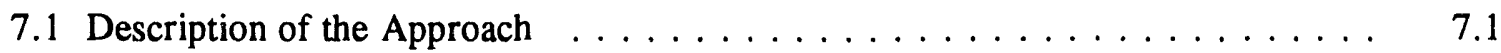

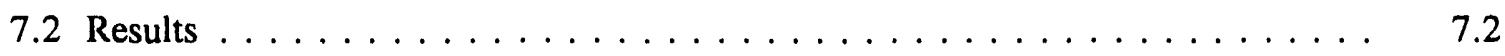

7.3 Summary of Conclusions $\ldots \ldots \ldots \ldots \ldots \ldots \ldots$

8.0 Reference Anode $\ldots \ldots \ldots \ldots \ldots \ldots \ldots \ldots \ldots \ldots \ldots \ldots \ldots$

8.1 Description of the Approach $\ldots \ldots \ldots \ldots \ldots \ldots \ldots \ldots \ldots \ldots \ldots$

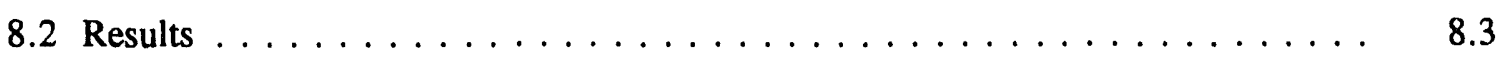

8.3 Summary of Conclusions $\ldots \ldots \ldots \ldots \ldots \ldots \ldots \ldots$

9.0 Digital Signal Analysis $(\mathrm{DSA}) \quad \ldots \ldots \ldots \ldots \ldots \ldots \ldots \ldots \ldots \ldots$

9.1 Description of the Approach $\ldots \ldots \ldots \ldots \ldots \ldots \ldots \ldots \ldots \ldots$

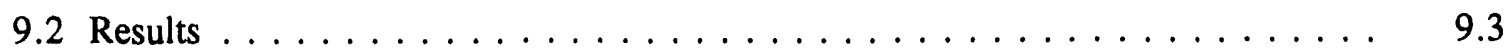

9.3 Summary of Conclusions $\ldots \ldots \ldots \ldots \ldots \ldots \ldots$

10.0 Conclusions and Recommendations $\ldots \ldots \ldots \ldots \ldots \ldots \ldots$

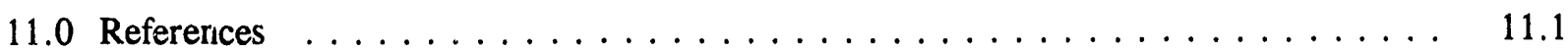




\section{Figures}

1.1 Plot of Bath Resistance Versus Alumina Concentration for a Typical

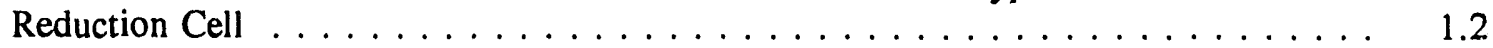

2.1 Radiometer-Pyrometer Method for Detecting Formation of Solid Film . . . . . . . 2.2

2.2 Liquidus-Temperature Measurement Device Concept $\ldots \ldots \ldots \ldots \ldots \ldots$

2.3 Block Diagram of Liquidus Temperature Measurement System $\ldots \ldots \ldots \ldots \ldots$

2.4 Comparison of Spectral Radiance of Cryolite with Radiance of a

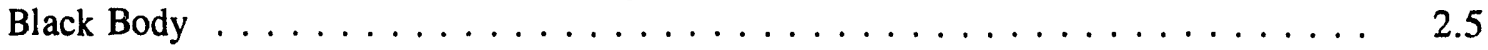

2.5 Typical Strip Chart Recording Using Radiometer-Pyrometer . . . . . . . . . . 2.6

2.6 Effect of Alumina Concentration on Specular-to-Diffuse Reflectance

Transition Temperature . . . . . . . . . . . . . . . . . . . . . 2.7

2.7 Temperature of Specular-to-Diffuse Reflectance Transition as a Function

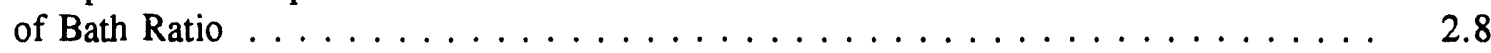

3.1 Experimental Arrangement for Tests Using a Spectral Radiometer . . . . . . . . . 3.1

3.2 Spectral Radiance Distribution of a Clean Cryolite Melt Surface

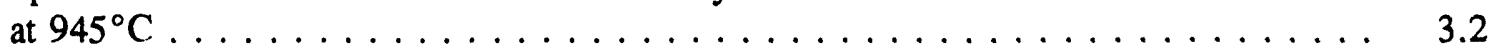

3.3 Energy Spectrum of $942^{\circ} \mathrm{C}$ Melt Surface Viewed Through Infrared Blocking Filter (Reference Spectrum) $\ldots \ldots \ldots \ldots \ldots \ldots \ldots$

3.4 Energy Spectrum of $927^{\circ} \mathrm{C}$ Solid Film Over Cryolite Viewed Through Infrared Blocking Filter (Test Spectrum) $\ldots \ldots \ldots \ldots \ldots \ldots \ldots . \ldots \ldots$

3.5 Ratio of Spectra: Test Spectrum/Reference Spectrum $\ldots \ldots \ldots \ldots \ldots \ldots$

4.1 Infrared Images of Cryolite Surface $\ldots \ldots \ldots \ldots \ldots \ldots \ldots \ldots \ldots \ldots \ldots \ldots$

5.1 Non-Specular Reflectance Spectra for Vapors Deposited from Baths with

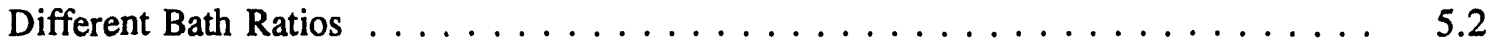

5.2 Summary of Reflectance Data for Vapor Deposits $\ldots \ldots \ldots \ldots \ldots \ldots$

5.3 Relative Reflectance of Vapor Deposits as a Function of Alumina Concentration in the Bath $\ldots \ldots \ldots \ldots \ldots \ldots \ldots \ldots \ldots \ldots$

5.4 Summary of Reflectance Data for Vapor Deposits Obtained Using a Chimney . . . . . . . . . . . . . . . . . . . . . 
6.1 Portable Contact System for Measuring the Liquidus Temperature of Cryolite

6.2 Photograph of Thermal Arrest Device Ready for Use $\ldots \ldots \ldots \ldots . \ldots \ldots$

6.3 Schematic Showing Dip Cup Immersed in Cryolite Bath $\ldots \ldots \ldots \ldots . \ldots$

7.1 Impedance Versus Current Density with Percent Alumina Saturation

Dependence . . . . . . . . . . . . . . . . . . . . . . 7.3

7.2 Reproducibility of Anode Impedance for $80 \%$ and $100 \%$ Alumina Saturation $\ldots \ldots 7.4$

8.1 Schematic Illustrating Principles of Reference Anode $\ldots \ldots \ldots \ldots \ldots$

8.2 Schematic of Simple Process Control Sensor Used to Monitor an Anode $\ldots \ldots \ldots .2$

8.3 Corrosion of Reference Anode $\ldots \ldots \ldots \ldots \ldots \ldots \ldots \ldots$

9.1 Schematic Illustrating Principles of DSA Approach to an Alumina Sensor $\ldots \ldots$. . . 9.2

9.2 Plot of Conductance, L, by Cross-Correlation, Versus Weight Percent

Alumina at Various Current Densities . . . . . . . . . . . . . . . 9.6

9.3 Plot of Conductance, L, by Cross-Correlation, Versus Weight Percent

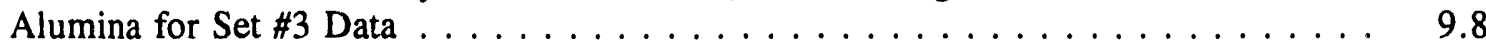

9.4 Typical Current and Voltage-Versus-Time Plots for the Pilot Cell Test $\ldots \ldots \ldots$

9.5 Comparison of Conductance, $\mathrm{L}$, and Alumina Concentration as a Function

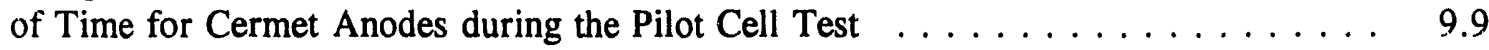

9.6 Variation in Current Though Cermet Anodes during the Pilot Cell Test . . . . . . . 9.10

9.7 Phase Space Plots for Data from the Pilot Cell Test at Various Alumina Concentrations (\% Saturation): a) $85 \%$, b) $76 \%$, c) $48 \%$, and d) $23 \% \ldots \ldots \ldots . . .13$

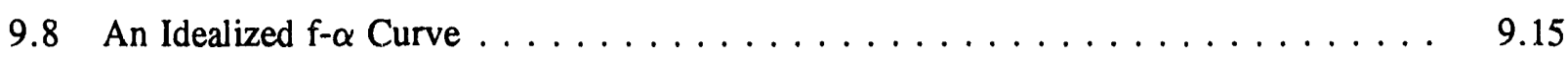

$9.9 \alpha_{\max } / \alpha_{\min }$ Ratios Versus Alumina Concentration for the Pilot Cell Test. . . . . . 9.16 


\section{Tables}

1.1 Criteria for Developing an Alumina Sensor $\ldots \ldots \ldots \ldots \ldots \ldots \ldots$

1.2 History of PNL Alumina Sensor Development $\ldots \ldots \ldots \ldots \ldots \ldots \ldots$

6.1 Data from Thermal Arrest Studies Using Laboratory Cells . . . . . . . . . . . . . . 6.4

6.2 Summary of Measurements for Second Field Test of the Thermal

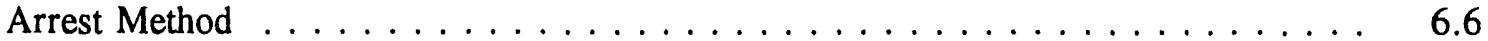




\subsection{Introduction}

The Sensors Development Program was conducted at the Pacific Northwest Laboratory (PNL) for the U. S. Department of Energy (DOE), Office of Industrial Processes (OIP). The work was performed from FY 1986 through FY 1992 in conjunction with the Inert Electrodes Program. The overall objectives of the Sensors Development Program were to 1) investigate and develop methods of process monitoring/control for operating electrolytic cells for aluminum production and 2) determine safe operating conditions for cermet anodes. ${ }^{\text {(a) }}$

One of the most important process control parameters for cermet anodes is alumina concentration (Weyand et al. 1986). In previous work at PNL (Windisch et al. 1991), it was shown that alumina concentration must be maintained at or very near saturation in the molten salt electrolyte to keep corrosion/dissolution of the anodes at acceptably low levels. To achieve these conditions in commercial cells, however, a technique for measuring alumina concentration is needed that works well at concentrations near alumina saturation and is easily adapted to the industrial environment. Without a technique to monitor alumina reliably and expeditiously, good performance from cermet anodes would be difficult to realize. The cermet anodes will be strongly influenced by variations in operating conditions, especially alumina concentration. Although these variations can probably never be completely eliminated during normal plant operation, they could be precisely detected and expeditiously corrected if a technique were available for accurate and frequent measurement of alumina concentration. Unfortunately, no known method satisfactorily meets the criteri 1 of accuracy near alumina saturation and ease of use in an industrial environment. For example, a well-established method for measuring alumina in existing Hall-Heroult cells uses measurements of bath resistance (Bonny et al. 1984). The bath resistance measurements are related to alumina concentration through a calibration curve like that shown in Figure 1.1. This approach works well in existing cells which use carbon anodes because these cells are normally operated at alumina concentraticns well below saturation, e.g., at 1 to $3.5 \mathrm{wt} \%$ (Bonny et al. 1984) compared to saturation values of 7 to $8 \%$ for typical electrolyte compositions and temperatures. The resistance of molten cryolite changes dri matically below $3 \mathrm{wt} \%$ as shown in Figure 1.1. Consequently, resistance measurements can be usc $f$ to control alumina concentration accurately near this concentration. At higher concentration, e.g., near saturation, the resistance-versus-alumina concentration curve "flattens out," making a good measurement of alumina concentration difficult. Under these conditions, the uncertainties in resistances are similar in magnitude to the actual variations as a function of concentration, i.e., the signal-to-noise ratio deteriorates to unacceptable levels for industrial applications.

Since the measurement of alumina concentration was considered so important for the successful use of cermet anodes and since a satisfactory technique for performing these measurements was not available, research in the Sensors Development Program was primarily focused on developing a

(a) Cermet arodes were investigated at PNL as nonconsumable alternatives to carbon anodes for the electrolytic production of aluminum metal. This work was performed under the Inert Electrodes Program and is discussed in numerous references, e.g., Windisch et al. (1991). 


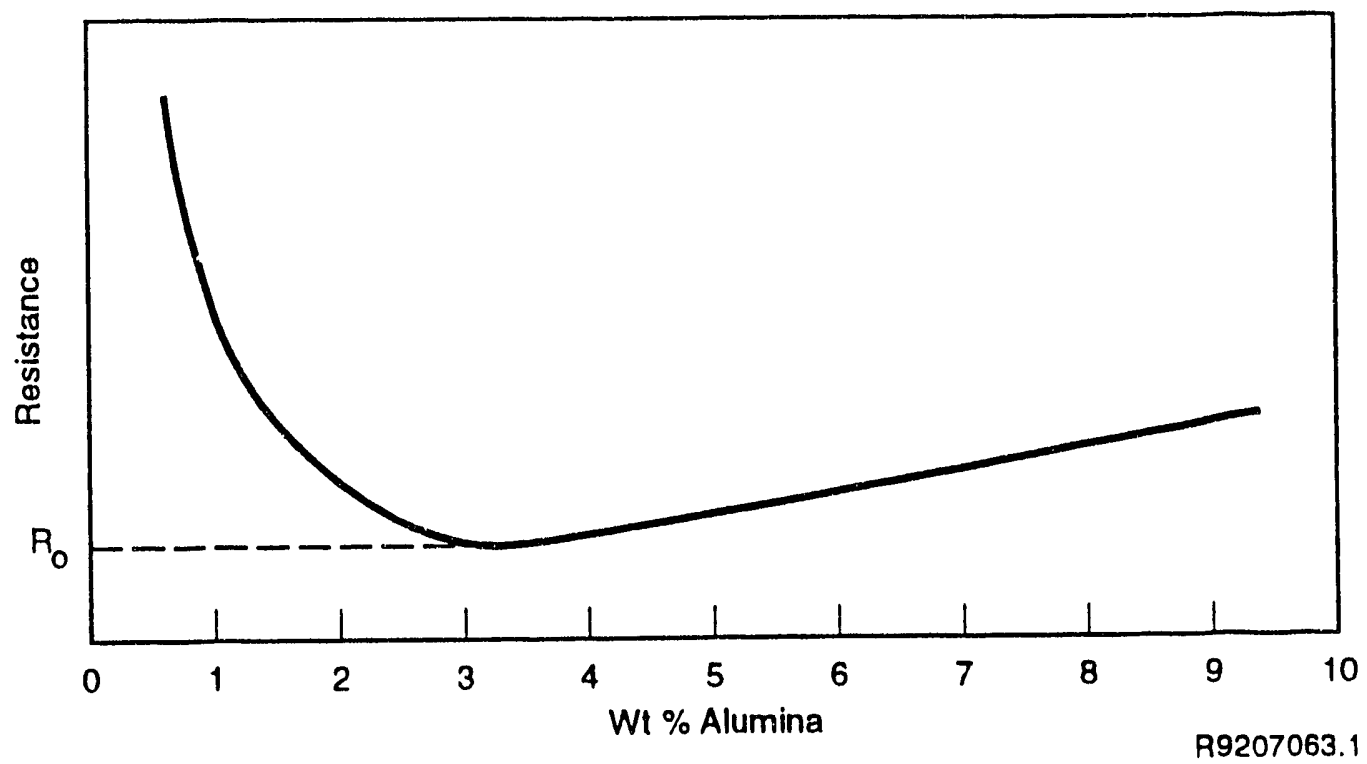

Figure 1.1. Plot of Bath Resistance Versus Alumina Concentration for a Typical Reduction Cell

sensor for alumina concentration. New methods for measuring other electrolyte characteristics, such as bath ratio (weight ratio of $\mathrm{NaF}_{\mathrm{F}}$ to $\mathrm{AlF}_{3}$ ) and conductivity, were also studied as part of this program. However, these studies played a minor part in the Sensors Development Program and, in most instances, were performed to support the alumina sensor studies, for example in understanding how variations in these other properties affected the sensitivity of the measurements to alumina concentration.

The basic idea in developing an alumina sensor is to find some easily measured property or parameter which is influenced significantly, consistently, and reproducibly by alumina concentration:

$$
\text { Parameter }=\mathrm{f} \text { (Alumina Concentration) }
$$

The first step in developing a sensor is to hypothesize various parameters that might show sensitivity based on results reported in the literature (or on common experience) and to perform preliminary testing of these parameters in a limited set of laboratory experiments over a wide range of alumina concentrations. For example, if it were hypothesized that the molten salt behaved like a grey body, exhibiting an emission spectrum that depended on composition, it might be proposed that the intensity of the light emitted at one frequency, or the power density of the entire radiation field, would depend on alumina concentration. Preliminary testing would involve measuring spectra of the light emitted from cells with a few, widely different alumina concentrations. If some sensitivity were demonstrated, then more carefui sensitivity studies would be performed to make sure the approach gave adequate correlations at concentrations near alumina saturation. If the sensitivity appeared acceptable, calibration curves relating the parameter to alumina concentration would be obtained. Sensitivity and, in particular, calibration curve development, also would involve checking sensitivity to other cell operating parameters such as current density and the concentrations of other bath components. The 
sensitivity of the parameter to alumina concentration may, after all, be affected by other cell operating conditions. Estimated uncertainties also would be determined for the parameters where appropriate. If the technique demonstrated adequate sensitivity in the laboratory, as evidenced by a useful calibration curve, or if there were significant improvements to sensitivity expected in scaling up the approach, then the approach would be tested in an actual commercial cell or a pilot-scale facility. The scale-up testing would be performed to evaluate the effects of scale-up on sensitivity and to determine the ease of using the technique in an industrial setting. A summary of the steps and criteria for developing an alumina sensor is given in Table 1.1.

Table 1.1. Criteria for Developing an Alumina Sensor

$\left.\begin{array}{l}\text { Steps to Development } \\ \hline \text { Hypothesize Parameter } \\ \text { Preliminary Screening } \\ \text { Sensitivity Studies } \\ \text { Calibration Curves } \\ \text { Experimental Uncertainties } \\ \text { Effects of Other Cell } \\ \quad \text { Parameters } \\ \text { Field Test }\end{array}\right\}$

Criteria for Successful Sensor

\author{
Sensitivity to Alumina at \\ Concentrations Near Saturation \\ Positive Effects of Scale-up and \\ Ease of Use
}

As shown in Table 1.1, there are two primary criteria for a successful alumina sensor: 1) adequate sensitivity to alumina concentration at concentrations close to saturation, and 2) ease of use in an industrial setting. These criteria were emphasized throughout the development project and in this report, and weighing the importance of each of them with the degree of success or failure of the experiments became the major undertaking in this work. Failure to meet one or both of these criteria to the satisfaction of the researchers or appropriate representatives from industry or management personnel was, ultimately, responsible for abandoning most of the approaches investigated in this work. Conversely, in one case, the approach was so successful in satisfying one of the two criteria, i.e., it was very easy to use, that it was not abandoned completely even though it gave no apparent correlation with alumina in the studies reported here.

In all, eight approaches to measuring alumina concentration were studied in PNL laboratories over the seven years of the Sensors Development Program. These approaches are listed in Table 2.1. Also shown in Table 1.2 are the Fiscal Year periods during which each approach was studied, an indication of what stage of development each approach was taken by PNL staff, and a brief summary of the results of the work and an explanation.

As indicated in Table 1.2, all of the methods for measuring alumina concentration that were investigated by PNL were either abandoned or suspended. Approaches that were abandoned appeared to show very little promise for any improvement even with significant further investment of effort. Approaches that were suspended seerned to show some promise, but problems were encountered that 
Table 1.2. History of PNL Alumina Sensor Development

\begin{tabular}{|c|c|c|c|c|}
\hline Approach & $\begin{array}{l}\text { FY of } \\
\text { Study }\end{array}$ & Stage & Result & Explanation \\
\hline Radiometer-Pyrometer & FY86-87 & Lab & Abandoned & Lacked sensitivity \\
\hline Spectral Reflectance & FY86 & Lab & Abandoned & Lacked sensitivity \\
\hline Infrared Imaging & FY86 & Lab & Abandoned & Calibration difficult \\
\hline Bath Vapor Analysis & FY87 & Lab & Abandoned & No correlation \\
\hline Thermal Arrest & FY87 & Field & Abandoned & Too intrusive \\
\hline Impedance Analysis & FY87-89 & Lab & Abandoned & Hysteresis effects \\
\hline Reference Anode & FY88-89 & Field & Abandoned & Materials problems \\
\hline Digital Signal Analysis & FY88-92 & Field & Suspended & No correlation \\
\hline
\end{tabular}

could not be resolved with funds or time left on the program. Three of the eight approaches were taken into the field. All were abandoned except for one: digital signal analysis (DSA). Tht DSA approach was suspended because of lack of any meaningful correlation involving alumina cicentration for any of the data sets collected in either the laboratory or in the field. Despite these failures, however, other considerations make the approach difficult to abandon completely and suggest that improvements in cell design and/or data collection strategies may result in the desired correlations. Moreover, the DSA approach is so easy to adapt to operating cells that systematic and long-term studies on various cells, both commercial and in development for future cermet anode testing, would seem to be in order.

The results of the development studies for all eight of the above techniques were reported, in part, in seven previous PNL documents (Hart et al. 1987; Brenden 1988; Strachan et al. 1988; Windisch et al. 1990; Strachan et al. 1990; Williford and Windisch 1992; Windisch 1992). The purpose of the present report is to summarize these results in one document and to include the results of the studies that, for one reason or another, were not previously reported in entirety. This report covers all studies to develop an alumina sensor for aluminum reduction cells performed under the Sensors Development Program from FY86 through FY92. Since no additional studies are planned by PNL at this time, the report is titled "Final Report on the PNL Program to Develop an Alumina Sensor." In this document, a separate section is devoted to each of the eight techniques that were introduced in Table 2, with each section describing the technique, the results of laboratory and field testing, and the action taken and/or recommendations made as a result. The last part of the report gives some overall observations and recommendations for future work in conjunction with cermet anode development. 


\subsection{Radiometer-Pyrometer}

The liquidus temperature is the maximum temperature at which both solid and liquid phases are present in the cryolite bath. This temperature is strongly affected by both the concentration of alumina and the weight ratio of $\mathrm{NaF}$ to $\mathrm{AlF}_{3}$ (bath ratio) in the bath. Since the bath ratio is comparatively constant, the liquidus temperature should be a function mainly of the alumina concentration. Consequently, the liquidus temperature and various parameters that relate to it, should serve as a good basis for an alumina sensor.

Three types of spectroscopic techniques were studied for determining the liquidus temperature of a cryolite-alumina melt. All of the methods were "non-contact" to eliminate materials/corrosion problems that would be encountered with an intrusive probe. The first approach, which is discussed in this section, is a combination of a radiometer, a pyrometer, and a laser. The second approach, discussed in Section 3.0, is a fast analyzer of spectral energy distribution in the 400 - to $1070-\mathrm{nm}$ range. The third approach, discussed in Section 4.0, is an infrared imager operating in the 8000 - to 14,000 -nm range.

\subsection{Description of Approach}

The radiometer-pyrometer approach uses a combination of a radiometer, a pyrometer, and a laser. In this approach, a portion of the surface of the bath is solidified by applying locally a stream of cool gas. The solidification event is detected by using the combination of laser and radiometer. As soon as solidification occurs, the temperature is measured with the pyrometer.

In an aluminum reduction cell under normal operation, the surface of the molten salt electrolyte is normally hot enough to be free of solids. When locally cooled at the surface, the solids initially form as a thin film in very good thermal contact with the liquid beneath it. With the film on the surface, a pyrometer would measure the temperature of that surface. It was proposed that this measurement would correspond to an accurate value for the liquidus temperature.

The radiometer-pyrometer approach used in this study is illustrated in Figure 2.1. A collimated beam of light from a laser is directed at the surface of the cryolite bath. When the surface is clean and free of a film of solid material, nearly all of the light should be reflected in the specular direction and only a small portion of it will reach the radiometer. There will be essentially no scattered light and the radiometer reading will be low. As the surface of the cryolite is cooled with a jet of cool argon gas, the liquidus temperature is eventually reached and a thin film of solid material will form. Unlike the original liquid surface, this solid material will not have a smooth specular appearance. It will scatter light in all directions as indicated by the oval shown in Figure 2.1. This will generate a high reading on the radiometer. With a high reading, the presence of film is indicated and the pyrometer reading can be taken as the liquidus temperature.

Figure 2.2 shows another design for the radiometer-pyrometer approach. This design incorporates a radiation pyrometer and would probably be easier to use in an industrial setting. The approach uses a radiometer in combination with signal processing electronics which interpret the radiometer signal in terms of temperature. The radiometer output would be sent both to a lock-in amplifier and to the pyrometer electronics. The lock-in amplifier would assist in verifying the 


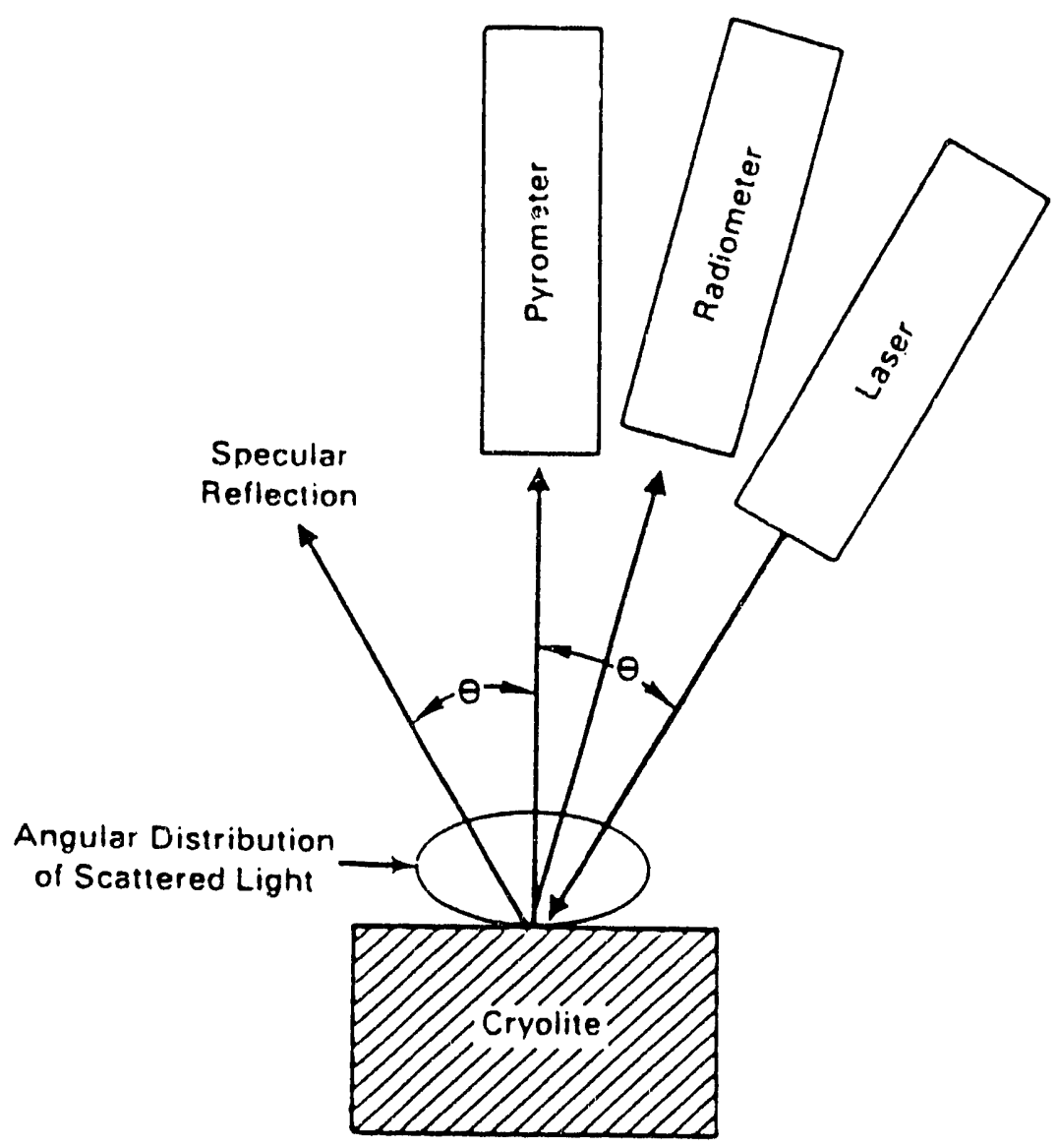

Figure 2.1. Radiometer-Pyrometer Method for Detecting Formation of Solid Film

presence of a film on the surface of the cryolite as discussed below. When the film is detected, the chopper would be positioned to cut off the laser beam, and the pyrometer electronics would begin to interpret the radiometer signal as a temperature. Output signals from the pyrometer electronics could be displayed, recorded, and, by correlation with liquidus-composition curves, used to provide information on alumina concentration.

\subsection{Results}

The instrumental setup used in these experiments is shown in Figure 2.3. (a) A beam of light from a SP 145 Spectra Physics helium-neon laser (Mountainview, California) was directed at the cryolite surface at an angle to the surface. The surface is free of solid material as long as it is

(a) For these experiments, the system was a collection of laboratory equipment. In a finished system, all of the individual pieces in Figure 2.3, except the recorder, were envisioned to be packaged in a single compact unit. 


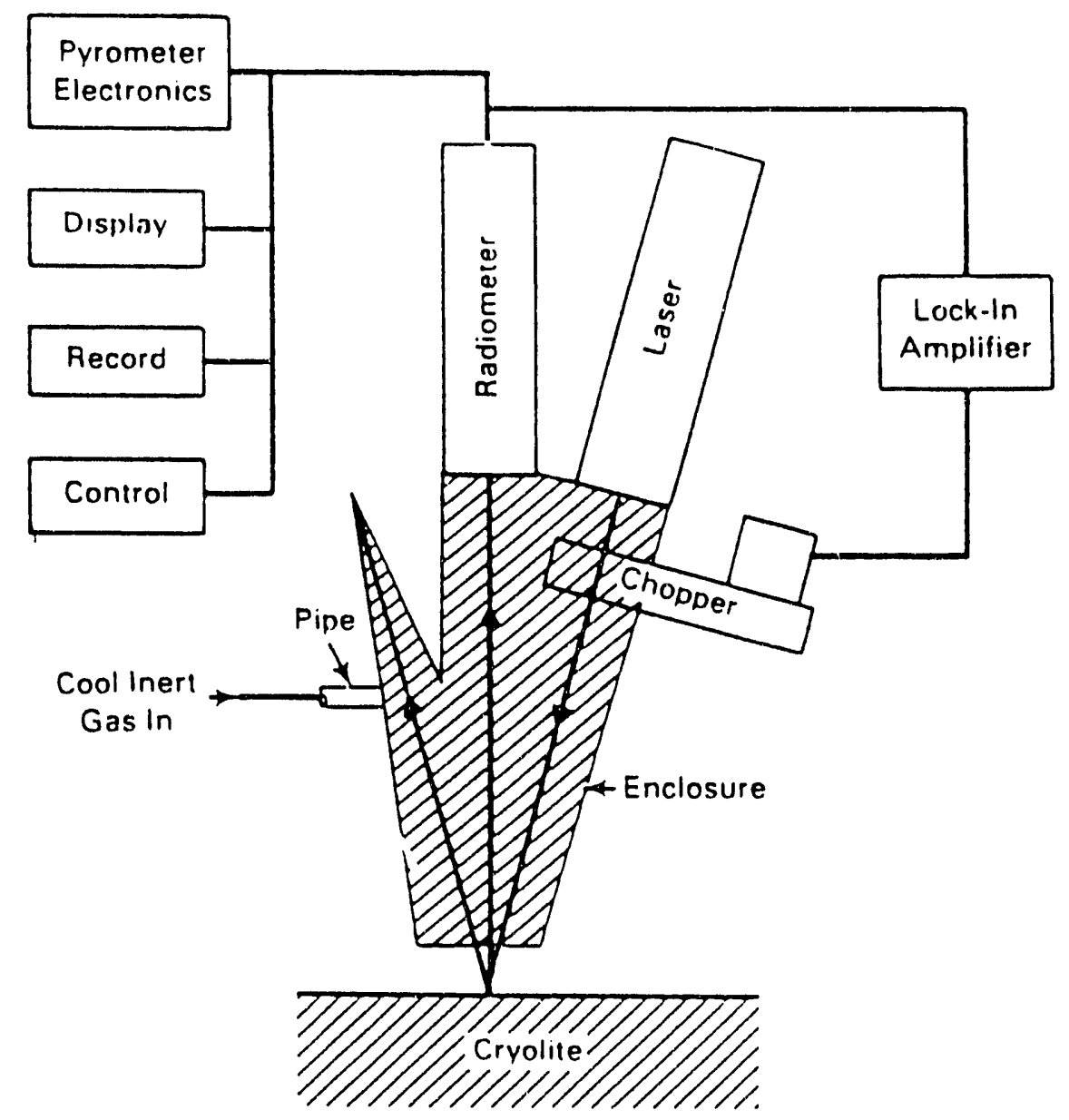

Figure 2.2. Liquidus-Temperature Measurement Device Concept

above the liquidus temperature. With no solid material on the surface, the laser beam is specularly reflected and does not enter the radiometer. At the liquidus temperature, the surface, which is the coolest portion of the bath, begins to crystalize, forming a thin film which generates diffuse reflectance. An EG\&G 5504 radiometer (Princeton, New Jersey) was used to sense the level of diffuse light and provide an indication that the temperature of the surface should be read using a Wahl Instruments HSA-7 pyrometer (Chicago, Illinois).

Since the bath temperature was well above $900^{\circ} \mathrm{C}$ in these experiments, it was radiating strongly in the spectral acceptance band of the radiometer. A narrow bandpass optical filter was used to restrict the spectral acceptance band of the radiometer to the region of the laser output at $632.8 \mathrm{~nm}$. Even within this narrow bandpass, the energy radiated from the cryolite overpowered the response of the radiometer to scattered laser light, so an EG\&G PAR 192 chopper was used to modulate the laser beam and phase-sensitive detection was employed. Using an EG\&G PAR 128 lock-in amplifier 


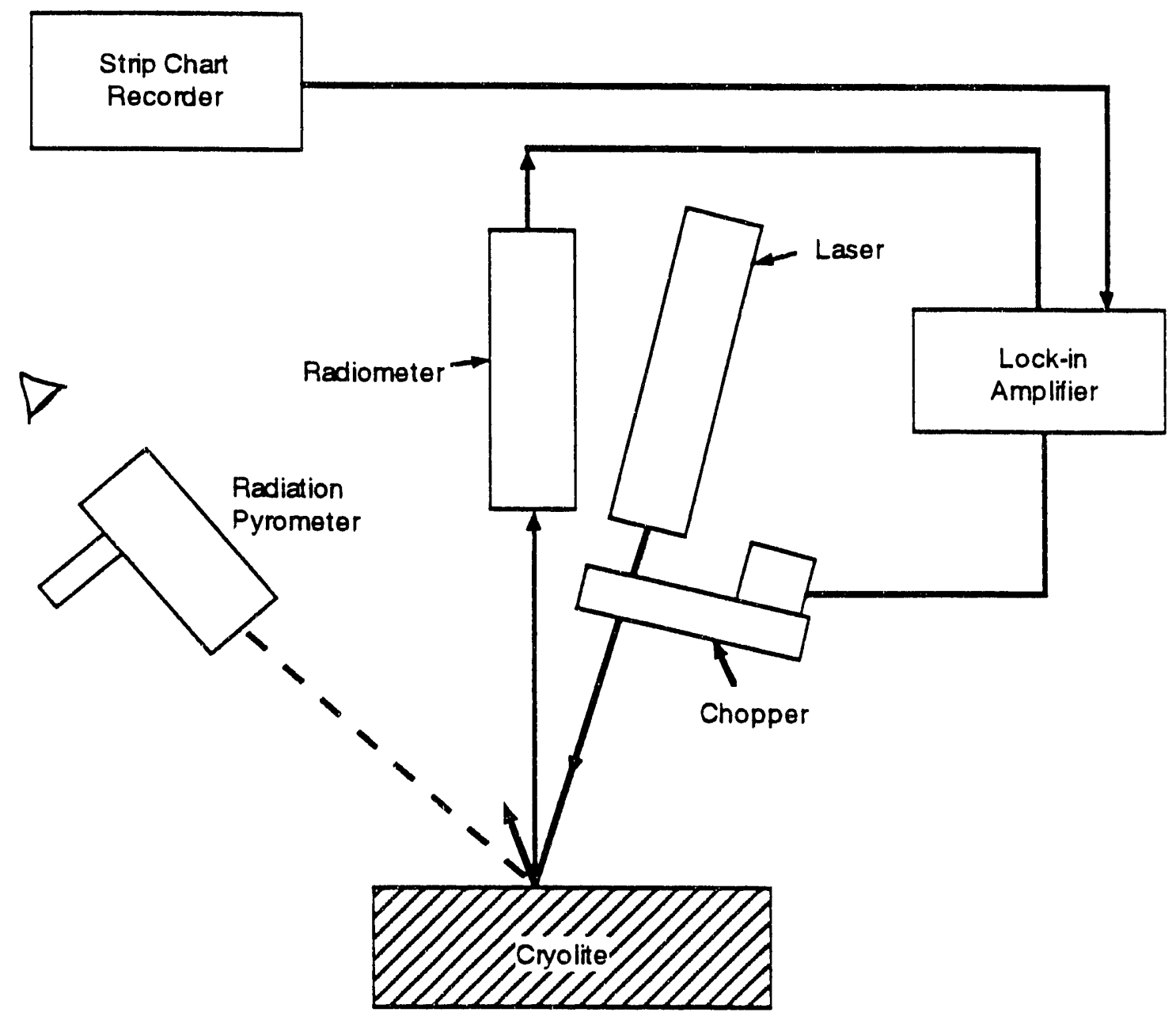

R9207063.13

Figure 2.3. Block Diagram of Liquidus Temperature Measurement System

synchronized to the chopper frequency $(500 \mathrm{~Hz})$, all of the effects of the radiant output of the cryolite upon the radiometer were nullified and the output of the lock-in amplifier became a function of the scattered light only.

A strip chart recorder was used to record and indicate the amplitude of the detected signal. Temperatures of the cryolite surface were taken at approximately 15-s intervals and hand written on the strip chart. Noise on recorded signal traces was diminished by increasing the time over which the signal was measured. Integration time was selected using the lock-in amplifier. The integration time was initially chosen as $0.1 \mathrm{~s}$ but was changed to $1 \mathrm{~s}$ to increase the signal-to-noise ratio.

The characteristics of the pyrometer component of the apparatus were also considered. The cryolite melt radiates much like a black body as illustrated in Figure 2.4. The figure shows the spectral radiance of a cryolite melt at $945^{\circ} \mathrm{C}$. The ratio of the radiance at any given wavelength to that at $1062 \mathrm{~nm}$ is plotted as the shaded region. This ratio is compared with the same ratio for a black body referenced to $1.07 \mu \mathrm{m}(1070 \mathrm{~nm})$, which is plotted as a solid line. The melt temperature 
was measured with a thermocouple immersed directly in the melt. Similar tests showed that the radiation characteristics of the melt capped with a solid film were also close enough to a black body to serve as basis for temperature measurement. A two-color pyrometer was used in these studies. This type of pyrometer has the advantage of using a ratio of radiances in two spectral bands to determine a "true" temperature without the knowledge of the emittance of the source. Its main disadvantage is that it assumes the emittance is the same in both spectral bands, which may not be the case for molten cryolite. Nevertheless, this choice of pyrometers appeared to be the best for these initial studies. Refinement of the approach or instrumental components was left to later phases of the study.

In the first preliminary experiments using this technique, the objective was to see if the combination of laser and radiometer could successfully detect the formation of solids upon cooling. In these tests, the whole bath was cooled as data were recorded. ${ }^{(a)}$ Figure 2.5 shows the results of one of these tests performed on an alumina-containing cryolite bath. At. a temperature well above the liquidus temperature, vapors leaving the surface of the bath interact with the laser beam to produce a small amount of diffuse scattering which is detected by the radiometer. The amount of vapor

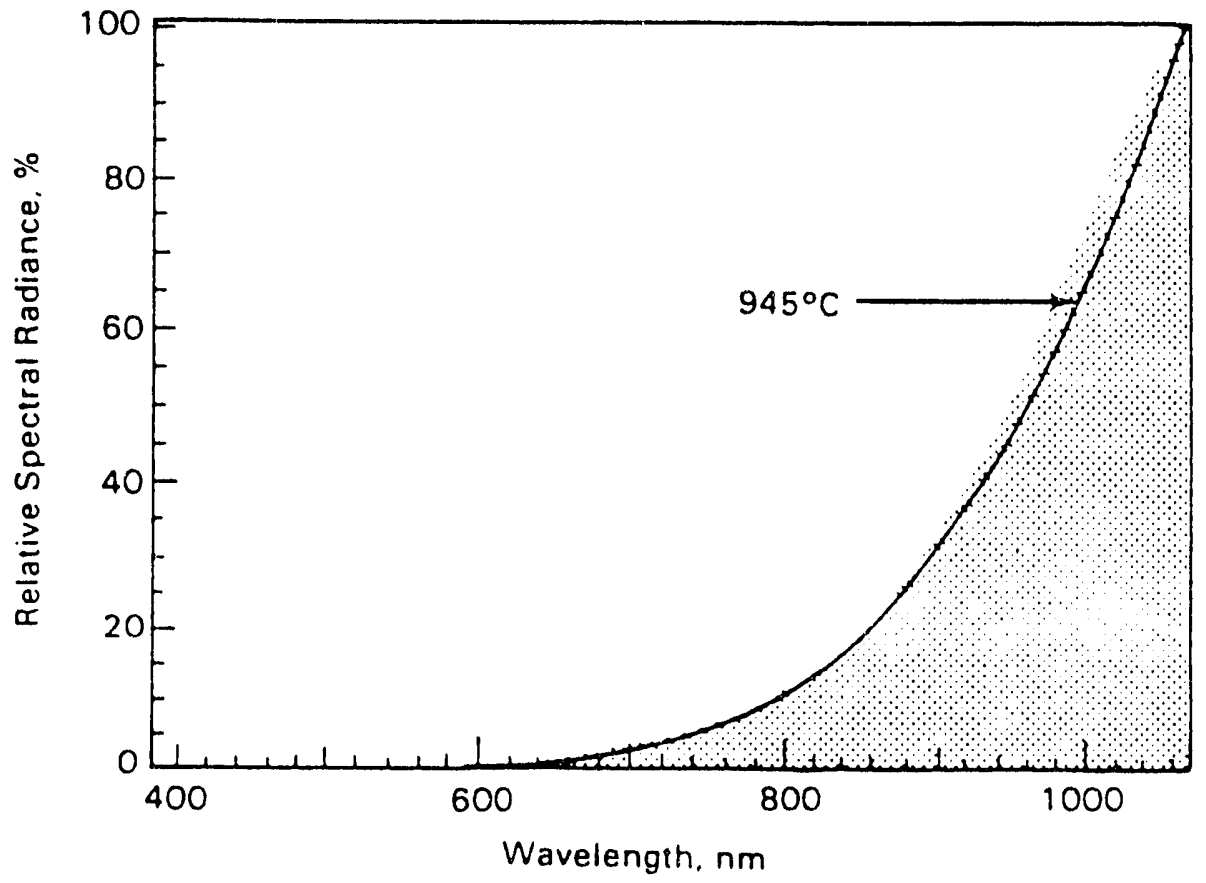

Figure 2.4. Comparison of Spectral Radiance with Cryolite to Radiance of a Black Body

(a) In practical application, a means of cooling a small local region must be provided. A special "hot" window may also be needed to protect the optical system from being coated by condensed vapor from the bath. 


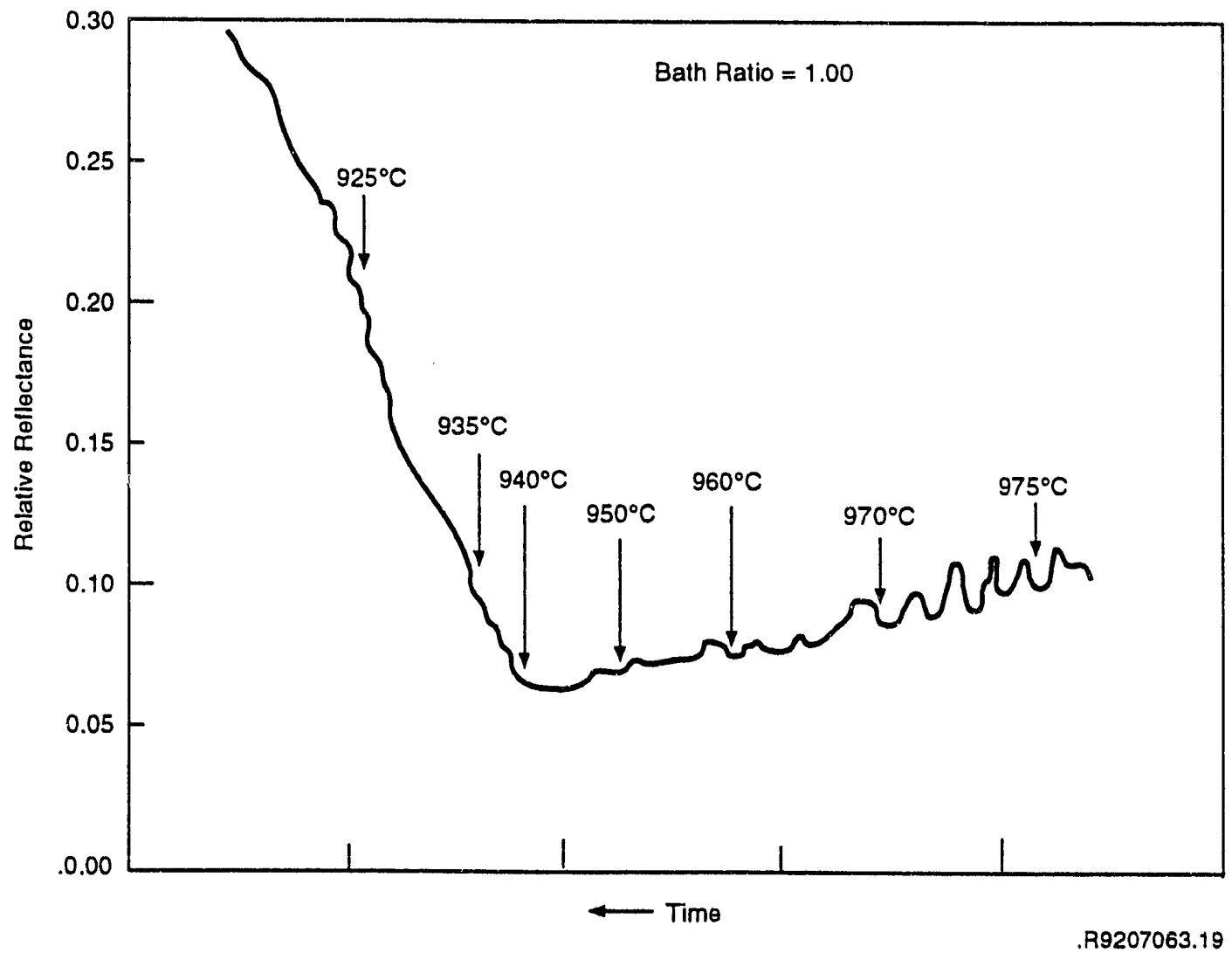

Figure 2.5. Typical Strip Chart Recording Using Radiometer-Pyrometer

fluctuates, causing fluctuations in the detected scattered light. The amplitude of this fluctuating signal decreases, although not dramatically, as the bath cools. Over the same time period, the mean level of the radiometer signal also decreases because less energy is radiated by the bath within the spectral pass band of the laser line filter. As a solid film forms on the surface of the bath, the amount of scattered light increases rapidly to well above the level of light scattered by the vapors. The liquidus temperature of the bath was taken as the temperature at the knee of the reflectance curve. The temperature, read by the radiation pyrometer, at the specular-to-diffused reflectance transition correlated well with the value for the liquidus temperature for this bath composition.

The experimental setup described above was then used to determine liquidus temperatures for cryolitic baths with alumina concentrations between $0 \%$ and saturation for various bath ratios. The results of these studies are shown in Figures 2.6 and 2.7. The temperatures corresponding to the specular-to-diffuse transitions (taken as the temperatures at the knees of the reflectance-versus-time curves similar to Figure 2.5) were very close to the literature data (Grjotheim et al. 1982) for liquidus temperatures up to about $6 \mathrm{wt} \%$ alumina for the bath ratios shown. Above this concentration, the literature data showed a very steep increase, whereas the experimental temperatures "bottomed out" or increased only slightly. This observation was made repeatedly on numerous data sets at various bath ratios. Unfortunately, this result indicates very poor sensitivity for the approach at alumina 


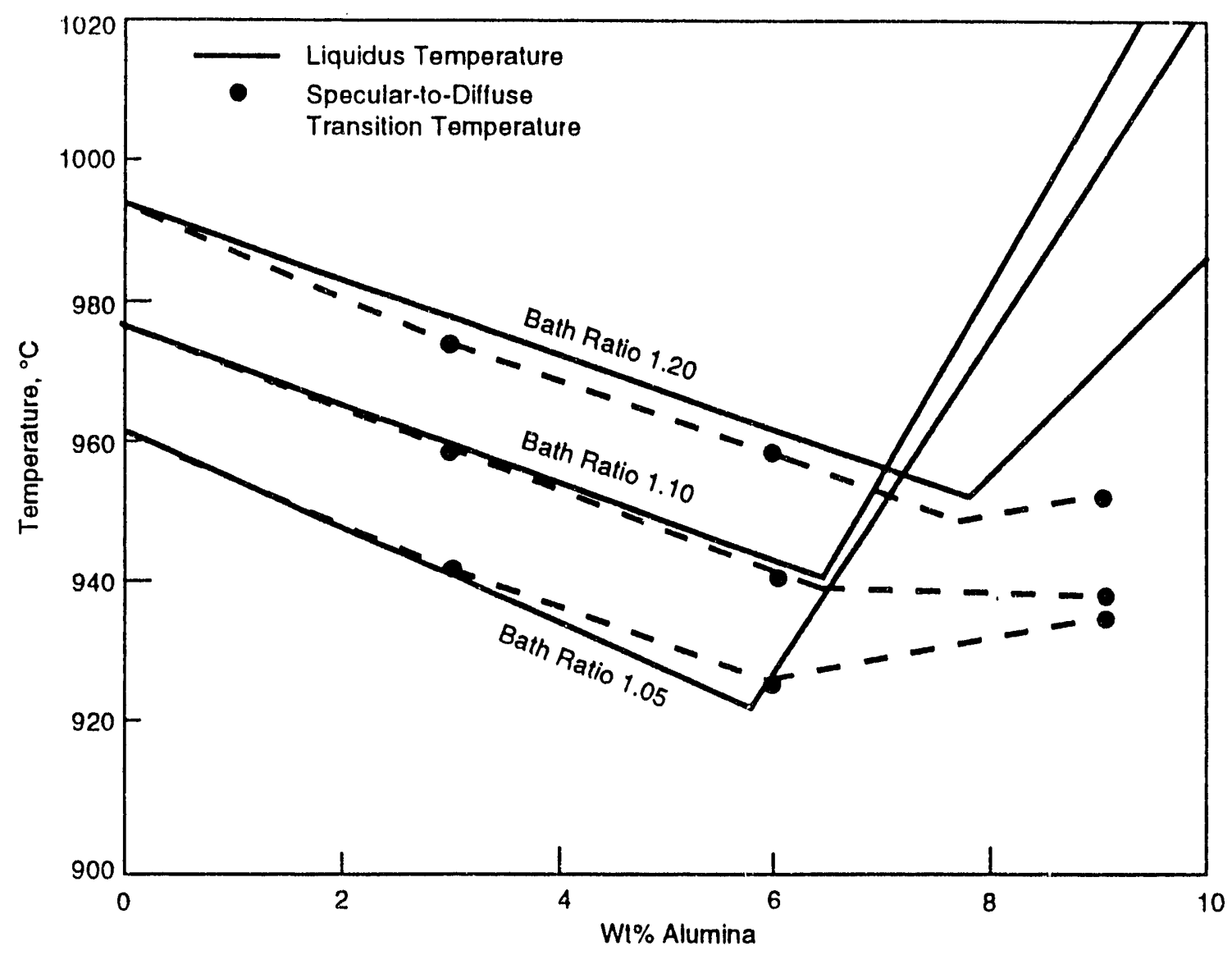

R9207063.18

Figure 2.6. Effect of Alumina Concentration on Specular-to-Diffuse Reflectance Transition Temperature

concentration above $6 \mathrm{wt} \%$. Since accurate measurement of alumina at concentrations higher than $6 \mathrm{wt} \%$ was considered necessary for a successful alumina sensor, the method was judged unsuitable and further development was not pursued. It is not clear why the deviation between the literature liquidus temperatures and the experimental temperatures deviated so much above $6 \mathrm{wt} \%$ but it is suspected that the problem was not strictly instrumental and therefore not easily "fixed." As shown in Figure 2.7, the transition temperatures showed very good correlation with the literature liquidus temperatures as a function of bath ratios at $0 \%$ alumina throughout the range of bath ratios studied. Some minor deviation toward higher values appears at bath ratios above 1.10 but this may have been due to radiation from the bath transmitting through the surface film.

Another disadvantage to the radiometer-pyrometer approach was debated during its development. This concerned the difficulty in incorporating the technique into the current design of aluminum reduction cells. Reduction cells typically operate with a thick crust over the molten salt bath. The presence of this crust would make it difficult to take routine measurements. The crust would have to be broken each time a measurement was taken. Moreover, since the detection equipment employed 


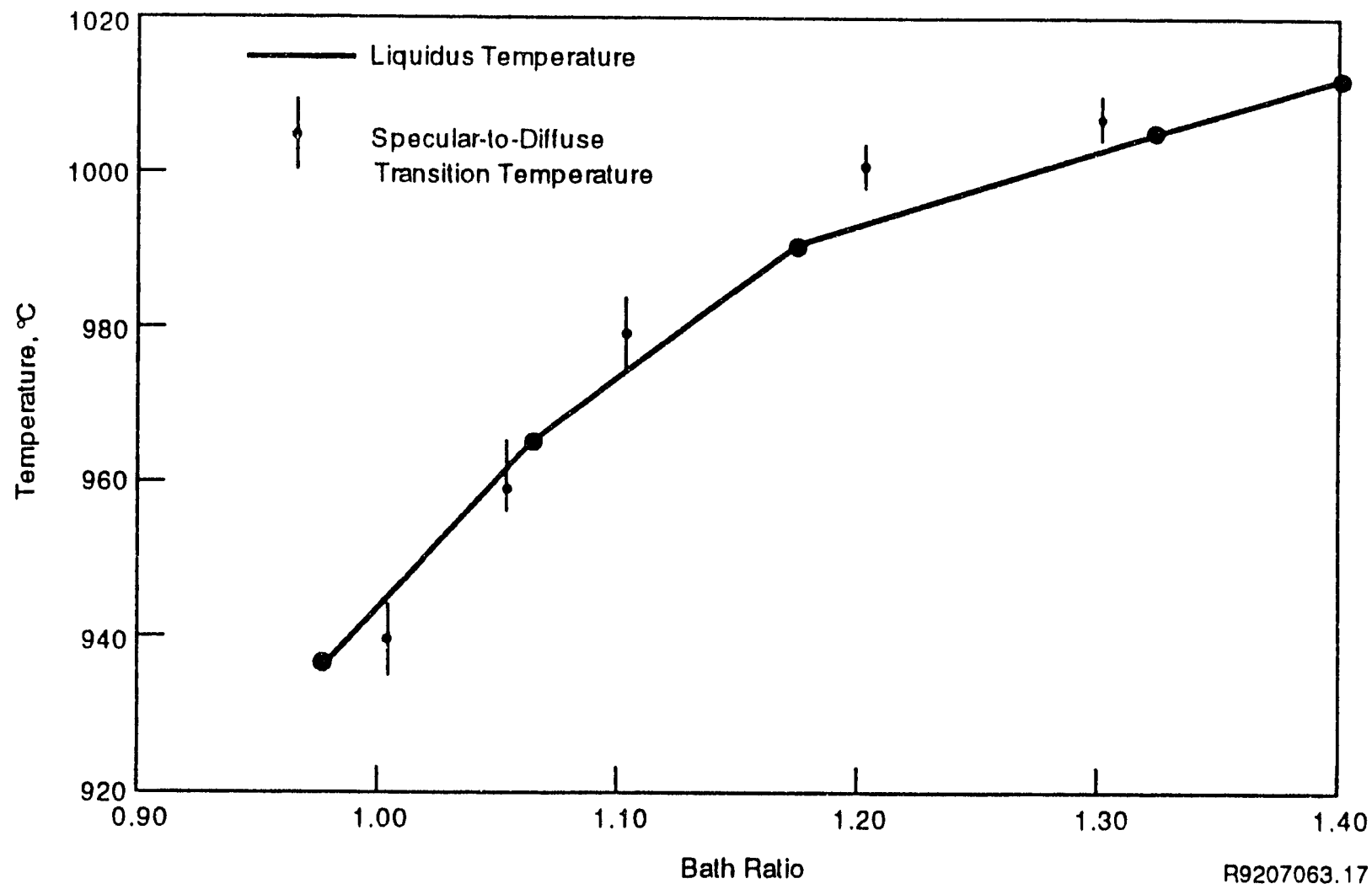

Figure 2.7. Temperature of Specular-to-Diffuse Reflectance Transition as a Function of Bath Ratio

optics, it could not be permanently affixed to a pot in a position where it was ready to take measurements. The environment would probabiy be too hostile for the equipment to tolerate continuous exposure, or it would be "in the way" for the various routine measurements and adjustments that have to be made on reduction cells. Consequently, the equipment would probably have to be moved repeatedly and therefore, even under the best circumstances, could be employed only on a comparatively infrequent periodic basis. Since some of the other approaches under study did not suffer from these disadvantages, the radiometer-pyrometer method was abandoned in favor of the alternative approaches.

\subsection{Summary of Conclusions}

Laboratory tests showed that the method produced inaccurate and "insensitive" results in measuring alumina concentration in excess of $6 \mathrm{wt} \%$. Because the measurement of alumina concentrations greater than $6 \mathrm{wt} \%$ was required, the method was judged unsuitable and further research was abandoned. 


\subsection{Spectral Reflectance}

The spectral reflectance method is similar to the radiometer-pyrometer method in that it uses a light source external to the molten salt bath and a detection system to measure scattered light. As with the radiometer-pyrometer method, the objective is to discriminate when solids begin to form on the surface of the melt during cooling and to measure the temperature at this point. The difference in the spectral reflectance approach is that a white light source is used and the entire spectrum of the reflected light is utilized.

\subsection{Description of Approach}

As shown in Figure 3.1, the spectral reflectance approach involves illuminating the surface of the cryolite melt with a microscope lamp and collecting and analyzing the reflected light with a spectrophotometer. When the surface of the melt is clean and clear, very little of the illuminating

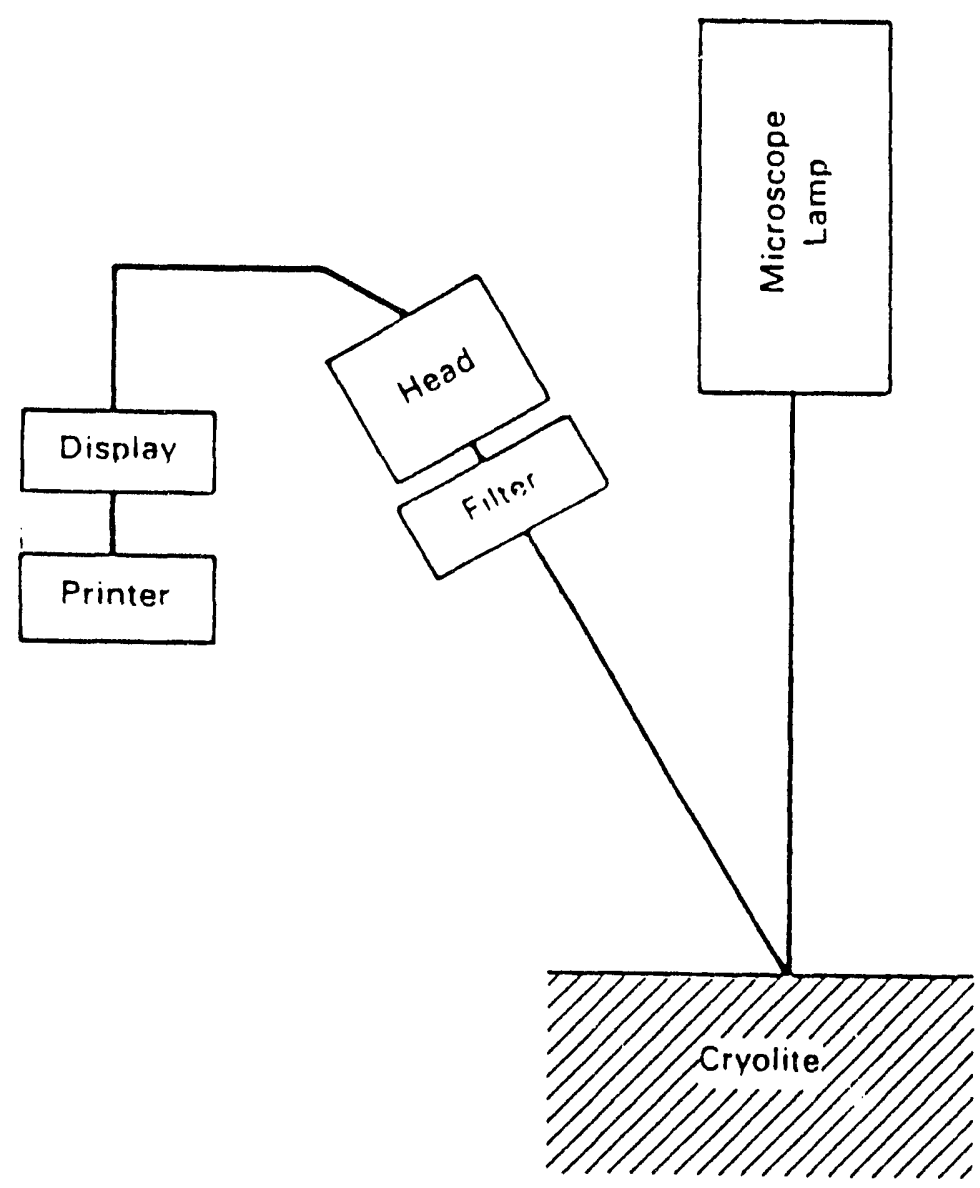

Figure 3.1. Experimental Arrangement for Tests Using a Spectral Radiometer 
light should be scattered to the spectrometer head. The measured spectrum should be characteristic mainly of the emitted light of the molten salt, i.e., black body radiation. When a film forms on the surface as a result of local cooling, the illuminating light should be scattered. The scattered light should alter the spectrum measured by the spectrophotometer. By measuring the spectrum before and immediately after the formation of the film and subsequent processing of these spectra, it was hoped that the differences would be large enough to indicate the onset of film formation, similar to the radiometer-pyrometer method. The temperature at which this onset occurs would be determined from the emission spectrum itself and should correlate with the liquidus temperature. If the correlation is good, the alumina $c^{\prime}$ ncentration should be ascertained similar to the radiometer-pyrometer method.

\subsection{Results}

A Photo Research Model TR713 Spectrascan spectrophotsmeter (Burbank, California) was used as part of the setup shown in Figure 3.1 to study the radiation characteristics of the cryolite melt surface both with and without a solid film present. The temperati'e of the melt in this study was $945^{\circ} \mathrm{C}$ as measured with a thermocouple immersed directly in the bath. Figure 3.2 shows the spectra generated by a clean melt surface at this temperature. Also shown are the radiation curves expected for black body radiators at various temperatures. Nearly all of the energy seen by the radiometer head in the experiment was due to the thermal radiation of the cryolite as indicated by the similarity of the experimental curve and that for the black-body radiator at $945^{\circ} \mathrm{C}$. In addition to the emission spectrum, the spectrophotometer provided information on the radiance in the spectral band from 390 to $1070 \mathrm{~nm}$, the luminance, the CIE (Comission Internationale d L'Eclairage) chromaticity coordinates and, where appropriate, the color temperature of the radiation. Comparison of the

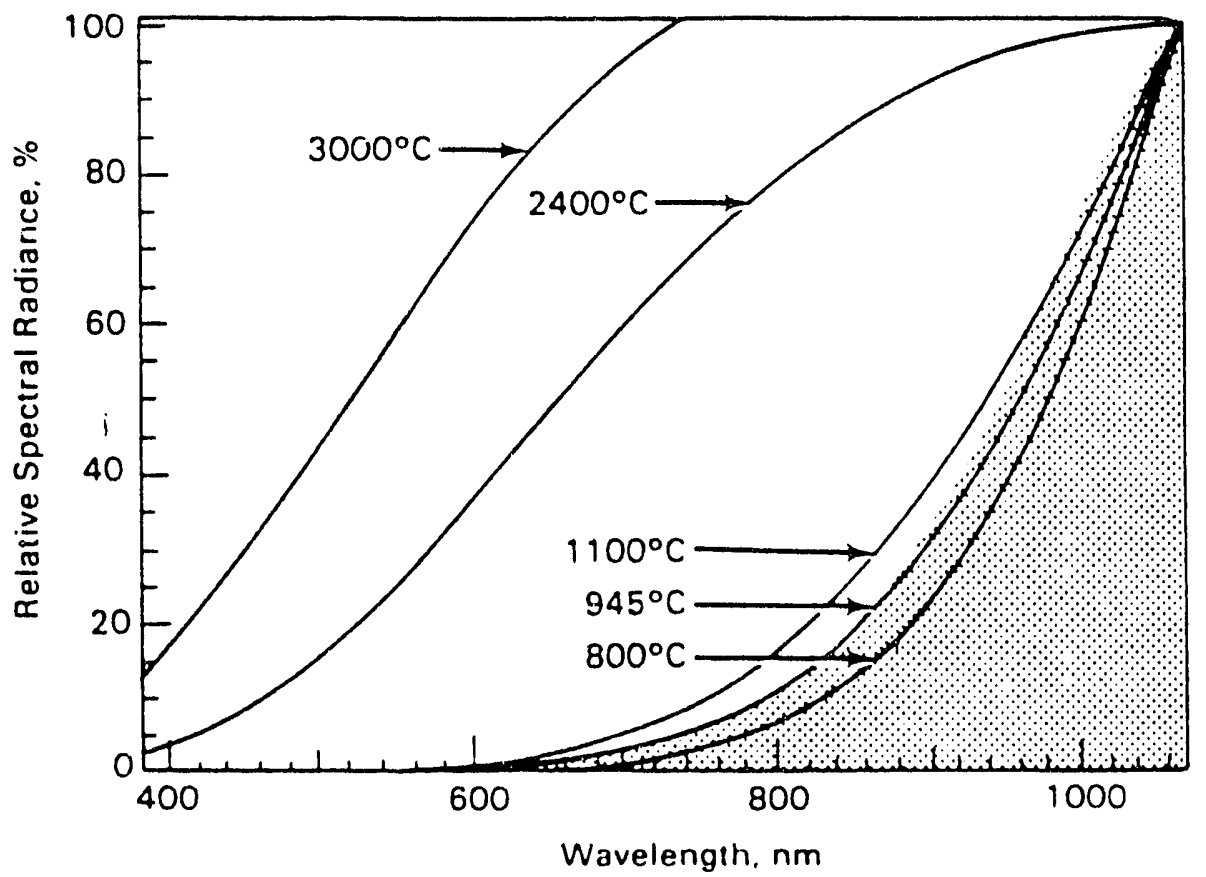

Figure 3.2. Spectral Radiance Distribution of a Clean Cryolite Melt Surface at $945^{\circ} \mathrm{C}$ 
spectrophotometric output of the cryolite bath with the equivalent iurve for a $945^{\circ} \mathrm{C}$ black body showed that the spectral radiance of the cryolite melt adequately approximates that of a black body of the same temperature.

Figure 3.2 also illustrates the strong predominance of the infrared component of the radiation. This prevented the calculation of accurate intensity ratios in the blue end of the spectrum. To address this problem, an infrared blocking filter was place in the system (Figure 3.1). The spectral radiance plot of a $941^{\circ} \mathrm{C}$ clean cryolite melt surface, modified by the filter, is shown in Figure 3.3. This was used as the reference spectra. The melt was allowed to cool to $927^{\circ} \mathrm{C}$. by which time a film of solid covered the surface. Figure 3.4 shows the corresponding spectral plot. Comparison with Figure 3.3 shows that the solid film produced a spectrum richer in the blue (short wavelength) region of the spectrum. The energy output of the microscope lamp, operating at about $3000^{\circ} \mathrm{C}$, was much richer in blue light than the cryolite at $927^{\circ} \mathrm{C}$. When the solid film forms, this blue-rich light was scattered into the detector. The plot in Figure 3.5 was obtained by dividing the $927^{\circ} \mathrm{C}$ spectra by the reference spectra. As shown, the formation of the film of solid material was readily detected by the buildup of the spectral energy in the 400 - to $500-\mathrm{nm}$ region.

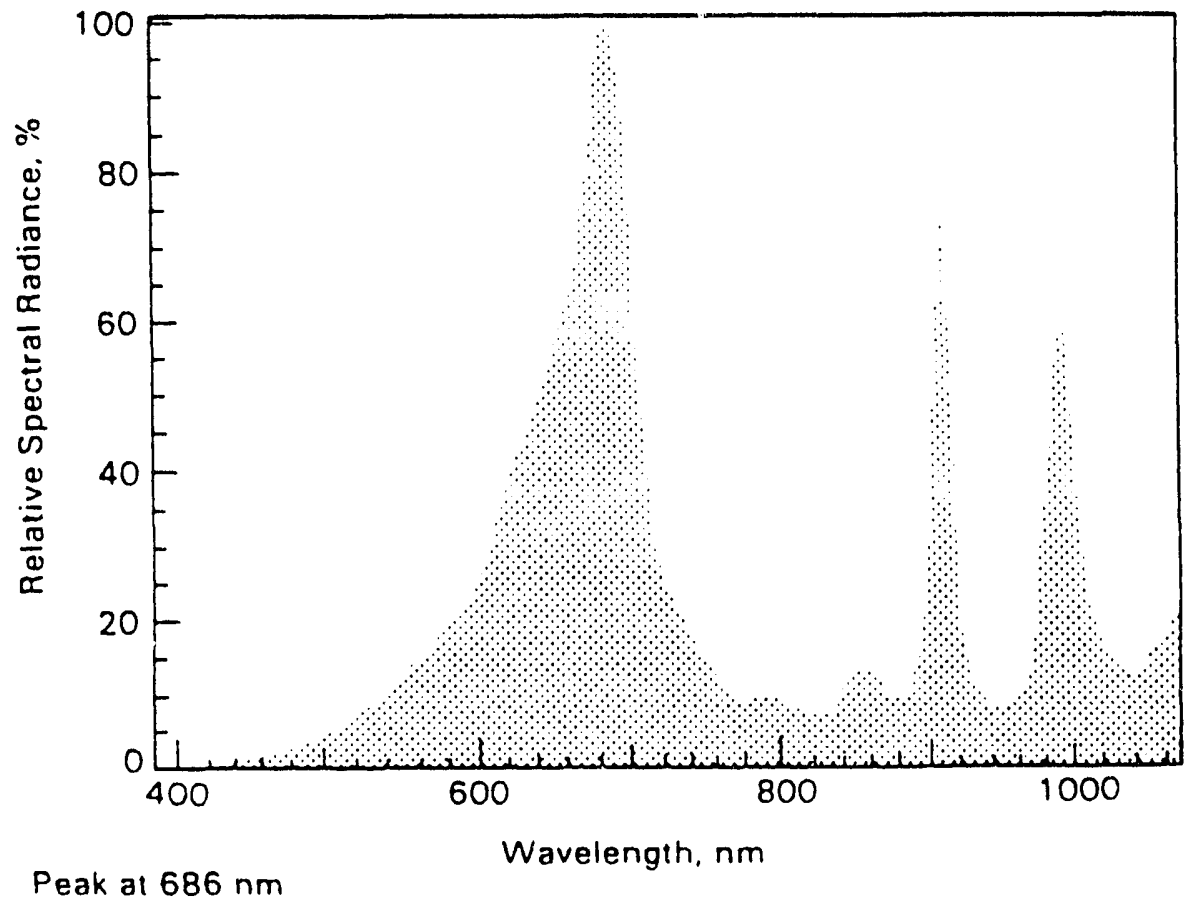

Figure 3.3. Energy Spectrum of $942^{\circ} \mathrm{C}$ Melt Surface Viewed Through Infrared Blocking Filter (Reference Spectrum) 


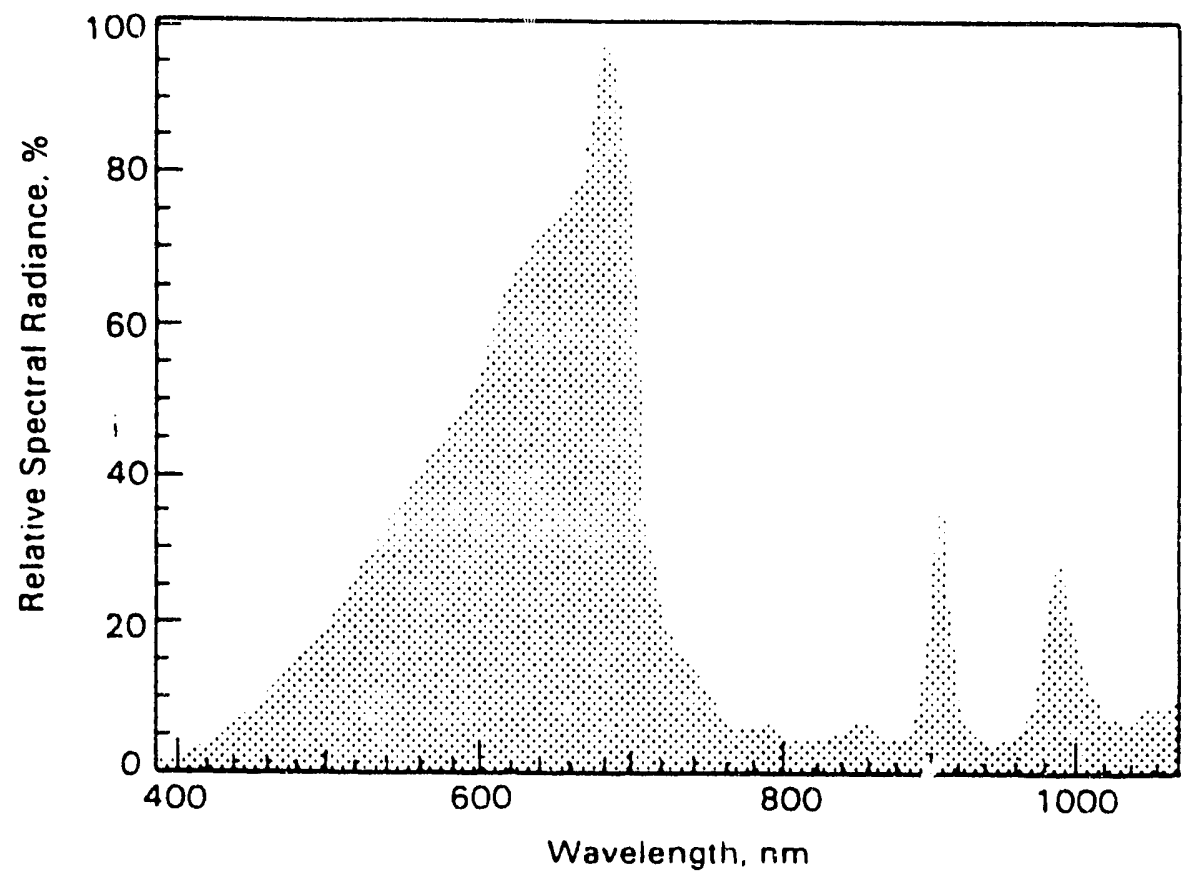

Peak at $682 \mathrm{~nm}$

Figure 3.4. Energy Spectrum of $927^{\circ} \mathrm{C}$ Solid Film Over Cryolite Viewed Through Infrared Blocking Filter (Test Spectrum)

It was recognized that a spectrophotometer of the type used for this study could not be used for continuous monitoring of the melt condition. Alternatively, it was conceived as a way to perform spot checks. A reference spectrum of the clear melt surface would be taken and stored in system memory. The formation of a thin solid film would be induced on a small area of the surface of the melt using a jet of cool inert gas. A second reflectance spectrum would be taken with the surface illuminated by a tungsten lamp. The reference spectrum would be divided by the film reflectance spectrum. If a film was present as indicated by a blue-rich spectrum, the liquidus temperature would be determined by the radiance computed for the film spectrum by the spectrophotometer system.

Because of the similarity of this approach and the radiometer-pyrometer method, further study of the spectral reflectance method was abandoned. The radiometer-pyrometer method seemed to have the advantage of more portable and easily accessible equipment. Consequently, it would be easier to apply on a routine basis. As it turned out, the radiometer-pyrometer method was also abandoned as discussed in Section 2.0, because of problems with sensitivity at high alumina concentrations. Since the spectral reflectance method is based on the same principles as the radiometer-pyrometer method, it was considered likely that it would suffer from the same shortcomings. Consequently, the spectral reflectance approach was abandoned as well. 


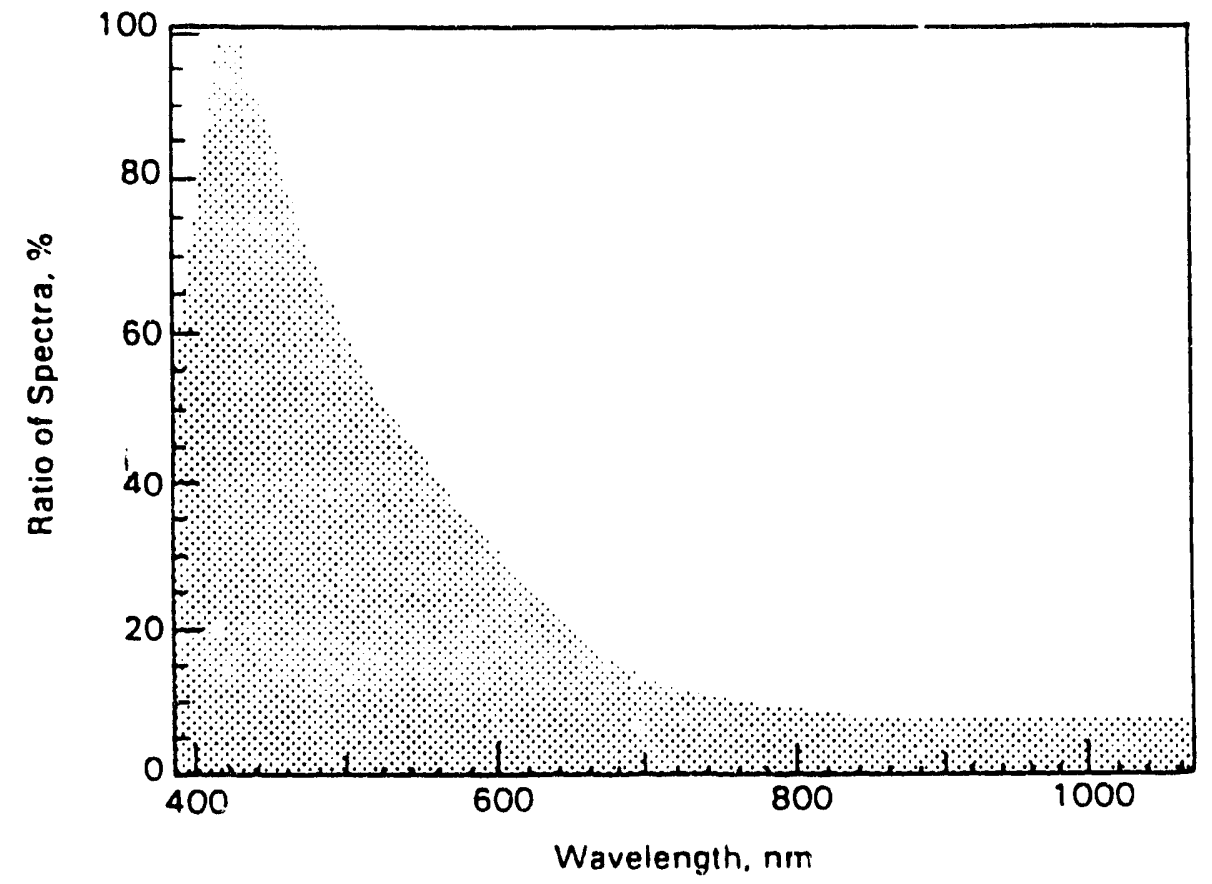

Peak at $426 \mathrm{~nm}$

Figure 3.5. Ratio of Spectra: Test Spectrum/Reference Spectrum

\subsection{Summary of Conclusions}

The spectral reflectance approach to measuring alumina was abandoned because it was based on the same principles as the radiometer-pyrometer method but was more difficult to apply in practice. Further development work was considered inappropriate at this time because it was perceived that the methods suffered the same sensitivity shortcomings. 


\subsection{Infrared Imaging}

Infrared imaging was another spectroscopic method evaluated for measuring the liquidus temperature and alumina concentration.

\subsection{Description of Approach}

The infrared imaging approach uses an infrared detector to detect and measure infrared radiation emitted from the molten cryolite. The approach is similar to those discussed in Sections 3.0 and 4.0, but it provides more of a visual perspective on the surface temperatures. Recent improvements in commercially available infrared imagers make them a powerful tool for the study of temperature distributions. The technique is capable of resolving a temperature field spatially (in 2-D), so it provides an interesting alternative to monitoring the formation of solids at the melt surface.

\subsection{Results}

A molten cryolite surface was studied in this work using an Inframetrics $600 \mathrm{~L}$ image analyzer (Bedford, Massachusetts). The device was positioned right over the exposed surface of the bath. The images were recorded on video tape, some of which were later converted to color photographs.

The infrared emitting characteristics of the clean, clear molten cryolite surface were first determined. Infrared images were obtained. The emittance of the surface was then determined by setting the emittance on the instrument so as to give a temperature read-out that coincided with that of a thermocouple placed in the molten cryolite near the surface. Measured in this way, the emittance was 0.97 , which is very close to that expected for a true black-body radiator (1.0). Consequently, it appears that the surface is a near perfect radiator in the 8- to $14-\mu \mathrm{m}$ spectral range. This is consistent with the similar studies over a broader spectral range discussed in Sections 2.0 and 3.0.

Measurement of the film-forming event required for liquidus temperature measurement proved to be difficult with the infrared image analyzer. When solid first began to form in the laboratory cells, it usually built up in a very uniform manner. This made it hard to detect using the imager. As the film became thicker, however, it broke up, forming something like an assembly of floating ice blocks. The formation of the blocks was easier to detect with the image analyzer. Unfortunately, correlating these blocks and their properties with the liquidus temperature was not as straightforward as correlating those for a thin film.

The formation of solids at the surface of the bath in a laboratory cell is shown in the infrared images in Figure 4.1. By positioning the crosshairs of the analyzer on a region of interest, the temperature of that region can be determined. Using this approach, the solids formed on the liquid surface were measured to have an apparent temperature as much as $50^{\circ} \mathrm{C}$ cooler than the underlying liquid. For example, as shown in Figure 4.1, the temperature of the liquid surface (a) was $927^{\circ} \mathrm{C}$ while the temperature of the large particle (b) was measured to be less than $877^{\circ} \mathrm{C}$ using the same emittance setting on the analyzer. Since any solid formed should have been in thermal equilibrium (or near equilibrium) with the liquid right beneath it, it is likely that the differences in measured temperatures were, at least partly, due to a difference in emittance between the solids and the molten 


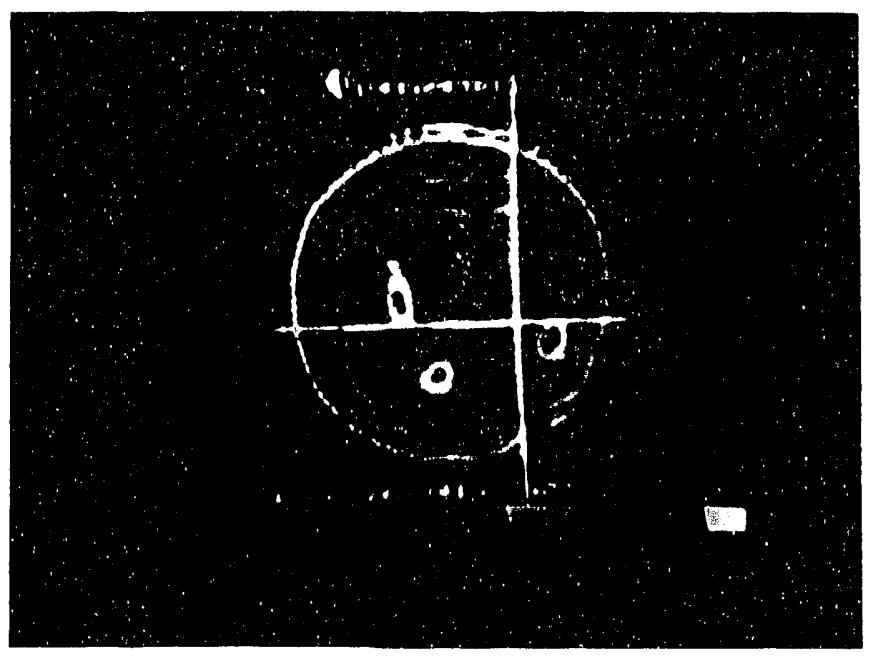

(a)

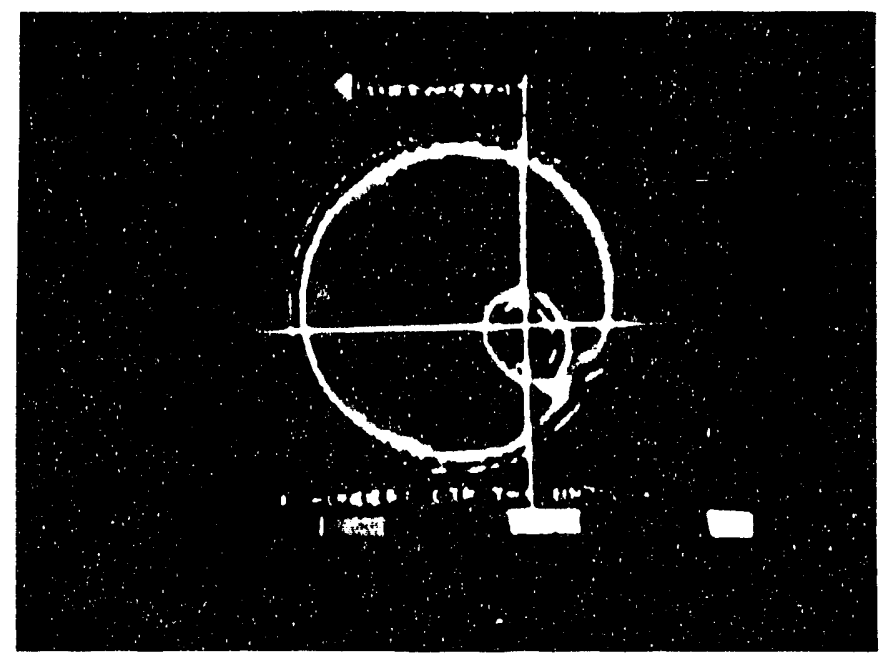

(b)

Figure 4.1. Infrared Images of Cryolite Surface: a) Shows Particle Formation. Three Particles Present. Temperature at Cursor is $927^{\circ} \mathrm{C}$. b) Shows a Large Particle. Temperature at Cursor is Less Than $877^{\circ} \mathrm{C}$.

salt surface. Without good information on the emittance characteristics of the solids formed (which will certainly vary with composition), it appeared that the approach would not be very useful for accurately measuring the liquid-to-solid transition temperatures. 


\subsection{Summary of Conclusions}

The development of the infrared imager was abandoned due to difficulty in calibrating the instrument to the emittance characteristics of the solids formed at the liquidus temperature. The technique might be a good way to make spot checks on the formation of solids or, with further study, be a useful tool for developing a better understanding of film formation. However, since other more promising techniques for alumina concentration measurement were under development at the time, no further research using this approach was performed. 


\subsection{Bath Vapor Analysis}

The purpose of the bath vapor analysis work was to determine if the spectral properties of vapors liberated from the molten salt bath and deposited on cool quartz plates correlated in any way with bath compositicn, in particular bath ratio and alumina concentration. Initial results indicated that measurements of the ratio of the reflectance at $300 \mathrm{~nm}$ to that at 740 correlated with the bath ratio. However, subsequent tests did not confirm this correlation or any correlation involving alumina concentration.

\subsection{Description of Approach}

The approach taken in this work was very straightforward. Partial pressures of the various components in the vapor above a molten cryolite bath should be related to the bath ratio and the concentration of other components, including alumina, in the bath. It was therefore reasonable to hypothesize that the composition of deposited vapors could be related to bath composition. If the composition of the deposited vapor could be measured by spectroscopic methods, instrumentation could be developed to perform noncontact bath analysis.

Quartz paltes ( $1.5 \times 1.5 \times 0.12$ in.) were placed a few inches above the bath for five or more minutes to permit bath vapors to condense on them. When the bath was held above the liquidus temperature, the vapors deposited on the plates in the form of coatings. Spectral reflectance measurements of the coatings were made using a Beckman UV 5270 spectrophotometer (Fullerton, California). The reflectance spectrum of a bare quartz plate was also run and subtracted from that of the deposit samples. In all cases, the specular reflection component was blocked. The residual spectra resulting from this subtraction were normalized to a reflectance of $10 \%$ at $740 \mathrm{~nm}$; the resulting reflectance at $300 \mathrm{~nm}$ was studied for possible correlation to bath composition. Possible correlations with bath ratio were investigated first.

\subsection{Results}

Initial data seemed to indicate a linear increase in relative reflectance at $300 \mathrm{~nm}$ with an increase in bath ratio. Figure 5.1 shows an example of a set of normalized reflectance spectra for deposits obtained on the specimen plates. The spectra shown are for a cryolite bath with three different bath ratios. The plots indicate that the reflectance is greater in the blue region of the spectrum, similar to the result reported in Section 3.0. As shown by the magnitude of the curves at the very left end of the plots, the amount of non-specular reflection at $300 \mathrm{~nm}$ appears to correlate with bath ratio. The amount of reflectance at this wavelength seems to go up with increasing bath ratio. Data obtained from a whole series of test of this type are plotted in Figure 5.2. The letter designations correspond to the names for the various data sets. Points D, E, and C were derived from Figure 5.1. Points D, E, C, F, G, H, and J were the first set of data obtained. As shown in Figure 5.2, with the exception of point $\mathrm{G}$, these points appear to exhibit a very good linear relationship with bath ratio.

The apparent correlation between the reflectance measurements and the bath ratio caused initial optimism, so the experiments were repeated. As shown in Figure 5.2, the second series of measurements (letters other than those indicated above), showed no apparent correlation with bath ratio. 


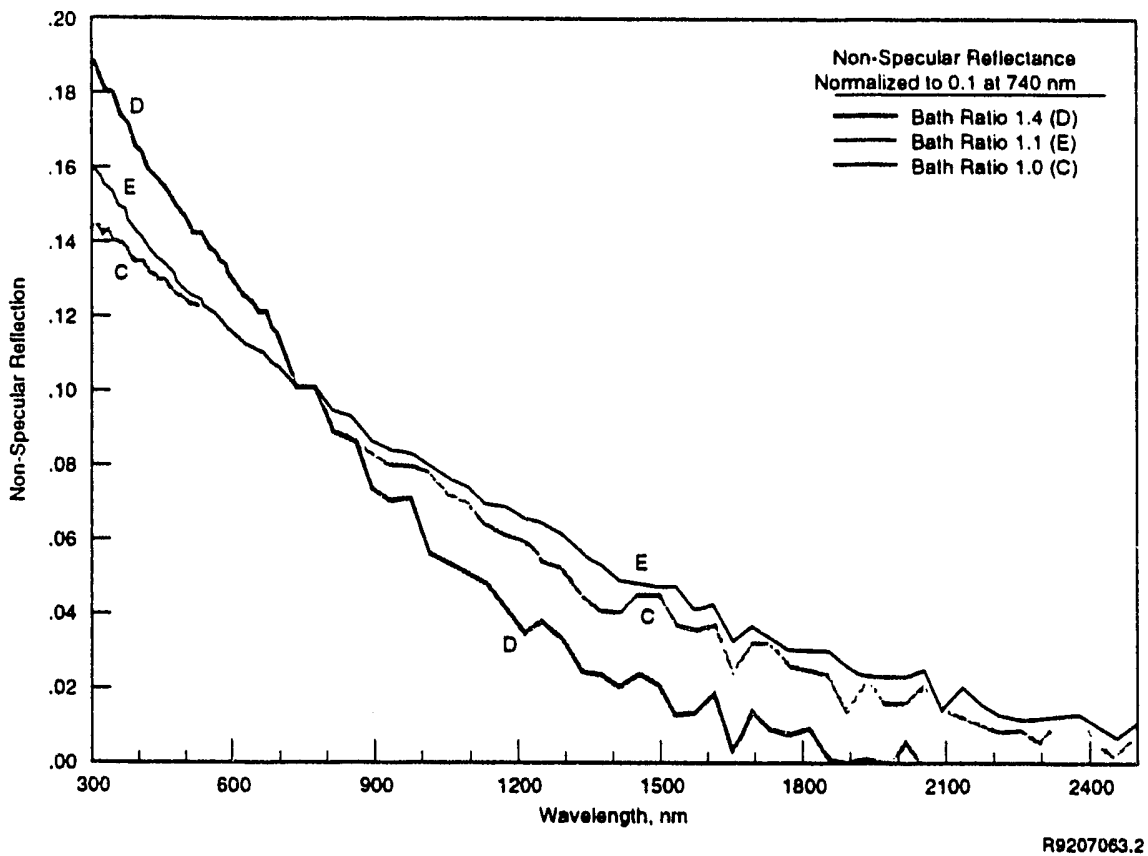

Figure 5.1. Non-Specular Reflectance Spectra for Vapors Deposited from Baths with Different Bath Ratios

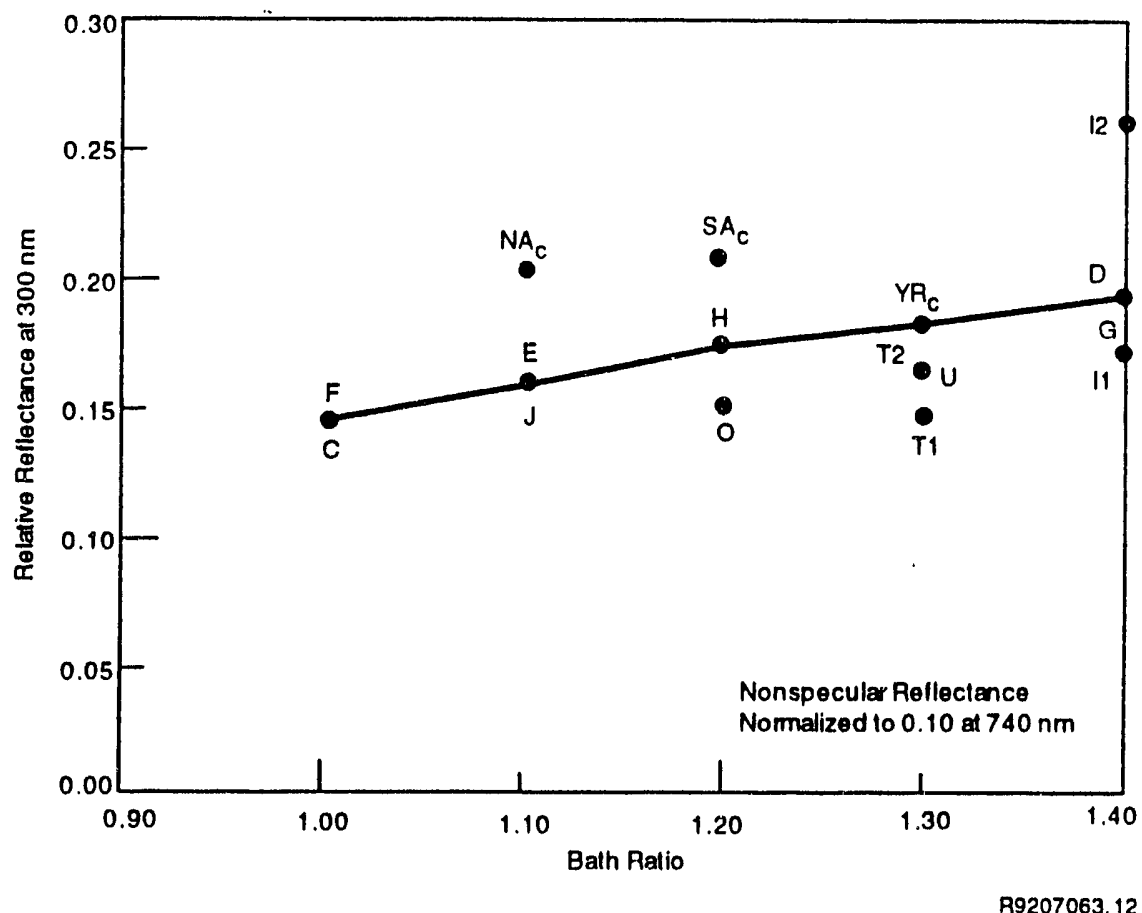

Figure 5.2. Summary of Reflectance Data for Vapor Deposits 
Another series of tests were run to determine sensitivity to alumina concentration. The results are shown in Figure 5.3 for bath ratios of $1.1,1.2$, and 1.3. In these experiments, a bath of a given bath ratio was heated to well above the liquidus temperature (over $1000^{\circ} \mathrm{C}$ in some cases). Two quartz plates were then inserted in the vapor. One plate was left in the vapor to accumulate a deposit throughout the succeeding series of measurements. The other plate was removed after $5 \mathrm{~min}$. of exposure. Before a clean plate was put in its place, alumina (5 wt \%) was added. Clean plates were exposed successively to $5 \mathrm{wt} \%, 10 \mathrm{wt} \%$, and $15 \mathrm{wt} \%$ solutions of alumina in cryolite while the one plate accumulated deposit throughout the test. The results (Figure 5.3) were very irregular showing no consistent trend with alumina concentration as a function of bath ratio. Moreover, the plates exposed to cumulative vapor collection did not give the same reflectance measurements as those exposed to $15 \mathrm{wt} \%$ bath vapors as expected. Clearly, experimental difficulties were present during these tests. Ccnsequently, the experiments were repeated again with some modification of test procedures.

During the last series of tests, the cryolite bath was covered and the vapors were channeled through a 10-in.-tall chimney. Quartz plates were placed about 1/8th in. above the chimney to receive deposits. The spectra obtained from these studies exhibited characteristics that differed significantly from those in the earlier tests. The increase in reflectance at the blue end of the spectrum of the deposited vapors was still present but was significantly less pronounced. Several specimens showed a sharp fall off in reflectance for wavelengths shorter than $400 \mathrm{~nm}$. The possibility of an absorption edge in the ultraviolet which varied with bath ratio was investigated by running ultraviolet spectra from $210 \mathrm{~nm}$ to $350 \mathrm{~nm}$ for three different bath ratios. Although an absorption edge was indicated in the region of $250 \mathrm{~nm}$, no shift in its position with bath ratio was observed.

The change in relative reflectance at $300 \mathrm{~nm}$, normalized to 0.10 at $740 \mathrm{~nm}$, for the tests involving the chimney is shown in Figure 5.4 under the conditions of two different gas covers. The relative reflectances are significantly different from those measured in the earlier studies. The lack of a reproducible and significant change as a function of bath ratio suggests that the approach is not
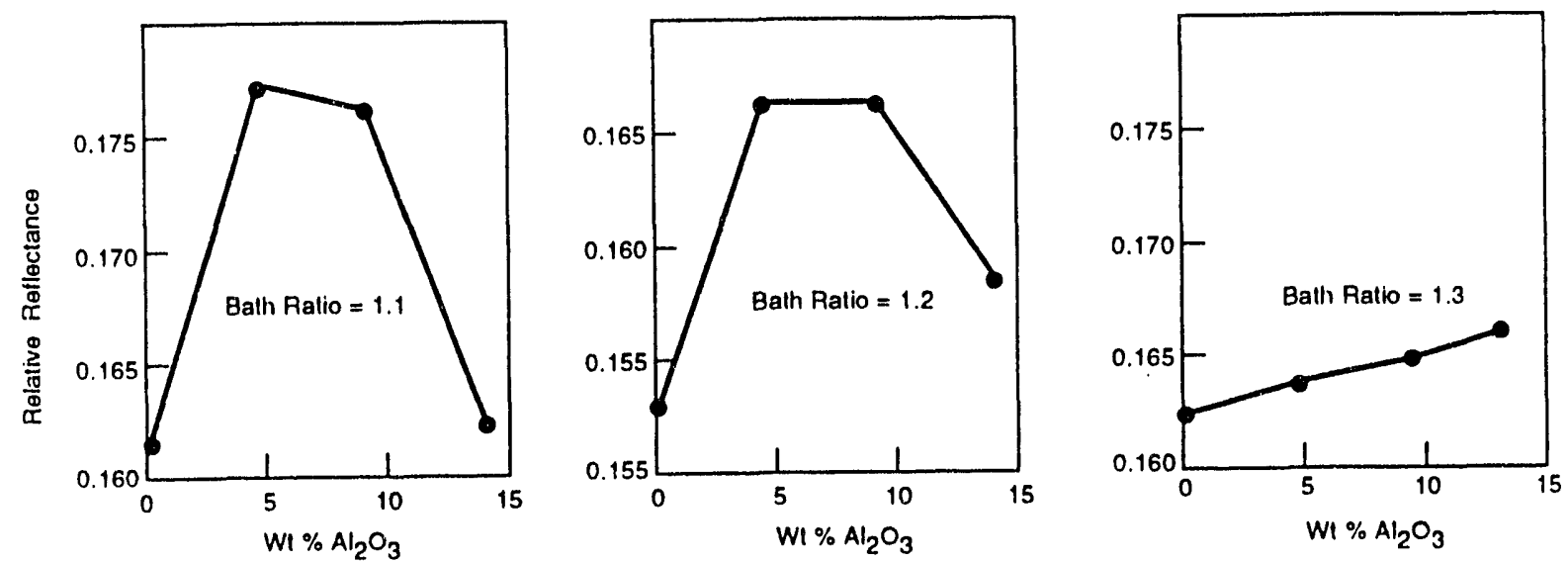

R9207063.16

Figure 5.3. Relative Reflectance of Vapor Deposits as a Function of Alumina Concentration in the Bath 


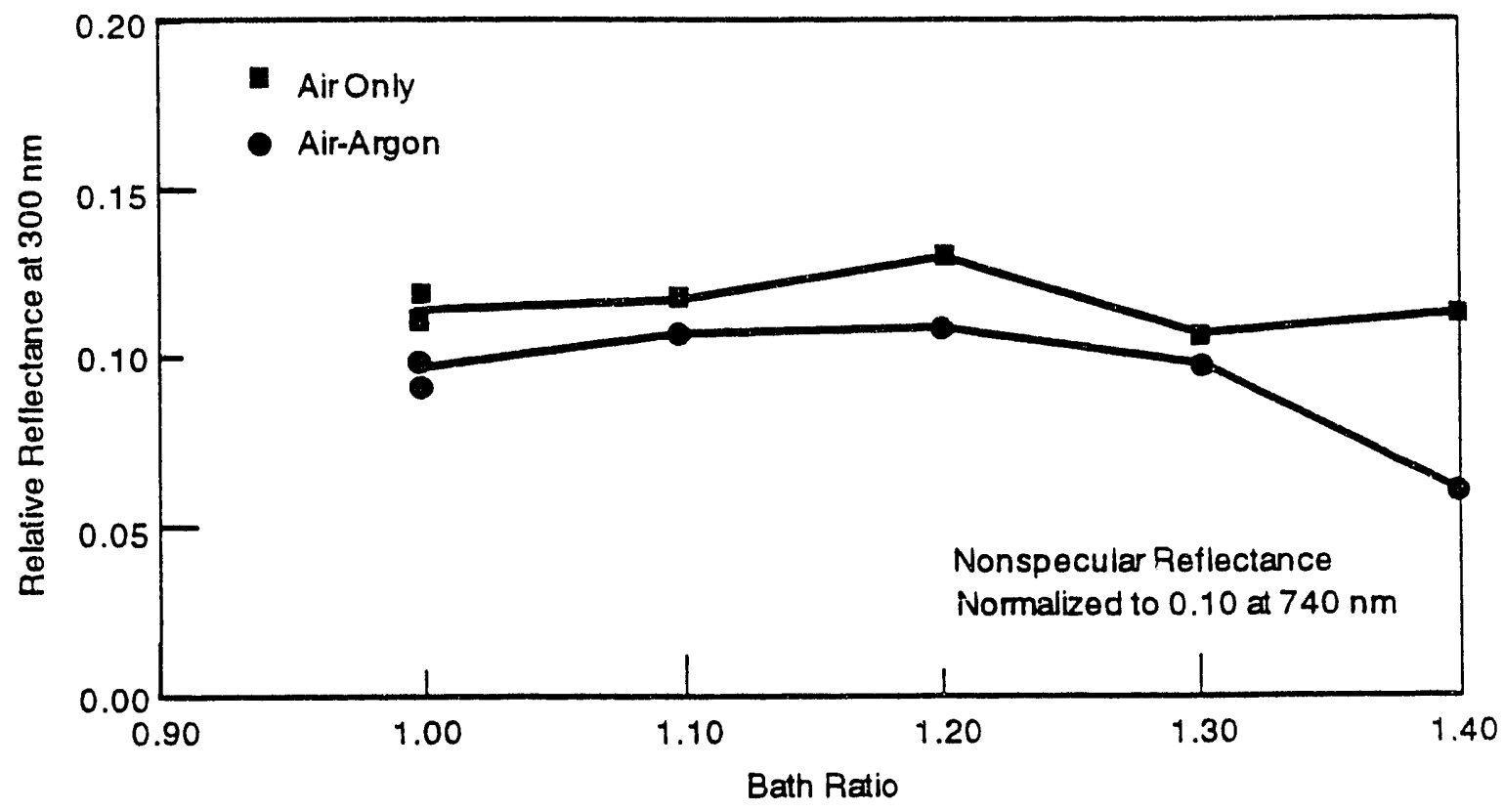

R9207063.14

Figure 5.4. Summary of Reflectance Data for Vapor Deposits Obtained Using a Chimney

useful for monitoring bath ratio. Given the difficulties in correlating the reflectance data with bath ratio and with alumina in the first set of studies, it was considered unlikely that the chimney design would give any better results in measuring alumina concentration.

The bath vapor spectral analysis approach was probably unsuccessful because of experimental problems in the sampling method. The effect of oxygen in the gas phase (suggested in Figure 5.4), the temperature of the sample substrate, and the thickness of the sample all probably affected the results. In particular, thick samples collected at higher temperatures showed little variation in the relative reflectance with bath ratio.

The conductivities of the vapor-deposited films were also measured after depositing them on the surface of a conductivity probe. The vapors formed above the bath were tested during heatup and cooldown of baths with bath ratios of 1.0,1.1, 1.2, and 1.3. A linear correspondence of $1 / T$ (temperature in $\mathrm{K}$ ) with the logarithm of the conductivity of the film was typically observed. The slopes of these curves were similar regardless of bath composition. These results suggested that either the composition of vapor above the bath does not vary with bath composition or that variations are too small to detect. Therefore, this technique did not appear to be applicable for confirming bath composition either.

\subsection{Summary of Conclusions}

Analysis of bath vapors deposited on cool substrates did not give a reliable indication of the composition of the bath. The data were apparently affected by characteristics of the deposited film 
that could not be sufficiently controlled in the laboratory cells. Given the control problems in the laboratory, it was considered unlikely that the approach would be successful in the field, where variations in operating and sampling conditions would probably be more severe. For this reason, further development of this technique was abandoned. 


\subsection{Thermal Arrest}

Cooling of any liquid eventually results in the precipitation of one or more solid phases. In the case of the alumina-cryolite molten salt bath, the temperature at which this transition occurs is the bath's liquidus temperature. Since the liquidus temperature depends on the composition of the melt, it should be useful in determining the melt composition, provided, of course, there is only one independent composition variable, e.g. alumina. During cooling, the temperature of the melt drops until the liquidus temperature is reached. At the liquidus temperature, the temperature of the bath remains the same, due to the heat of fusion, until the precipitation is complete. In a temperature-versus-time trace obtained during cooling, the result is an inflection, or thermal arrest, at the liquidus temperature. This phenomenon was used as the basis for the alumina sensor discussed in this section. Samples of bath removed from a reduction cell were cooled and their cooling curves obtained. The thermal arrest temperature was measured and related through a calibration curve to alumina concentration.

\subsection{Description of Approach}

The initial laboratory setup used to measure the thermal arrest of molten cryolite mixtures employed a simple combination of a thermocouple, a temperature meter, and a stripchart recorder. The preliminary results indicated that the liquidus temperatures could be measured reliably this way, so a more sophisticated and more portable system was assembled. As shown in Figure 6.1, this system consisted of a Hewlett-Packard HP-321 data acquisition unit (Palo Alto, California), a HP-71B hand-held computer, a type $\mathrm{K}$ thermocouple, and a $3-\mathrm{cm}^{3}$ graphite dip cup with a lightweight handling arm. The electronics package weighed less than ten pounds and could be stored in a small 21 in. $x 15$ in. $x 7$ in. suitcase for easy transport and use. The system, which facilitated application in field testing, also operated on an internal, rechargeable battery power supply. Figure 6.2 is a photograph of the assembly ready for use.

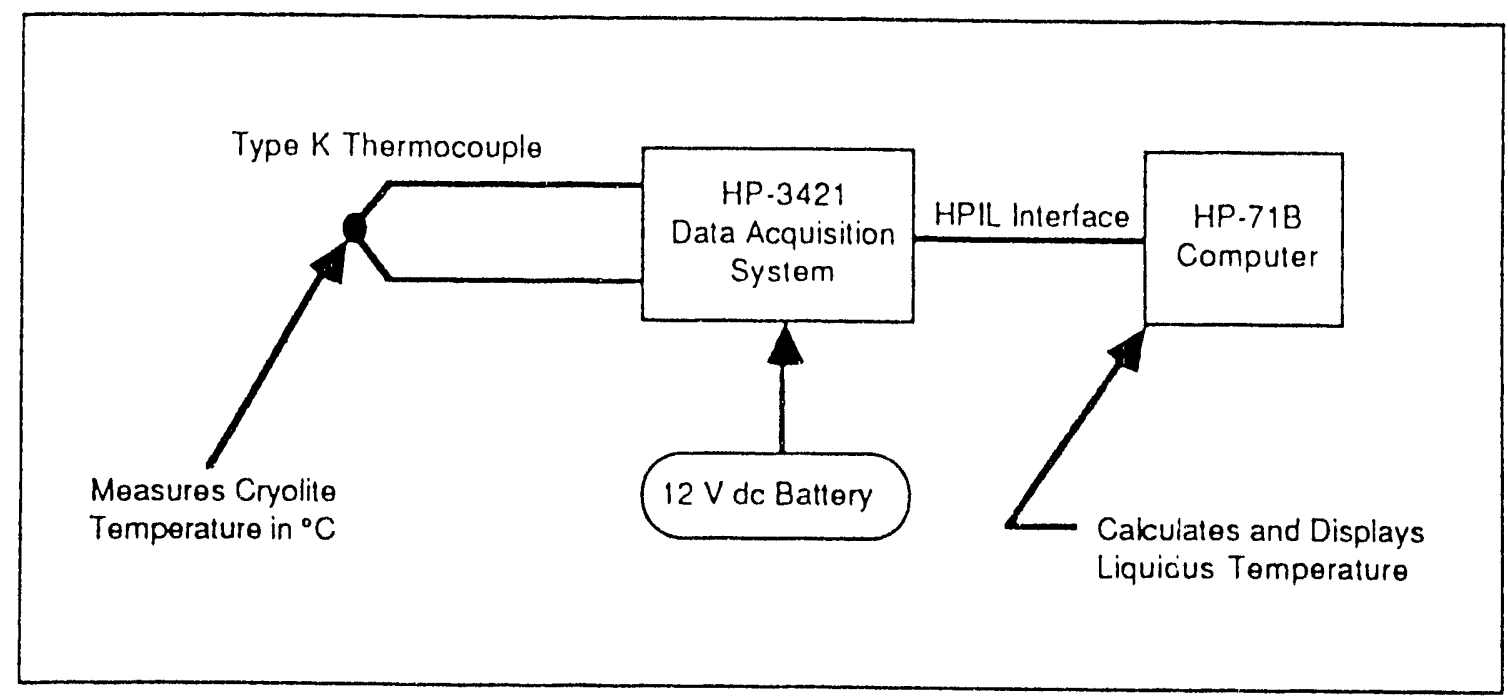

Figure 6.1. Portable Contact System for Measuring the Liquidus Temperature of Cryolite 


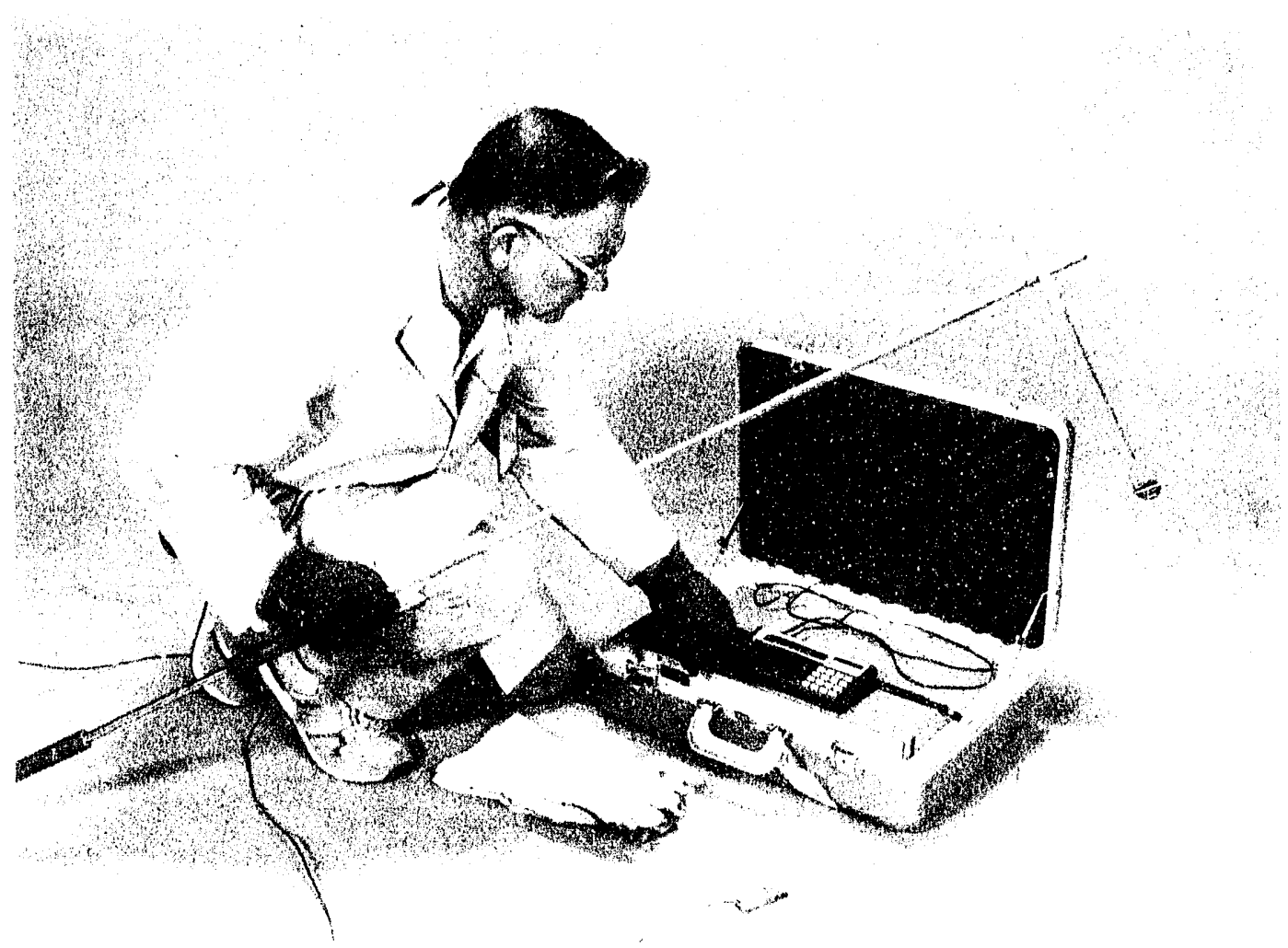

Figure 6.2. Photograph of Thermal Arrest Device Ready for Use

Figure 6.3 is a schematic of the apparatus in use. In a typical measurement, a sample of molten bath was withdrawn, temperatures were measured with the thermocouple, and the temperature-versustime data were digitally stored with the computer. To facilitate data analysis, a program was developed for the HP-71B that allowed the system to identify the temperature at which the thermal arrest occurs. Identification of this temperature is based on the observation that a typical cooling curve is characterized by three regions with different slopes. These three regions are the initial cooling period with the fastest cooling rate, the thermal arrest period with the slowest cooling rate, and the final period with a cooling rate of intermediate magnitude. The computer was programmed to calculate the slope $(\mathrm{S})$ of the cooling curve and the rate of change of the slope $(\mathrm{H})$. The temperature at which the thermal arrest occurs was determined by finding the maximum value of $\mathrm{H} / \mathrm{S}$, since a maximum value of $\mathrm{H}$ occurs in the region where the slope $\mathrm{S}$ is at a minimum. The resultant inflection point in the cooling curve as the system cools through the liquidus temperature was reported, as was the process temperature. By selecting the appropriate bath ratio, a wt $\% \mathrm{Al}_{2} \mathrm{O}_{3}$ value was also reported. 


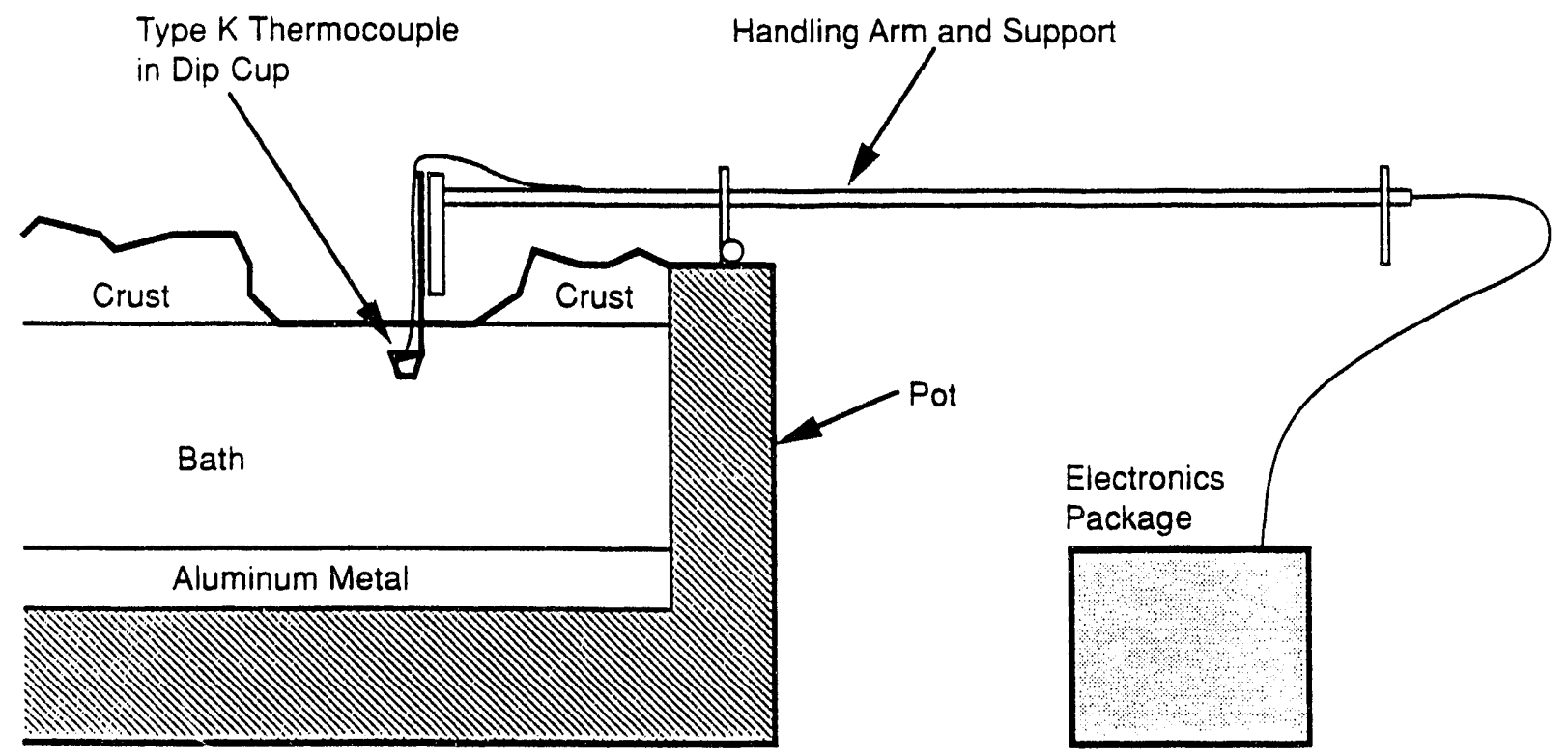

R9207063.3

Figure 6.3. Schematic Showing Dip Cup Immersed in Cryolite Bath

\subsection{Results}

Data from laboratory tests of this system using a bath ratio of 1.1 with $6,7,8$, and 9 wt $\%$ alumina are shown in Table 6.1.

The wt\% alumina values in the first column were determined on the basis of the weighed amounts of alumina powder added to the bath. The mean wt $\%$ alumina data in the last column were determined from a calibration curve developed from the mean temperatures at $6 \mathrm{wt} \%$ and $9 \mathrm{wt} \%$ alumina. A linear calibration curve between these two calibration points was assumed. In addition to displaying the transition temperature, the c $\supset$ mputer also displayed the maximum temperature recorded during the data run (starting temperature) and a quality factor. The quality factor gives a measure of how well-defined the thermal arrest was. Note that the third and fifth data points at $6 \mathrm{wt} \%$ alumina had very low quality factors. The reason for this is suggested by the very low maximum (starting) temperatures, indicating that the dip-cup contents had cooled below the true transition temperature before the data collection began. These two data points with low quality factors were excluded from the calculation of the mean.

As shown in Table 6.1, the repeatability for the determination of the transition temperatures was excellent. The maximum uncertainty in the alumina content was better than $\pm 0.17 \mathrm{wt} \%$. Success in these laboratory studies generated sufficient interest to perform field testing of the technique. As a result, two separate field tests were performed at the Kaiser Aluminum and Chemical Corporation facility in Mead, Washington. Results of the second field test were first discussed in Brenden (1988). 
Table 6.1. Data from Thermal Arrest Studies Using Laboratory Cells

\begin{tabular}{|c|c|c|c|c|c|}
\hline$\underline{w t} \% \mathrm{~A}_{2} \underline{\mathrm{O}}_{3}$ & $\begin{array}{c}\text { Transition } \\
\text { Temperature, }{ }^{\circ} \mathrm{C}\end{array}$ & $\begin{array}{l}\text { Quality } \\
\text { Factor }\end{array}$ & $\begin{array}{c}\text { Starting } \\
\text { Temperature, }{ }^{\circ} \mathrm{C} \\
\end{array}$ & $\begin{array}{l}\text { Mean Transition } \\
\text { Temperature. }{ }^{\circ} \mathrm{C}\end{array}$ & $\begin{array}{c}\mathrm{Wt} \% \mathrm{Al}_{2} \mathrm{O}_{3}, \\
\text { Mean } \\
\end{array}$ \\
\hline 6 & 941.4 & 2.1 & 997.9 & & \\
\hline 6 & 945.8 & 8.2 & 972.1 & & \\
\hline 6 & 901.5 & 0.4 & 922.5 & & \\
\hline 6 & 944.0 & 43.8 & 959.9 & & \\
\hline 6 & 901.4 & 0.0 & 911.0 & & \\
\hline 6 & 942.3 & 8.6 & 1006.0 & & \\
\hline 6 & 943.4 & 6.2 & 1009.0 & $943.27 \pm 1.03$ & $6.00 \pm 0.17$ \\
\hline 6 & 944.1 & 6.8 & 979.6 & & \\
\hline 6 & 943.4 & 9.1 & 995.6 & & \\
\hline 6 & 942.6 & 8.1 & 990.7 & & \\
\hline 6 & 942.8 & 6.1 & 997.7 & & \\
\hline 6 & 943.2 & 10.8 & 992.3 & & \\
\hline 6 & 943.2 & 13.3 & 991.1 & & \\
\hline 6 & 943.0 & 16.5 & 999.8 & & \\
\hline 7 & 938.8 & 13.8 & 981.0 & & \\
\hline 7 & 939.1 & 8.0 & 997.9 & & \\
\hline 7 & 938.8 & 10.0 & 987.4 & $939.13 \pm 0.58$ & $6.67 \pm 0.05$ \\
\hline 7 & 939.5 & 7.7 & 998.0 & & \\
\hline 7 & 939.6 & 7.6 & 991.7 & & \\
\hline 7 & 939.0 & 9.3 & 984.3 & & \\
\hline 8 & 932.7 & 11.1 & 982.0 & & \\
\hline 8 & 932.6 & 10.0 & 985.2 & & \\
\hline 8 & 932.7 & 11.9 & 986.2 & $932.6 \pm 0.58$ & $7.76 \pm 0.09$ \\
\hline 8 & 931.2 & 8.9 & 996.1 & & \\
\hline 8 & 932.6 & 6.4 & 1002.0 & & \\
\hline 9 & 925.3 & 35.0 & 1003.2 & & \\
\hline 9 & 924.6 & 42.0 & 990.6 & & \\
\hline 9 & 924.9 & 38.8 & 985.3 & $924.70 \pm 0.37$ & $9.00 \pm 0.06$ \\
\hline 9 & 924.6 & 20.6 & 996.2 & & \\
\hline 9 & 924.7 & 6.6 & 992.9 & & \\
\hline 9 & 924.1 & 12.7 & 997.7 & & \\
\hline
\end{tabular}

The first field test of the thermal arrest probe was performed at the Kaiser plant on September 22,1987 . A set of four readings were taken on one reduction pot and seven readings on another. During this test, certain difficulties were encountered. Most importantly, it was found that the cup assembly had to be in the bath long enough to reach thermal equilibrium. This was necessary to assure that the starting temperature for the cooling curve was at least $5^{\circ} \mathrm{C}$ higher than the transition temperature. Discarding the measurements that failed this criterion gave standard deviations in the measurements of about $0.3 \mathrm{wt} \%$ (estimated). Also, it was found that the pots in the Kaiser facility 
contained $5-6 \% \mathrm{CaF}_{2}$, which precluded the use of calibration curves developed in the laboratory for an accurate determination of alumina concentration. Other problems encountered during the first field test included some instrumental problems such as melt-off of the dip-cup support and heat damage to the thermocouple connection sockets. With these exceptions, however, the measuring system was found to be very convenient to use. The hand-carry size of the system had strong appeal as did the automatic transition temperature display and $w t \%$ alumina display.

To address the problems with the first field test, a second test was performed at the Kaiser plant on August 18, 1988. The apparatus and procedure were modified to correct the difficulties. An extra-long thermocouple was used to eliminate need for a connector in the heat zone, and a nichrome wire was used instead of a nickel wire to secure the dip cup better. The computer program was also modified to permit the operator to read the temperature of the dip cup before the cup was removed from the bath. This refinement helped ensure that the starting temperature was above the transition temperature. In addition, the equation developed by Lee et al. (1984) was used to convert the transition temperature (taken as the liquidus temperature) to alumina concentration. This equation was reported to be accurate for $\mathrm{CaF}_{2}$ concentrations between 3.8 and $11 \mathrm{wt} \%$ and for excess $\mathrm{AlF}_{3}$ concentrations between 5 and $20 \mathrm{wt} \%$.

During the second field test, a series of 17 measurements were made over a time period of 90 minutes. Thus, a measurement cycle was 5 min long (on the average). During this period, one thermocouple developed a short and was replaced and one dip cup fell off as a result of the failure of the nichrome wire support during its fourth insertion into the bath. The replacement of this dip cup was also included in the 90-minute activity. The nichrome wire on the first and the last (third) dip cups did not indicate any weakness or melting even though one was dipped nine times and the other was dipped six times.

The data taken during the second field test are shown in Table 6.2. A total of eight readings taken in Pot \#2 yielded a mean transition temperature of $942.3^{\circ} \mathrm{C}$. Nine measurements from Pot \#3 gave a mean transition temperature of $964.3^{\circ} \mathrm{C}$. Since the transition temperature may not be identical to the liquidus temperature due to peculiarities in the cooling curve (inflection is not perfect), the equation of Lee et al. (1984) was modified by the addition of a small constant. It is interpreted that this small constant accounts for discrepancies between the liquidus temperature and the transition temperature. The modified equation that resulted from incorporating this small constant (equal to -8.4) and substituting the appropriate conditions for the Kaiser plant into the original equation (Lee et al. 1984) was

$$
A I_{2} O_{3}=\left(1001+K-T_{t}\right) / 5.33
$$

where $\mathrm{K}$ is defined the same as in the original formula and $T_{t}$ is the transition temperature. The modified formula worked very well in predicting alumina concentrations in this field study. The alumina concentrations calculated with this formula were $3.29 \mathrm{wt} \%$ for Pot $\# 2$ and $3.67 \mathrm{wt} \%$ for Pot \#3. These compared well with the concentrations measured by Kaiser personnel using wet chemical analysis: $3.34 \mathrm{wt} \%$ for Pot $\# 2$ and $3.60 \mathrm{wt} \%$ for Pot $\# 3$. Unfortunately, the estimated standard deviations for the alumina concentrations calculated from the transition temperatures were quite large: 
Table 6.2. Summary of Measurements for Second Field Test of the Thermal Arrest Method

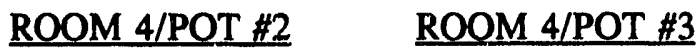

Bath Ratio

$\mathrm{CaF}_{2}$ (wt\%)

Measured Transition Temperatures $\left({ }^{\circ} \mathrm{C}\right)$

Mean Transition Temperature $\left({ }^{\circ} \mathrm{C}\right)$

Standard Deviation of the Mean $\left({ }^{\circ} \mathrm{C}\right)$

Calculated Alumina Concentration (wt\%)

Alumina by Wet Lab Analysis (wt\%)
1.123

4.8

1.238

5.08

937.8

937.7

943.0

939.8

945.9

941.2

946.7

946.8

942.3

3.9

3.29

3.34
956.5

962.5

958.9

958.4

971.0

971.0

962.0

973.0

965.0

964.3

6.1

3.67

3.60

0.73 wi\% for Pot \#2 and 1.14 wt\% for Pot\#3. The large standard deviations detracted from the positive aspects of the results, suggesting that numerous replicate measurements would be required to obtain a reliable number. It was estimated that at least nine replicate measurements would be required to reduce uncertainties to acceptably small values.

\subsection{Summary of Conclusions}

Despite the successes of the first laboratory and field tests of the thermal arrest method, the technique was abandoned. The primary reason for not continuing development of the technique was concerns over it being an intrusive or "contact" method. About the time this method was being developed, the digital signal analysis method (Section 9.0) was also being investigated. The latter approach has the very important advantage of using no intrusive probes; it presents no materials corrosion problems involving probe materials. The technique simply monitors signals on the existing electrodes. With the thermal arrest method, the sensor would have to be inserted into the bath each time a measurement was taken. Furthermore, the results of these initial studies suggested that numerous replicate readings would have to be taken for every measurement in order to give acceptably low uncertainties. This proved to be a significant obstacle for industrial acceptance. As it turns out, there is at least one other portable, contact-type alumina sensor which is already used in the aluminum industry (Tabereaux and Richards 1983). However, the probe also cannot be used to make continuous measurements and it gives results that, while reliable, do not match the accuracy of wet laboratory measurements. Since the thermal arrest method was seen as adding very little in terms of advantages over the alternative methods, any work to develop the technique further was abandoned. 


\subsection{Impedance Analysis}

Experimental studies conducted at the Pacific Northwest Laboratory (PNL) in FY 1987 through early FY 1989 indicated that the cermet inert anodes evaluated by PNL exhibited a characteristic impedance during the electrolytic production of aluminum in bench-scale Hall-Heroult cells. This impedance was found to have the following characteristics (Strachan et al. 1988):

- It was largely resistive in nature.

- It varied as a function of current density, giving a minimum at about $0.5 \mathrm{~A} / \mathrm{cm}^{2}$.

- It appeared to depend on alumina concentration in the electrolyte. In general, the impedance seemed to increase with increasing alumina concentration.

- At high current densities ( $>1 \mathrm{~A} / \mathrm{cm}^{2}$ ), discontinuous changes in the impedance occurred, causing "spikes" in the current or voltage data.

Based on these characteristics, PNL originally proposed that a resistive film formed on inert anodes during electrolysis. It was argued that the formation of this film was necessary to protect the inert anode from corrosion reactions that would otherwise occur in the molten electrolyte. It was also proposed that an anodic current density of $0.5 \mathrm{~A} / \mathrm{cm}^{2}$ formed a film with optimum passivating-like characteristics. At lower current densities, the film was proposed to be incompletely formed, resulting in corrosion of the cermet's metallic phase. At higher current densities, it was proposed that the film would become too thick and its resistance would become too high to sustain the current density. Consequently, the film would rupture, resulting in sudden and severe corrosion at the electrode's metal phase. The rupturing events in the film were indicated by sudden drops in impedance and appeared as "spikes" in the voltage data for a cell under galvanostatic (constant current) control. It was also proposed that the quality of the film depended on the alumina concentration in the electrolyte. Higher alumina concentrations seemed to favor a more resistive, presumably thicker, film. Consequently, film rupturing behavior was considered to be more likely at high alumina concentrations (close to saturation) when current densities were above $0.5 \mathrm{~A} / \mathrm{cm}^{2}$.

Two of the main properties of the proposed film therefore seemed to indicate something about alumina concentration and it was suggested that each of them could serve as the basis for an alumina sensor. First of all, resistivity of the film as measured by impedance techniques appeared to be related to alumina concentration. Secondly, "film rupturing events" as monitored by spikes in the electrical data might serve as an indicator of undesirable alumina concentrations or conditions. These two approaches to an alumina sensor are discussed in the nex $\hat{\imath}$ two sections of the report. The present section (Section 7.0) covers impedance studies; Section 8.0 deals with attempts to monitor the spikes in the electrical data using what came to be called a "reference anode."

\subsection{Description of the Approach}

From FY 1987 through FY 1989, numerous studies were performed using PNL bench-scale laboratory cells to measure the impedance of the cermet anodes at various current densities and 
alumina concentrations. One of the objectives of this work was to see if an alumina-impedance relationship could be established that might serve as a basis for an alumina concentration sensor.

\subsection{Results}

The experimental apparatus used in these studies varied somewhat from test to test, but in most cases the setup consisted of a laboratory-scale reduction cell operated at constant current using a PNL developed device that allowed the dc current from a power supply to be modulated with white noise. A Rockland Model 804 Fast Fourier Transform Frequency Analyzer (Waveteck Rockland Scientific, Inc., Northvale, New Jersey) was used to monitor the resistance, capacitance, phase angle, and coherence of the anode over the frequency range of 0 to $100 \mathrm{~Hz}$. It was recognized that the instrumentation used in these development studies would have to be modified significantly if the approach were to be used in industry. The studies reported here were intended merely to demonstrate whether the approach worked, i.e. whether the anode impedances could be related to alumina concentration. If successful, the method would then be streamlined to facilitate its use in a commercial cell.

The cermet anodes were small cylinders that were sheathed with boron nitride to expose $1 \mathrm{~cm}^{2}$ of surface to the electrolyte. The carbon crucible containing about $1 \mathrm{~kg}$ of the molten salt electrolyte was used as the counter electrode (cathode). In these studies, the carbon crucible was also used as a pseudoreference electrode, which was considered appropriate since the voltage drop at the cathode was negligible in this cell design. ${ }^{(a)}$

Early laboratory studies at PNL (Strachan et al. 1988) had indicated that the impedance due to reactions at the anode surface was largely resistive, i.e., its capacitive component was negligible. Consequently, the strategy used in this work was to monitor the resistance at the anode surface only. This was done by using a $50 \mathrm{~Hz}$ excitation signal to make an impedance measurement and then correcting the measurement for ohmic loss through the electrolyte.

Figure 7.1 shows the anode impedances obtained in one set of studies. These data were obtained using a cermet anode in a bath at $983^{\circ} \mathrm{C}$ with bath ratio equal to 1.15 . The impedances are shown as a function of current density and at varying alumina concentrations (expressed as a percent of saturation which is about $8 \mathrm{wt} \%$ under these conditions). ${ }^{(b)}$ In these plots, definite trends are observable as a function of current density and alumina concentration. In particular, the impedance appears to reach a minimum at around $0.5 \mathrm{~A} / \mathrm{cm}^{2}$. More importantly, the impedance appears to correlate with alumina concentration, becoming larger at higher alumina concentrations. These results were interpreted in terms of the formation of a resistive film. At high alumina concentrations, the film became thicker and its resistance larger. The possibility that the resistance of this film could be used

(a) The cathode surface area was about 300 times greater than the anode surface area.

(b) In many of the correlations performed in this program, alumina concentration was expressed in units of \% saturation. This approach was taken primarily in response to the DOE-HQ criterion that the sensor work well close to saturation. The \% saturation scale highlighted this sensitivity. Conversion from wt\% to \% saturation was performed using a number of empirical formulae, e.g. Skybakmoen et al. 1990. 


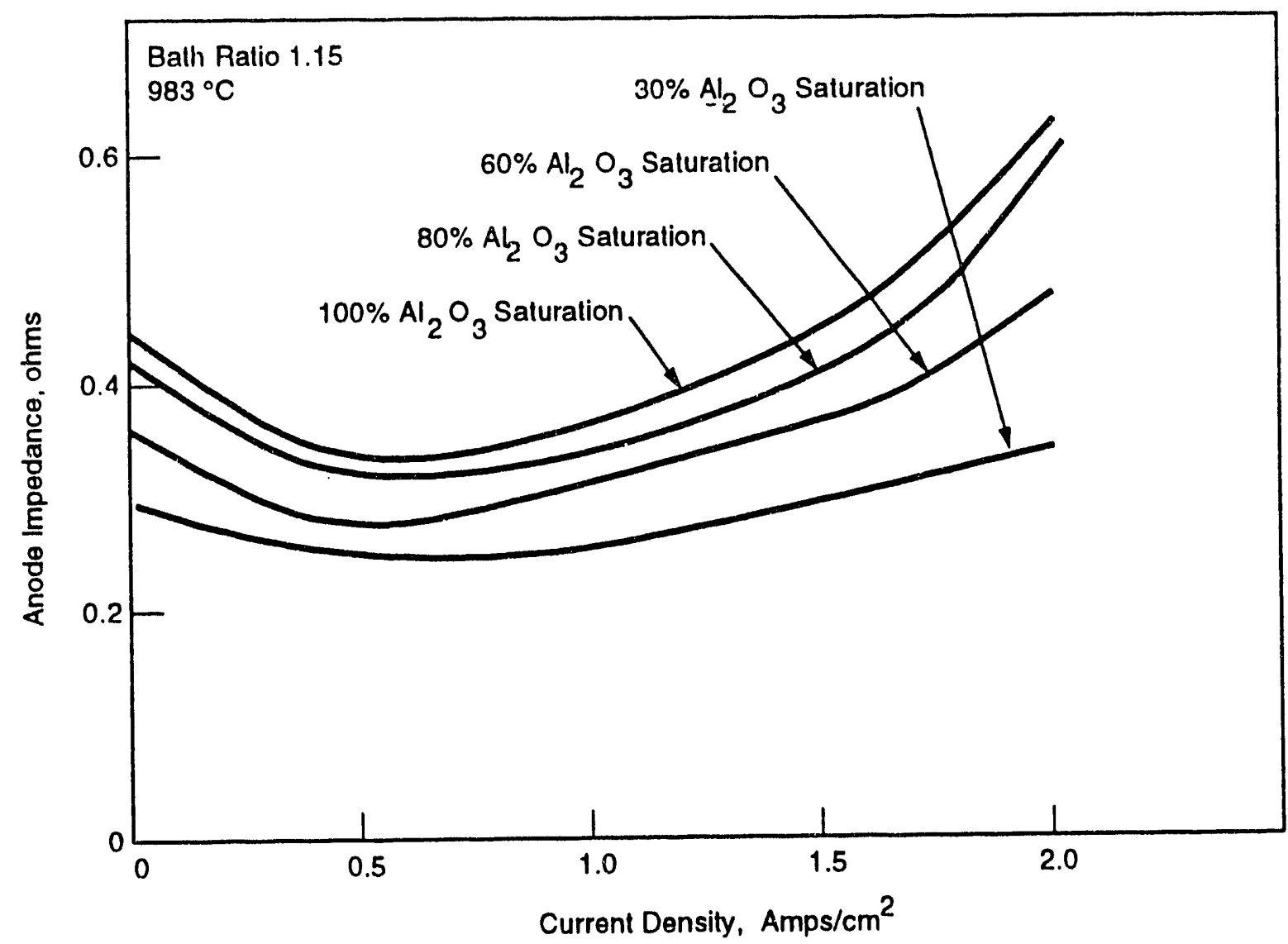

38912079.3

Figure 7.1. Impedance Versus Current Density with Percent Alumina Saturation Dependence

as the basis for an alumina sensors caused a great deal of optimism at that point, so additional studies were performed to determine how reproducible this correlation was.

Attempts to reproduce the relationship between anode resistance and alumina concentration proved disappointing. Figure 7.2 shows the results of one such attempt. Despite the persistent trend of a minimum at $0.5 \mathrm{~A} / \mathrm{cm}^{2}$, wide variability in the impedances at the anode was observed in the test results. In Figure 7.2, data are plotted for alumina concentration at $80 \%$ of saturation at two different times during the experiment. As shown, the data appeared to exhibit severe hysteresis effects. This lack of consistency in the data made this approach to an alumina sensor untrustworthy, so the approach was abandoned. At the time, it was concluded that the film impedance was dynamic, changing with time and with small fluctuations in cell conditions. Additional impedance studies performed in FY 1989 and FY 1990 (Windisch and Stice 1991a) using a different experimental setup, however, put into question the whole argument concerning the formation of a film, and, in particular, its role as the principal source of the anode impedance. 


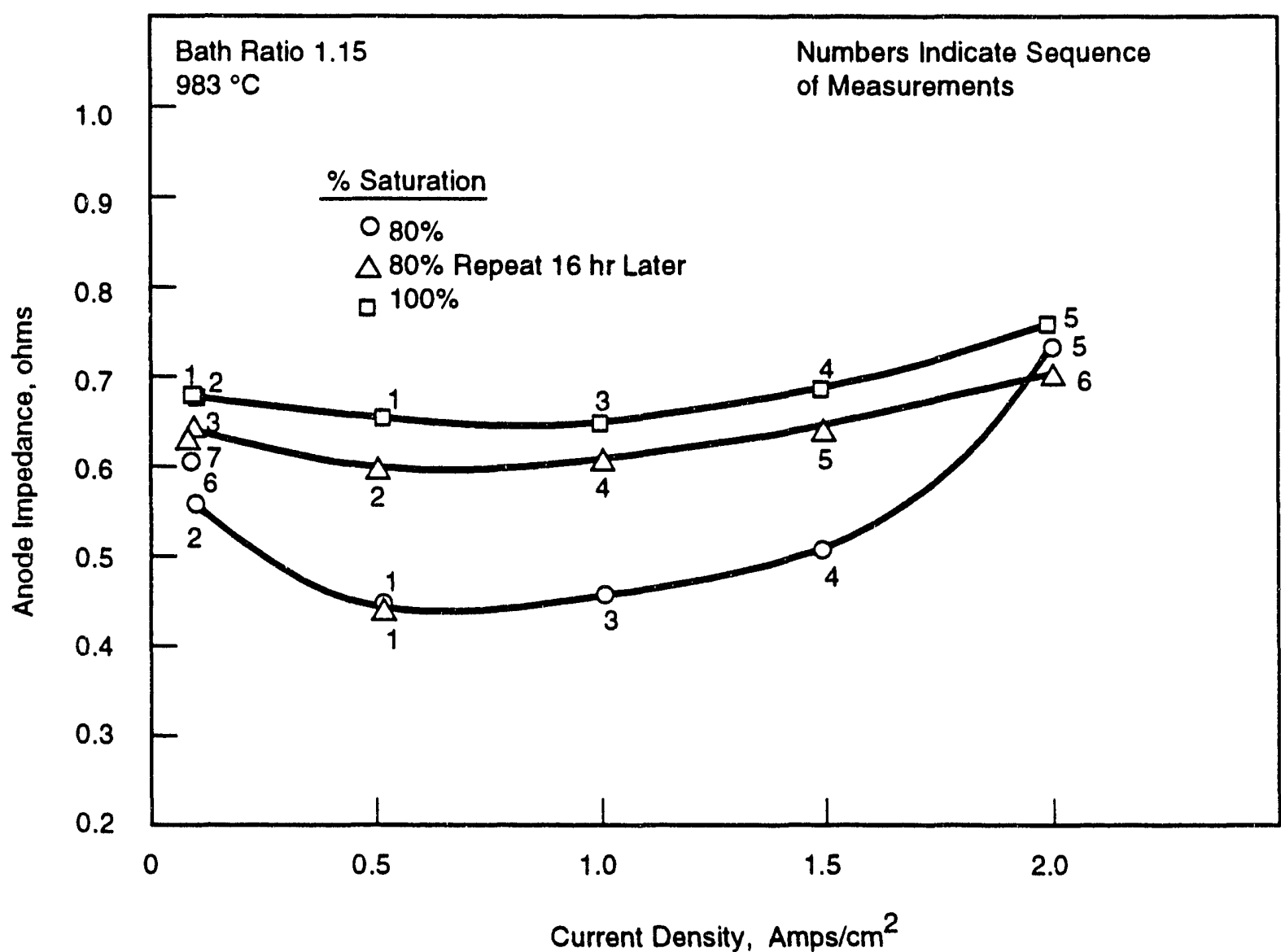

38912079.4

Figure 7.2. Reproducibility of Anode Impedance for $80 \%$ and $100 \%$ Alumina Saturation

The results of the studies performed in FY 1989 and FY 1990 indicated that the principal source of the anode impedance was not a film but rather the oxygen gas bubbles produced during electrolysis at the anode. This explanation was provided after numerous laboratory experiments that were discussed in three separate PNL reports (Windisch and Stice 1990; Windisch and Stice 1991a; Windisch and Stice 1991b) and also in one literature publication (Windisch 1991). In these studies, the anode impedance was also found to depend strongly on anode surface structure and on cell geometry. These effects are not completely independent of the bubbling phenomena ${ }^{(a)}$ and also possibly explain the variability in the impedances as a function of time that was illustrated in Figure 7.2. Variations in anode surface structure would be expected to occur on fresh cermet anodes during their initial stages of polarization in the melt. Some dependence on alumina concentration was also observed in these studies, which could be explained by the effect of alumina concentration on the

(a) For example, a rough surface will have more hindered bubble flow than a smooth surface. While the roughness itself may contribute to the impedance (perhaps as an area correction), its effect is difficult to distinguish from that of the change in gas flow dynamics that accompanies roughening. 
bubbling phenomena, i.e. by modifying viscosity and surface tension. Unfortunately, similar to the earlier experiments, other operating variables had too great an effect to permit sorting out the alumina concentration dependency accurately and reproducibly.

\subsection{Summary of Conclusions}

Due to the lack of reproducibility of the correlation between the anode impedance and alumina concentration, this approach was abandoned. Correlation curves relating anode impedance to alumina concentration could be developed but they varied widely with time. It was concluded that the variation in other conditions of the anode overwhelmed the sensitivity to alumina. The explanation of the source of the anode impedance also evolved during these studies. The principal source of the impedance is presently believed to arise from the oxygen gas bubbles produced at the anode during electrolysis. 


\subsection{Reference Anode}

As discussed in Section 7.0, the impedance of a cermet anode was observed to depend on alumina concentration. This relationship was first interpreted in terms of a film that was proposed to form on the anode. It was also proposed that this film was protective (Strachan et al. 1988; Marschman 1989). As long as it was present (but not too thick!), the cermet anode would be protected from corrosion by the molten salt during electrolysis. This argument was supported by the observance of "spikes" in the current or voltage versus time traces obtained in laboratory cells. These spikes seemed to occur whenever a cermet anode was operated under what were known to be "dangerous" conditions, i.e., low alumina concentration and/or high current density.

The relationship between the spikes and the performance of a cermet anode was interpreted as follows. As long as the operating conditions were favorable, the film would form, attain some equilibrium thickness with a characteristic impedance, and protect the cermet material from corrosion. Under these conditions, the anode voltage and current would remain smooth or "quiet." If conditions of high current density were encountered, the film would rupture in order to sustain the large impressed currents. Similarly, if the alumina concentration was too low, the film would become so thin it would rupture. In either case, the unprotected surface of the anode would be exposed momentarily and corrosion would occur. This would cause a sudden jump in the current or drop in the voltage (depending on whether the experiment was performed under potentiostatic or galvanostatic control) that would persist (momentarily) until the film had reformed to some extent. Because of the momentary nature of these events, the result would be spikes in the voltage or current traces.

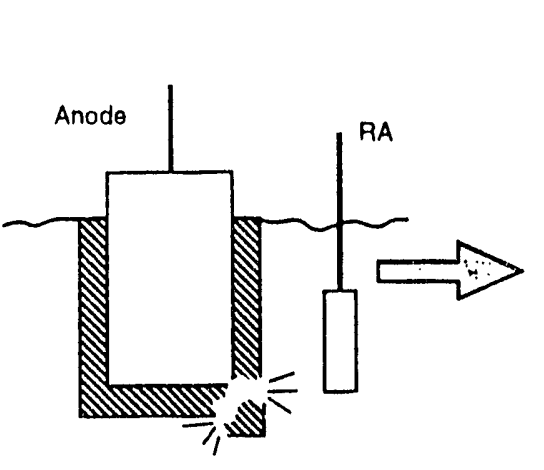

Low Alumina
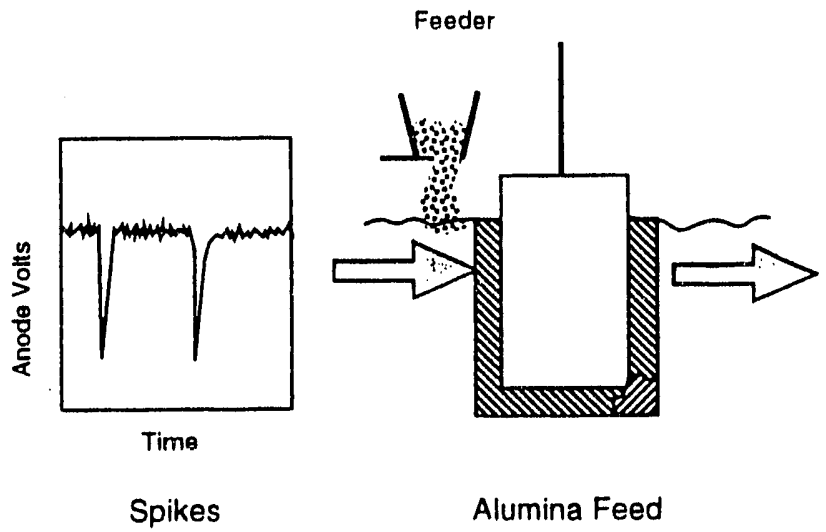

Spikes $=f($ Film Integrity $)=1($ Alumina Concentration $)$

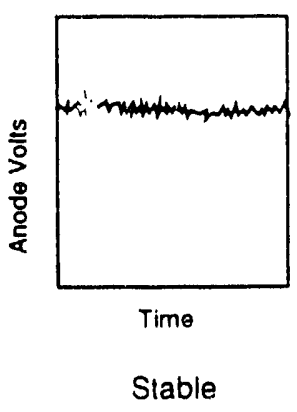

38912079.5

Figure 8.1. Schematic Illustrating Principles of Reference Anode 


\subsection{Description of the Approach}

At the time the impedance characteristics of the anodes were being investigated, it was proposed that the spikes in the current or voltage traces could be used to monitor the performance of the cermet anodes. While not being an alumina sensor per se, the approach would accomplish the same objective. It would serve as an indication of instability of the anode or onset of corrosion. In practice, the approach would be even more advantageous in that it would signal all sorts of problems that might put the cermet anode at risk, not just low alumina concentration. The schematic in Figure 8.1 illustrates the basis for this sensor for a cell under galvanostatic control. At low alumina concentrations, spikes would be observed in the voltage-versus-time trace due to failure events associated with the protective film. Via feedback, either manual or automated, the spikes would signal the need for higher alumina concentrations so the film could be restabilized. Alumina feed would be increased and would continue until a sufficiently high alumina concentration was achieved. This would be indicated when the voltage-versus-time trace exhibited a "quiet" reading once again.

To maximize the sensitivity to these spikes, it was proposed that a separate reference electrode be used. The reference electrode would be placed close to the cermet anode so that other fluctuations in the cell would not confuse or "wash out" spikes that arose from the proposed film rupturing events. Toward this end, the "reference anode" (RA) was developed. The RA was actually a reference electrode but had the same composition as the working cermet anode (the reason it's called an "anode"). The RA was used with a small voltage applied to it to maintain the minimal current required to "passivate" it. The small current was considered necessary since the anode material had been observed to corrode under open circuit conditions. With this configuration (Figure 8.2), it was believed that the signals would represent the behavior of the working electrode and not reflect any materials changes in the RA.

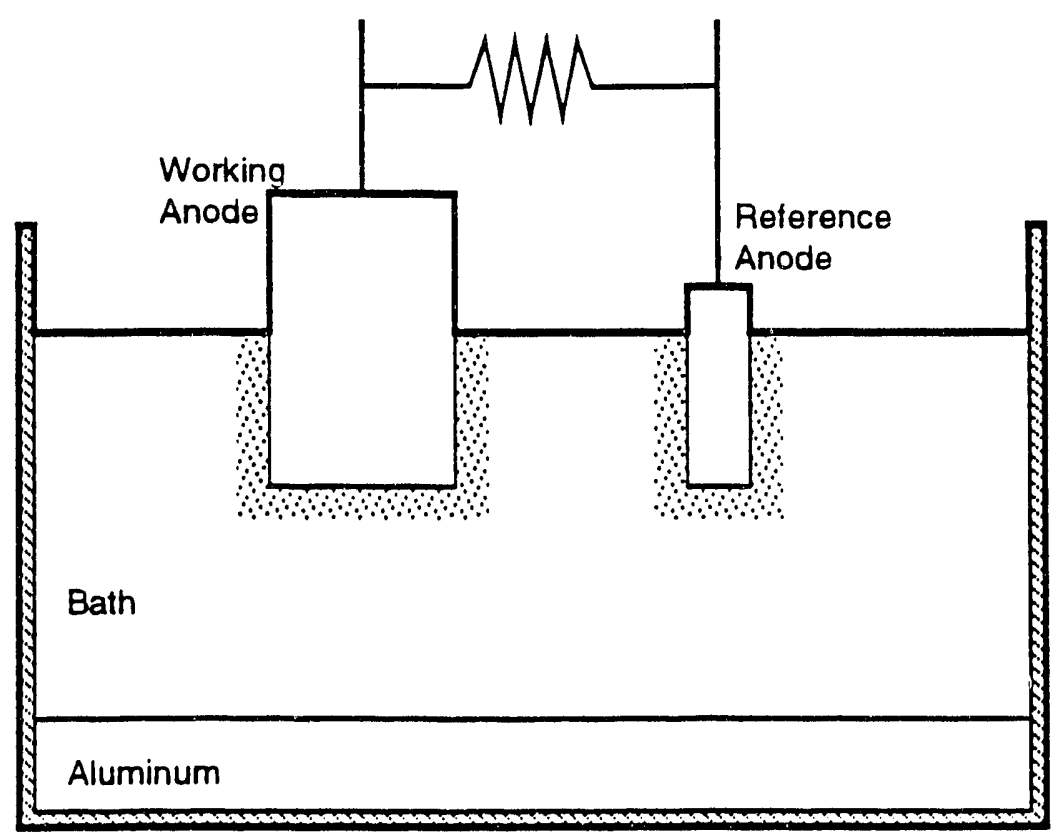

R9207063.4

Figure 8.2. Schematic of Simple Process Control Sensor Used to Monitor an Anode 


\subsection{Results}

The RA was used successfully in a number of laboratory tests during FY 1988 and 1989 (Marschman 1989). In these tests, whenever the RA was used in conjunction with a cermet anode, the occurrence of spikes or noise in the RA-to-cermet anode voltage seemed to indicate poor performance. In almost all cases, those anodes which exhibited very "noisy" behavior when monitored with the RA were found to have corroded severely. The RA was also patented for use in controlling cermet anode corrosion in commercial cells (Koski and Marschman 1987).

In FY 1989, the RA was tested in the prototype anode test performed at the Manufacturing Technology Laboratory, Reynolds Metals Company, Muscle Shoals, Alabama. The primary purpose of the prototype anode test was to evaluate the performance and control of the cermet anode composition which was under development at PNL. The test was also the first scaled-up evaluation of the RA. The details of the test are discussed in Strachan et al. (1990).

In all, four RAs were used in sequence during the prototype anode test, which lasted more than $100 \mathrm{~h}$. During the test, the prototype anode was found to corrode severely, however no indication of this corrosion was given by the signals monitored with the RA. Moreover, the RAs used in the test themselves experienced difficulties. Only two of the four RAs used in the test were recovered. Two fell off their connector rods (as a result of the catastrophic corrosion of the connector rod) and into the reduction cell. Post-test examination of the recovered RAs showed that both had corroded severely during use. Figure 8.3 shows the extent of corrosion in one case.

The corrosion of the RA occurred despite attempts to protect it by impression of a small anodic current using a shunt to the working anode as shown in Figure 8.2. It had been proposed that such a current should foster the formation of a protective film or reaction layer and thus minimize corrosion. During the prototype anode test, it was observed that the RA current was only slightly affected by the magnitude of the process current. The current was generally noisy but with a stable long-term trace, suggesting stable alumina content. An attempt to verify the response of the RA to variable alumina content was made during the termination of the experiment by stopping the addition of alumina. The results were inconclusive, however. The trace remained steady and it was concluded that, during this time, the alumina liner continued to dissolve and maintain an almost constant alumina content in the bath. Before the alumina content could change significantly, the cell furnace failed and the test was terminated. Other problems encountered during the test included a persistent variation of the surface area of the RA exposed to the molten bath, the condensation of electrically conducting bath vapors on all exposed surfaces, and the formation of a "bridge" of frozen bath above the surface of the molten bath which caused electrical shunting during the test.

The results of the prototype anode test suggested that, despite the amount of effort expended on the RA and the optimistic results of using the RA in the laboratory, serious issues regarding the operation of the electrode and of its durability remained. The most important of these issues are summarized below:

- The viability of the RA in the prototype anode test was inconclusive at best. As discussed in Strachan et al. (1990), the prototype anode corroded severely. However, no significant corrosion was indicated by signals from the RA. 


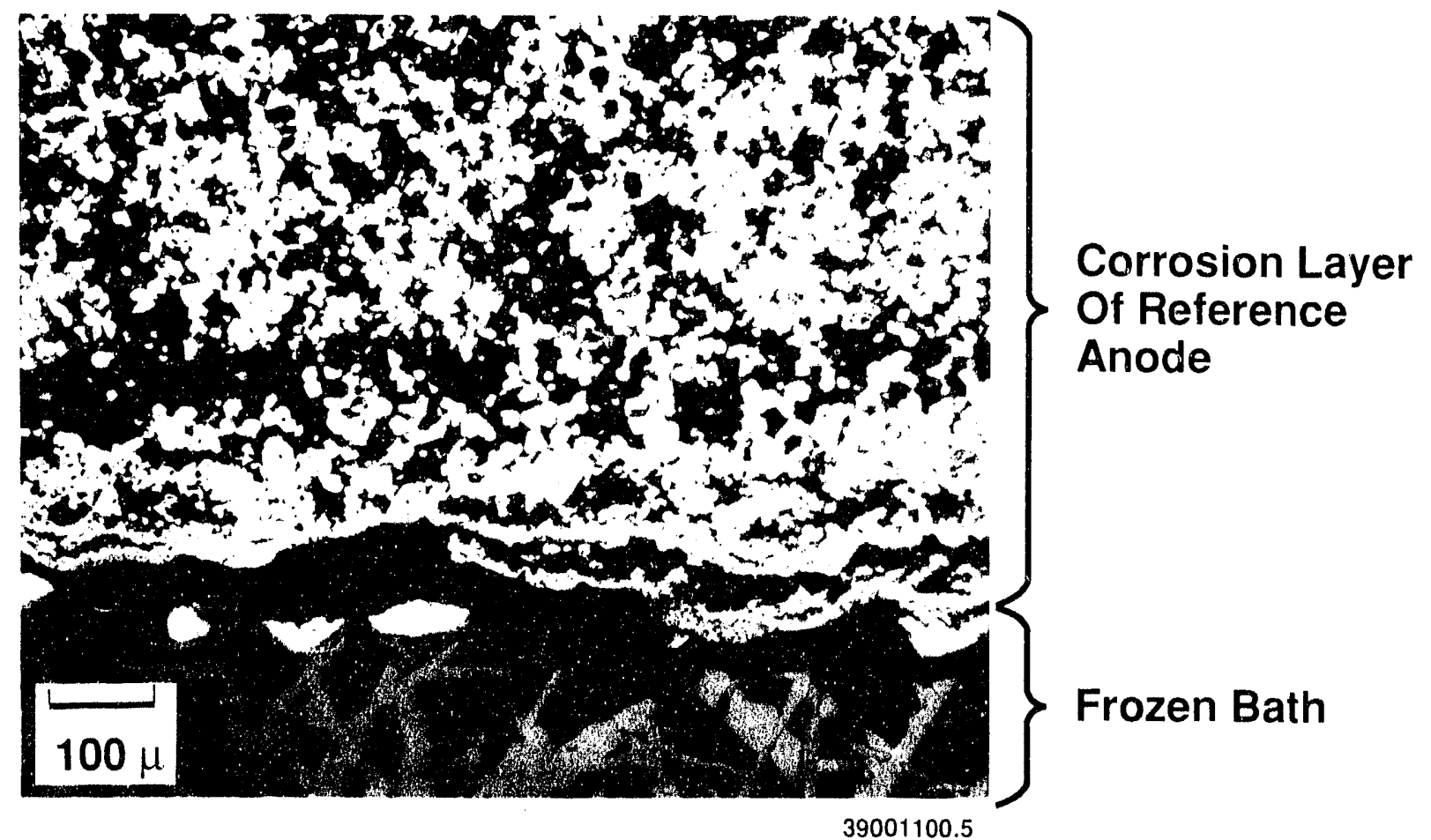

Figure 8.3. Corrosion of Reference Anode

- The effects of size of the working anode on the magnitude and quantity of the proposed protective layer's breakdown signals were not fully determined.

- Since the RA must be operated with a small current flowing through it, a reliable circuit has to be designed to give this current and also to keep the RA potential constant. A successful reference electrode must exhibit a stable potential in the electrolytic medium. Only in this way can the potential of another electrode be measured reliably against it. It is not clear whether this condition is even possible for the RA in an operating cell. Attempts to do this in the prototype anode test gave questionable results.

- The RA exhibited severe corrosion in the prototype anode test even with the impressed anodic current. The reason for the corrosion is not certain.

- The RA design had some serious mechanical problems incurred by - among other factors - the difficulty in joining the connector rod to a long narrow cermet electrode.

Finally, and perhaps most importantly, the basis for the RA was put into question by the results of studies performed at PNL beginning in FY 1989 (Section 7.0). Electrochemical impedance studies suggested that the impedance was primarily due to oxygen gas bubbles generated at the anodes and not to a protective film. Other factors contributed to this perspective as well. Laboratory tests showed that the impedances were persistent, i.e., they could be "created" on a anode in one cell and would remain on the anode when moved to another cell. This phenomenon was originally interpreted in terms of a film which would form on the anode in one cell and then stay with the anode when 
moved to another cell. However, the presence of a film could never be corroborated with the results of post-test optical or spectroscopic analysis, which called into question the existence of a film that remained intact when removed from an operating cell. The explanation in terms of gas bubbles, however, was much more "realistic" as was substantiated by numerous subsequent testing (Windisch and Stice 1991a) and previous experience with carbon anodes (Dewing and van der Kouwe 1975).

Given the unsuccessful evaluation of the RA in the prototype anode test and the tenuous interpretation of the RAs signals on the integrity of a protective film, it seemed unwise to invest further resources to develop this approach to monitoring anode performance. Consequently, at the end of FY 1989 it was decided to abandon development of the RA and focus all of the sensors development efforts on digital signal analysis (DSA). As discussed in Section 9.0, the DSA approach relies on the analysis of electrical signals from the reduction cell similar to the RA, but, unlike the RA, uses no additional probes or electrodes. The signals are collected directly from the existing anodes and cathode. This approach eliminates the possibility of materials problems associated with another electrode as was clearly illustrated in the case of the RA in the prototype anode test.

\subsection{Summary of Conclusions}

The RA showed good potential for monitoring the performance of cermet anode in laboratory cells but gave very poor results in the scaled-up prototype anode test. Due to the problems encountered in scale-up and the results of impedance studies that suggested that a reinterpretation of the basis of the RA was in order, further development of the RA was abandoned. 


\subsection{Digital Signal Analysis}

Early in FY 1990, it was determined that the approach for developing an alumina sensor that had the best chance for acceptance by the aluminum industry was one based on digital signal analysis (DSA). Consequently, from FY 1990 through FY 1992 all of the efforts of the Sensors Development Program were focused on developing the DSA approach.

The principal reason that the DSA approach was considered most desirable is that it is completely nonintrusive, i.e., no separate probes or devices have to be inserted into the cell. In addition, the method could conceivably be used without any special modification to existing commercial cells (once the cermet anodes have been incorporated) other than connecting the cells to the signal monitoring equipment. DSA would use signals from the cermet anodes and the existing cathodes for analysis. This makes the approach very advantageous in that no separate materials corrosion issues need to be addressed for the monitoring electrodes. In other words, if the cermet anodes are shown to be successful, they might also be used as reliable "taps" for DSA analysis of their own performance.

\subsection{Description of the Approach}

The DSA approach consists of collecting current and voltage signals from the operating cermet anode (versus the cathode in the case of voltages) and determining the alumina concentration from some aspect of these signals. The approach will be successful, of course, only if there indeed exists a correlation between some aspect of these signals and alumina concentration. There are numerous aspects or characteristics of the current and voltage signals which conceivably could exhibit some correlation with alumina concentration, e.g. the frequency of certain noise components, the intensities of these components, the "shapes" of the signals, or certain nonlinear characteristics that are embodied in the frequency spectrum as a whole. These characteristics are typically referred to in this work as "signal parameters." The focus of the Sensors Development Program from FY 1988 through FY 1992 was to determine whether any of the many possible signal parameters determined from current and voltage signals collected from reduction cells exhibit any meaningful and reproducible correlation with alumina concentration. Data from both laboratory-scale and pilot-scale reduction cells were used in these analyses. The results of all of the analyses performed at PNL using DSA have been published in three reports (Windisch et al. 1990; Williford and Windisch 1992; Windisch 1992).

A schematic of how the DSA approach was conceived to work in practice is shown in Figure 9.1. Current and voltage signals would be collected as a function of time from the cermet anodes during normal operation. These signals would be processed by a computer. The processing would involve computation of the appropriate signal parameter and correlation (via an algorithm determined previously) to alumina concentration. Using a feedback circuit, the computer would control alumina feed appropriately, i.e., if the alumina concentration was found to be too far below saturation, the computer would activate alumina feed using some predetermined recipe. In its simplest form (Figure 9.1), the DSA-based sensor is extremely simple in principle. The most difficult task in its development is finding the specific signal parameter - if there is one - which gives the most sensitive and reliable measure of alumina concentration. Moreover, to be useful, this signal parameter must be sensitive at high alumina concentrations and it cannot be strongly influenced by variations in other 


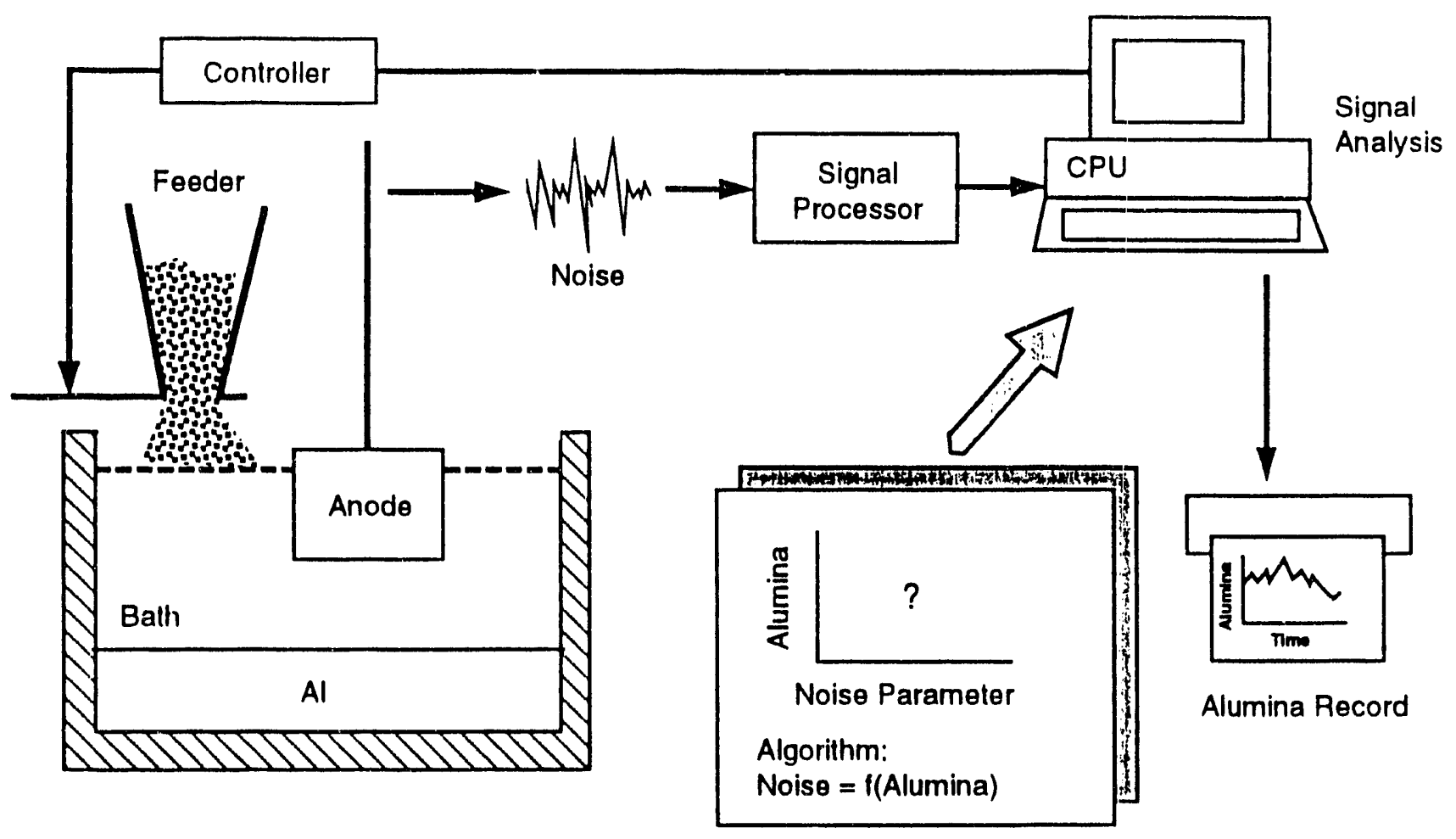

38912079.6

Figure 9.1. Schematic Illustrating Principles of DSA Approach to an Alumina Sensor

cell conditions such as bath ratio and composition, temperature, and fluid flow. Alternatively, if it is affected by variations in other cell conditions, its response must be easily corrected via some calibration scheme. Typically, in an operating cell, conditions other than alumina concentration will probably vary widely, so it is especially important that, in this development work, sensitivity to other conditions be considered also.

Determining the specific phenomena that give rise to the noise or affect its characteristics proposed here as the basis for the DSA sensor - was not the primary focus of this work. Rather, this research was directed at screening as many of the signal parameters as possible to see if any of them showed promise in correlating with alumina concentration. Nevertheless, the underlying causes for the noise are worth speculating about and have shaped some of the strategies used in the DSA analysis. The most probable source for the noise is the production of oxygen gas bubbles (Windisch and Stice 1991a). These bubbles, which are released at a frequency of about $1 \mathrm{~Hz}$, would be expected to show an effect from alumina concentration. This is because varying alumina concentration is known to alter both the surface tension and the viscosity of molten cryolitic media (Grjotheim 1982). Surface tension and viscosity are properties that are known to affect bubble size and flow, so they should also affect bubble noise. This explanation provides added credibility to the approach and suggested that meaningful alumina-concentration information would most likely be found in the low-frequency end $(<25 \mathrm{~Hz})$ of the noise spectra. Of course, in this work, the entire 
frequency spectrum was investigated for completeness. Again, the phenomenological explanations were considered only as a matter of interest and directed the course of the work only when specific choices had to be made for the sake of expediency.

Two DSA approaches were taken at PNL during FY 1988 through FY 1992. The first approach used more traditional DSA methods such as the Fourier transform analysis, although other more advanced nonlinear models were also used in this work. In this report, the work is called the "Traditional DSA Analysis." The data reduction was performed under subcontract by Dr. C. L. Nikias, University of Southern California, Los Angeles, California, on data collected by PNL staff using both laboratory-scale and pilot-scale reduction cells. The results of the traditional DSA analyses were discussed in detail in Windisch et al. (1990) and Windisch (1992). The second approach used techniques from chaos theory and in this report is called "Chaos Theory Analysis." This second approach was conceived of as a result of discussions between Dr. C. F. Windisch Jr. and Dr. R. E. Williford and was performed at PNL using similar laboratory-scale and pilot-scale data. The results of the chaos theory approach were discussed in detail in Williford and Windisch (1992).

\subsection{Results}

The following two sections cover the results of applying the traditional DSA analysis (Section 9.2.1) and the chaos theory analysis (Section 9.2.2). Section 9.3 contains a set of general conclusions that are appropriate to both sets of analyses.

Current and voltage data were collected using laboratory-scale reduction cells at PNL, a scaledup laboratory cell at the MTL (the prototype anode test), and a pilot-scale reduction cell (the pilot cell test) also at the MTL. Detailed procedures for all of these experiments are given in Windisch et al. (1990), Windisch (1992), and Williford and Windisch (1992). The PNL laboratory cell tests were performed using small $1-\mathrm{cm}^{2}$ (exposed area) cermet anodes to get as much information as possible on alumina concentration sensitivity. Current and voltage signals were collected as a function of alumina concentration, cell voltage/anode current density, anode-to-cathode distance (ACD), and with or without small ac "ripples" of varying size to simulate industrial "noise." During the prototype anode test, data were collected using a large 6-inch-diameter cermet anode. Conditions, including alumina concentration close to saturation, were maintained except for the very end of the test when alumina concentration was intentionally dropped. The pilot cell test used similar large-scale anodes but in a six-pack cluster and was performed under more realistic industrial conditions. For most of the pilot cell test, alumina concentration was kept as close as possible to saturation, but in actuality it varied widely. At the end of the test the alumina concentration was dropped deliberately, similar to the prototype anode test.

The number of digital data analysis techniques attempted in this work was very large. Unfortunately, none of the techniques were shown (to date) to give signal parameters with sufficiently good sensitivity to alumina concentration to serve as the basis for a sensor. During the evolution of this work, however, some approaches seemed to offer more promise than others. To facilitate the presentation of this work, the following discussion is limited to those approaches which, at least at some time during their development, showed some promise. Much of the theory behind the approaches is also omitted from this document. The reader is referred to the more complete discussion of the other techniques as well as the theoretical bases of the analyses given in Windisch et al. (1990), Windisch (1992), and Williford and Windisch (1992). 


\subsubsection{Traditional DSA Analysis}

Many traditional DSA approaches were taken to calculate signal parameters for the current and voltage data, with the objective of determining whether any of these signal parameters showed sufficient sensitivity to alumina concentration to serve as the basis of a sensor for alumina concentration. These approaches included the following:

- Conductance Computation by Cross-Correlation and Average Value Methods

- Power Ratio Computation

- Welch Method for Power Spectrum Estimation

- Yule-Walker Autoregression Method

- Magnitude-Squared Coherence Method

- Linear Modeling

- Nonlinear Second-Order Volterra Modeling

The first of these approaches, i.e., conductance computation, gave results that were considered promising during the early stages of this work. Ultimately, however, the result of applying this approach was similar to that of the others: the calculated parameters were simply not sensitive enough to alumina concentration to serve as the basis for a sensor. The following discussion focuses on the results of the conductance computation approach. The reader will find more complete descriptions of the results of some of the other approaches in Windisch et al. (1990) and Windisch (1992).

The basic assumption in the conductance calculation is

$$
\mathrm{I}(\mathrm{n})=\mathrm{L} \times \mathrm{V}(\mathrm{n}) ; \quad \mathrm{n}=1,2, \ldots, \mathrm{N}
$$

where $L$ is the conductance ( $L=1 / R$ where $R$ is the resistance), and $I$ and $V$ are the current and voltage signal values, respectively, measured at time " $t$ " whose channel number or discrete time element is given by $n$. Two methods were used to estimate $L$ from the data: the cross-correlation method and the average value method. Both gave similar results. 
The cross-correlation method gives the estimate

$$
L_{c c}=\frac{\sum_{n=1}^{N} I(n) V(n)}{\sum_{n=1}^{N} V^{2}(n)}
$$

whereas the average value method uses the equation

$$
L_{A V}=\frac{\sum_{n=1}^{N} I(n)}{\sum_{n=1}^{N} V(n)}
$$

In both cases, the current and voltage signals at each time (or $n$ value) are summed, or used to calculate a function which is summed, and these summed values are used to calculate $L$ as indicated. One current and voltage value represent each time (or $n$ value) between the time at which measurement began $(n=1)$ until the data acquisition was completed $(n=N)$. For example, a typical laboratory cell data set consisted of 10,000 sequential current and voltage measurements $(\mathrm{N}=10,000)$ collected over a period of $0.5 \mathrm{~s}$ ( $20 \mathrm{kHz}$ sampling frequency). The pilot cell data were collected at a much lower frequency $(3 \mathrm{kHz}$ ) for the same time period (giving $\mathrm{N}=1500$ ).

The laboratory cell tests were conducted at PNL to provide data for evaluating the sensitivity of the many calculated signal parameters to alumina concentration (and to the parametric variables current density, signal frequency, and ACD). The earliest data collected from the laboratory cells appeared to show a correlation between the estimated conductance, $\mathrm{L}$, and alumina concentration. Success with using $\mathrm{L}$ was considered consistent with the similar, although more limited, information obtained with the total power functions for current and voltage separately (Windisch et al. 1990). Additional experiments were performed, however, and these reduced some of the initial optimism regarding reproducible application of $L$ to monitor alumina concentration. In particular, the parameter $L$ and its apparent correlation with alumina appeared either to be overly sensitive to other cell operating conditions or was simply not as sensitive to alumina concentration as was previously thought from the results of analyzing the earlier data sets.

A plot of $\mathbf{L}$, calculated by cross-correlation, versus alumina concentration is shown in Figure 9.2. Data are presented for different current densities, with $A C D=1.5$ in., and with a superimposed ripple of $\pm 10 \mathrm{mV}$ at $10 \mathrm{~Hz}$. (These data were obtained in experiments named "ACD Tests" and "DSA Tests.") Similar results were obtained for other ACD values, both with and without the applied ac ripple. 


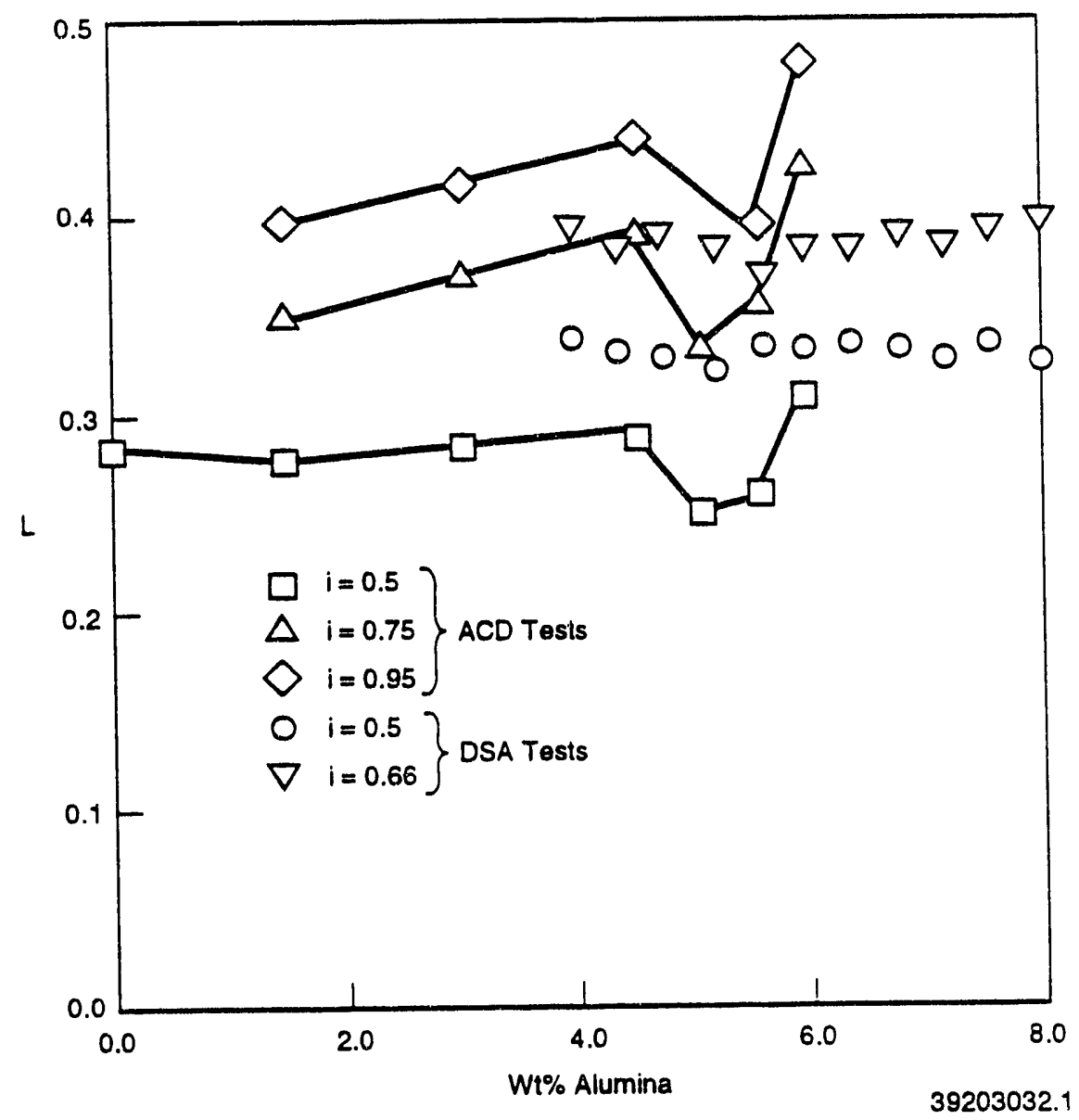

Figure 9.2. Plot of Conductance, L, by Cross-Correlation, Versus Weight Percent Alumina at Various Current Densities. ( $A C D=1.5$ in.; a $10 \mathrm{~Hz}$ Ripple was Used; $\mathrm{i}$ is Current Density in $\mathrm{mA} / \mathrm{cm}^{2}$.)

In each case, the curves are relatively "flat" at lower current densities and have a slight positive slope at higher current densities. (a) There is also a slight dip in the curves at alumina concentrations between 4 and $6 \mathrm{wt} \%$. This dip was observed in similar plots for most of the other parameters as well. At concentrations above $6 \mathrm{wt} \%$, the curves appear much "flatter."

Upon initial inspection, the curves shown in Figure 9.2 contain some aspects of a relationship that might serve as the basis for an alumina sensor. In particular, there appeared to be a strong dependency (large slope) between $L$ and alumina concentration in the vicinity of the dip between

(a) It is not clear why the conductance increases with alumina concentration in these plots.

Conductance should decrease as discussed in numerous references (Grjotheim et al. 1982). The conductance did, in fact, decrease in another data set (Set \#3) discussed later in this section. 
4 and $6 \mathrm{wt} \%$. Unfortunately, it was not clear if the dip was reproducible. Different data, albeit collected with different ac excitation voltages, gave dips with somewhat different appearances. There was a question also as to whether there was any dependence on the size of the ac ripple. This would suggest a problem is applying this technology to commercial cells. The idea was to use noise inherent in the commercial cell rectifiers as the ripple. Ordinarily this noise can be expected to vary appreciably during cell operation. Sensitivity of the signal parameter to this variation would make the above approach unreliable. Finally, since the primary objective of this work was a parameter showing sensitivity to high alumina concentrations, sensitivity only in the intermediate ranges, i.e., 4-6 wt\% where $8 \mathrm{wt} \%$ is saturation, would appear to be a disadvantage.

To address the above concerns, additional data were collected using the laboratory cells (Set\#3). Specifically, these experiments were meant to 1) determine the general reproducibility of the results from the earlier tests (Figure 9.2), 2) see if the dip between 4 and $6 \mathrm{wt} \%$ could be reproduced and to quantify it better, and 3) obtain more data in the 6-8 wt \% range where alumina sensitivity was especially required.

Unfortunately, analysis of the additional data could not corroborate unambiguously the results from the earlier data. For example, as shown in Figure 9.3, a dip was observed in $\mathrm{L}$ when the current density was $0.75 \mathrm{~A} / \mathrm{cm}^{2}$, but it occurred at $3 \mathrm{wt} \%$ alumina instead of in the expected 4-6 wt \% range. ${ }^{(a)}$ More importartly, as also shown in Figure 9.3, there was no significant and consistent correlation with alumina concentration at higher weight percent values. This result was especially disappointing since the need for sensitivity at higher concentration was a prerequisite for a sensor to be used successfully with the cermet anodes.

In addition to screening for sensitivity to alumina concentration, the signal parameters were tested for sensitivity to other operating conditions including current density and ACD. As discussed in Windisch (1992), these analyses failed to provide any workable strategies for improving sensitivity to alumina concentration. The only beneficial result from this additional work was the apparent lack of any effect from high frequency filtering (i.e., the signals could be low-passed at a cutoff frequency of $25 \mathrm{~Hz}$ with no loss of information). This facilitated the pilot cell studies, which required filtering to avoid aliasing.

Figure 9.4 shows a typical signal-versus-time plot for the current and voltage data collected during the pilot cell test. The most obvious feature in the data is a residual $360 \mathrm{~Hz}$ rectifier signal, which appeared as a significant component of all of the signals from the pilot cell, even after filtering. Figure 9.5 shows the variation in $\mathrm{L}^{(b)}$ as a function time for one of the anodes in the pilot cell test.

(a) There is also a possibility that the single point contributing to this difference may have been a "flier." In light of the atypical behavior of this one point (compared to other data in Fig. 9.4), it is recommended that not too much significance be placed on this dip until replicate data are obtained.

(b) The values for $\mathrm{L}$ are plotted using an arbitrary scale so that they overlap the alumina concentrations which are also plotted in this figure. Plots of this type were generated by Dr. C. L. Nikias to see if $L$ (and the other signal parameters) "tracked" the alumina concentration to any reasonable and consistent extent during the pilot cell test. 


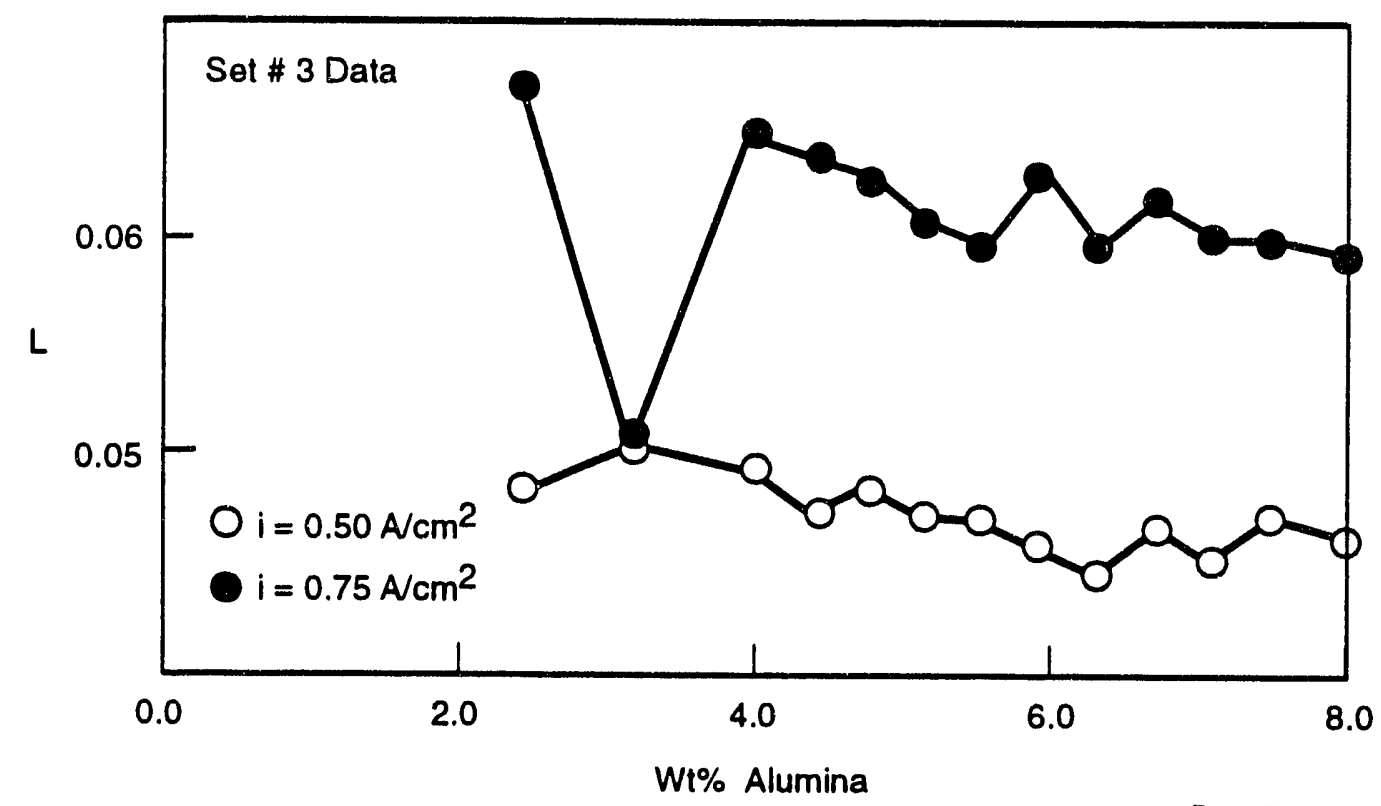

Figure 9.3. Plot of Conductance, L, by Cross-Correlation, Versus Weight Percent Alumina for Set \#3 Data. (ACD = 1.5 in.; a $10 \mathrm{~Hz}$ Ripple was Used.)

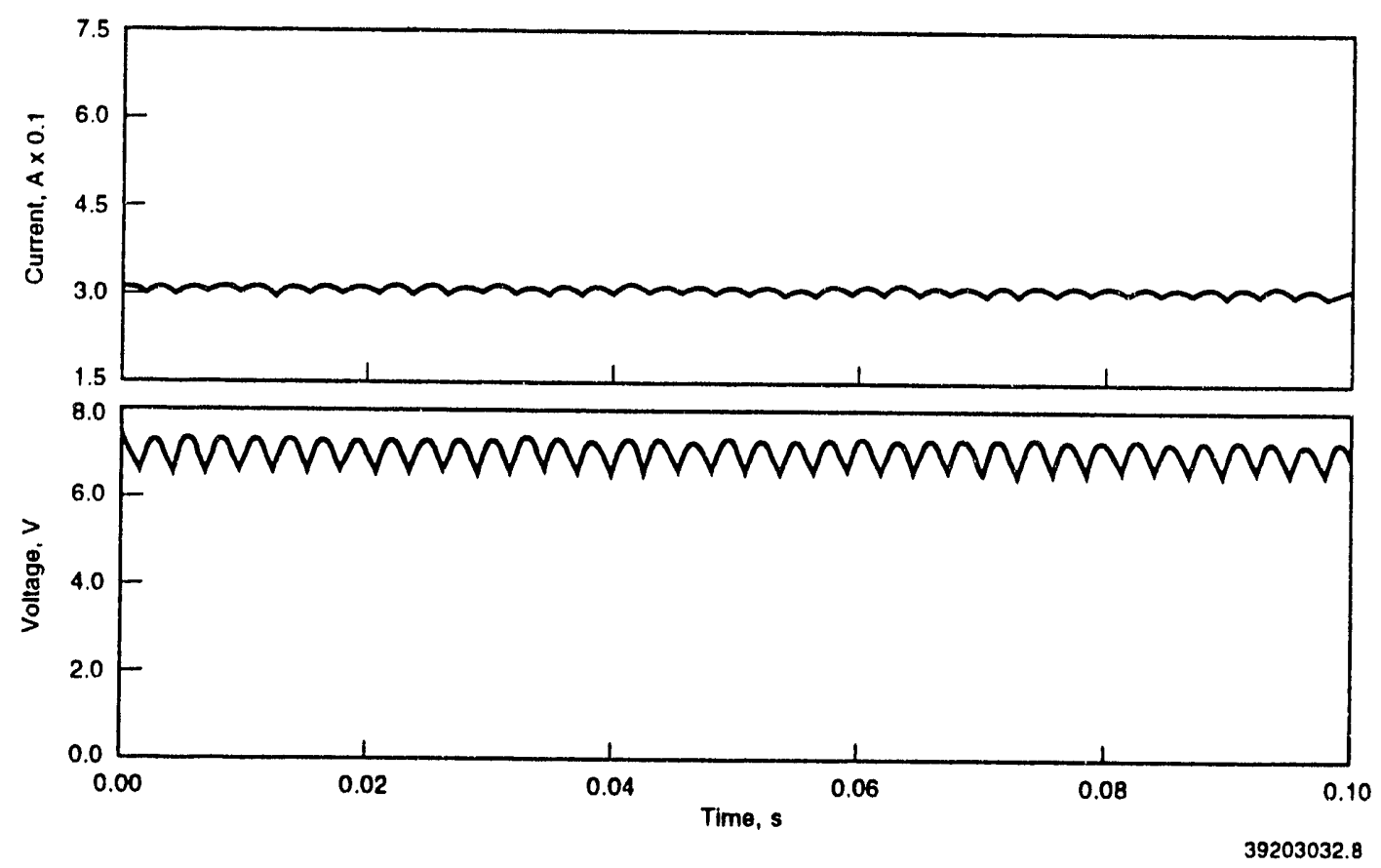

Figure 9.4. Typical Current and Voltage-Versus-Time Plots for the Pilot Cell Test. 


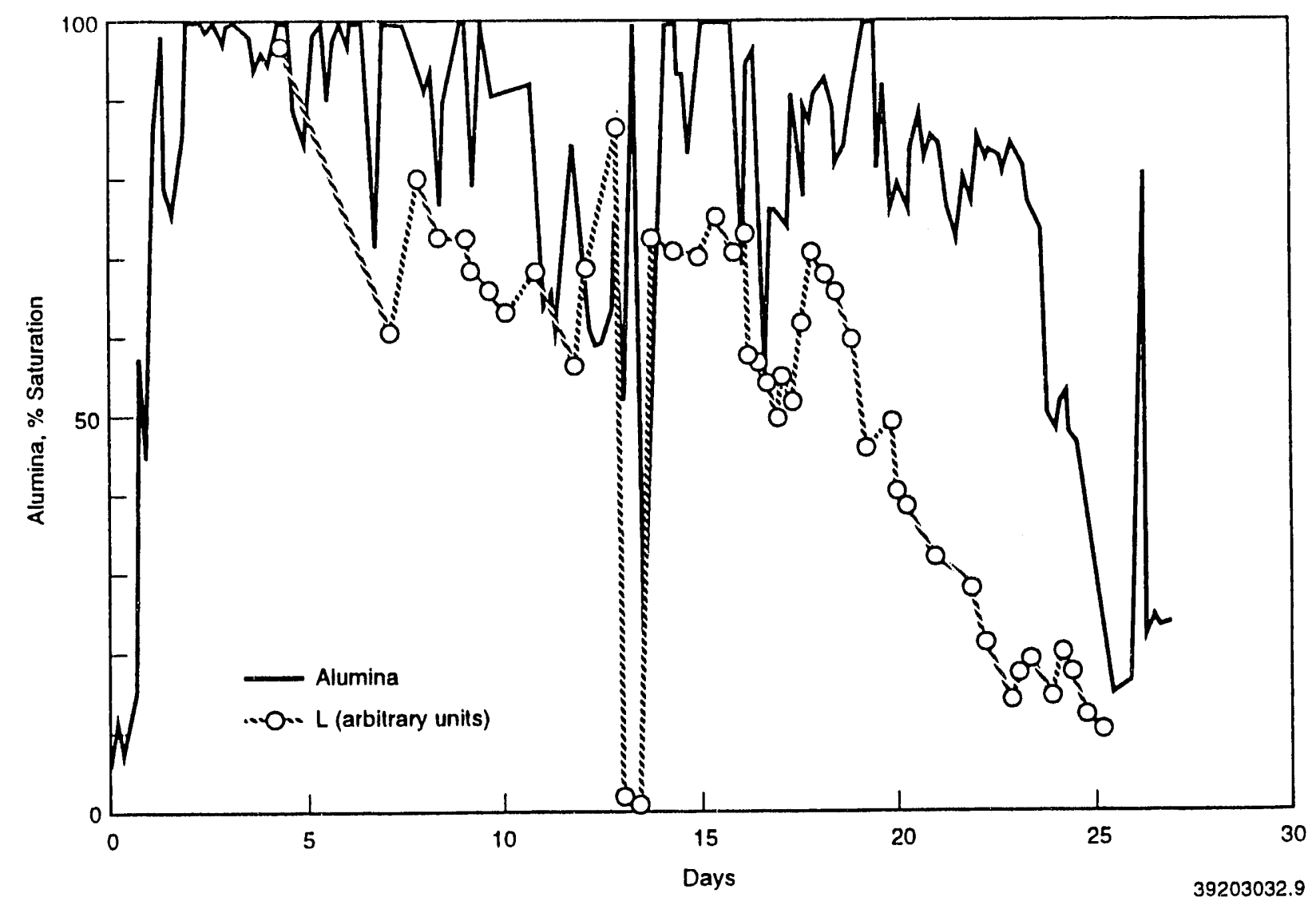

Figure 9.5. Comparison of Conductance, $\mathrm{L}$, and Alumina Concentration as a Function of Time for Cermet Anodes during the Pilot Cell Test.

(As in the case of the laboratory cell data, the behavior for the other signal parameters for the same anode was similar.) Also shown in the same figure is the plot of the variation of alumina concentration (expressed as percent of saturation) as a function of time during the test. Upon initial inspection, there appeared to be some "tracking" of the alumina concentration by $L$. For example, at about 13 days alumina concentration shows a dramatic drop and $L$ drops dramatically also. During the period between 23 to 26 days, where alumina concentration drops (due to the deliberate stoppage of alumina feed), $\mathrm{L}$ is dropping also. In addition, as shown in the figure, there are numerous other instances throughout the test where the value for $L$ is observed to go down when alumina concentration goes down, or up when alumina concentration goes up.

Closer examination of the data in Figure 9.5, however, indicates there are some important discrepancies that cannot be explained at this time. Also, some of the operating conditions put into question even those situations where correlations seem promising. For example, the dramatic drop in $\mathrm{L}$ at about 13 days occurs at precisely the time when the anode was exchanged and therefore electrically disconnected. It appears that this drop in $\mathrm{L}$ is irrelevant in regards to alumina concentration, and, consequently, its apparent correspondence to the observed drop in alumina concentration completely fortuitous. The decrease in the value for $L$ during the drop in alumina concentration between 
23 and 26 days is also suspicious in that it actually begins earlier than the time at which the drop in alumina starts! L begins to drop even before day 20 when alumina is near its highest concentration. An alternative explanation for this drop in $L$ may be the decrease in current through this anode that begins around day 20 as shown in the current-versus-time curve in Figure 9.6. (Note that day 20 corresponds to $8 / 23$ in Figure 9.6.) The parameter $L$ may be tracking current more closely than it is tracking alumina concentration.

In addition to the above-mentioned problems in the data analysis for the pilot cell anodes, there are numerous instances earlier on in the test when $\mathrm{L}$ and the alumina concentrations appear to show trends in opposite directions. For example, at measurements near days 10 and 12 in Figure 9.5, $\mathrm{L}$ goes down as the alumina concentration goes up. Clearly, the relationship between $\mathrm{L}$ and alumina concentration, which seemed promising on first inspection, is not so promising under closer scrutiny and in light of variations in other cell conditions, especially the anode currents.

In summary, neither the laboratory-cell data nor the pilot cell data gave sufficient evidence for a reliable sensor based on traditional DSA methods. As an alternative DSA approach, methods from chaos theory were used on data from both the laboratory cells and the pilot cell.

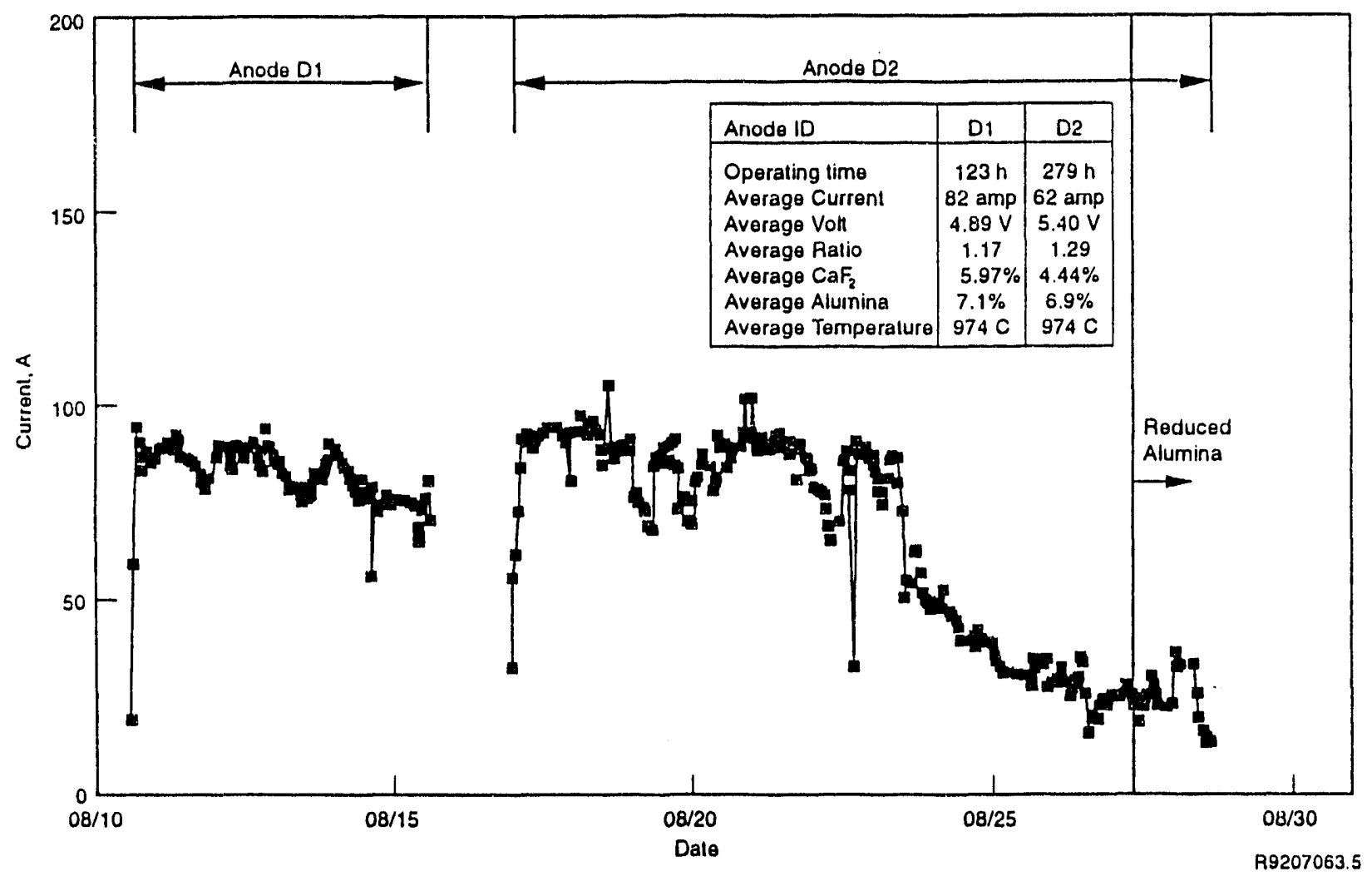

Figure 9.6. Variation in Current Though Cermet Anodes during the Pilot Cell Test 


\subsubsection{Chaos Theory Analysis}

The methods discussed in this section are based on applications of the theory of chaotic phenomena to the analysis of time series data. Chaos theories are a relatively recent development that combines features of classical mechanics with certain aspects of statistical mechanics and topology. The term "chaos" was attached to this combination of sciences in the mid-1970's. Chaotic phenomena may be viewed as the manifestation of order within highly nonlinear behavior, in the form of patterns in phase space plots, or in the form of patterns within intermittent (noisy) time series signals. The unique feature of the chaos approach that makes it different from the traditional methods is that the chaos approach generally employs very high order statistical moments in the data base to develop the needed correlations between alumina and process variables, whereas the traditional approaches typically employ lower order moments. It was believed that the higher order moments could provide the needed sensitive measure of alumina concentration.

Current and voltage data from both laboratory-scale reduction cells and the pilot cell test were used to test four methods from chaos theory for sensitivity to alumina concentration. The primary objective was to see if any of these approaches produced signal parameters or a signal analysis strategy useful for quantifying alumina concentration or for portending its variance from nearsaturation conditions. This was the first time chaos theory approaches were used to analyze signals from aluminum reduction cells.

The following four chaos theory approaches were evaluated in this work:

- Phase Space Plots

- Hurst Exponent Analysis

- Multifractal Analysis Based on Thermodynamic Arguments

- Multifractal Analysis Based on Probabilistic Arguments

A complete discussion of the above approaches and their results is given in Williford and Windisch (1992). For the sake of brevity, only two of these approaches are highlighted in this report. These are phase space plots (the simplest approach) and the multifractal analysis based on probabilistic arguments (the most accurate approach). By and large, however, all of the approaches gave similar results: with the current level of development, none have exhibited the required combination of sensitivity and reliability that is needed for a useful alumina concentration sensor.

The foundations of the phase space plot originate from classical mechanics where they have long been used to study complicated dynamical systems. "Phase space" means that the variables of a process are plotted against each other, e.g., the position of a pendulum versus its velocity. The resulting plots often exhibit certain specific patterns, such as a spiral for a damped pendulum. If the system is "chaotic," the pattern may be more complex, but nevertheless recognizable, and is called a "strange attractor." This means that the system is dynamically attracted to a specific set of "orbits" or to a specific region of phase space. An example is the famous Lorentz attractor which resembles a butterfly or an owl's mask. 
Phase space plots were envisioned as the simplest approach to employ in this work. They were the context in which applications of chaos theories to an alumina sensor were first discussed. Because simple solutions are easier to apply in industrial practice, this method was attempted first. Conceivably, a plant operator could monitor a "pattern" on a video screen. A certain pattern indicative of acceptable alumina content would signify proper cell operating conditions. Any deviation from this pattern would alert the operator to make sufficient adjustments in alumina concentration to bring the pattern back to "normal." High-speed data acquisition, processing, and display would be required to facilitate such an operation.

In this study, the phase space approach involved plotting the cell electrical resistance $R$ at time $t$ versus the resistance at time $t+1$, or $t+2$, etc. Resistance was computed by simply dividing the instantaneous cell voltage by the instantaneous current, and plotting the results as shown in Figure 9.7a for one set of data obtained from the pilot cell. As shown in Figure 9.7a, a distinctive pattern occurred for these data. Such a pattern could be recognizable and useful to an operator in an industrial setting if it also exhibited consistent changes as the alumina concentration changed. However, this was not the case: Figures 9.7 a through $9.7 \mathrm{~d}$ show only one of the many observed pattern changes as a function of alumina concentration. Relatively minor differences were observed, and these were attributed to scatter in the data rather than to a consistent correlation versus alumina concentration. For example, there is no significant difference between Figure $9.7 \mathrm{a}(85 \%)$ and Figure 9.7d (23\%).

Multifractal approaches to data analysis were attempted when it was apparent that the simpler chaos approaches such as phase space plots did not yield acceptable results in early laboratory studies. The multifractal approach is described briefly as follows. A fractal is a geometric object with a noninteger dimension. That is, it describes geometric complexity in terms of transitions between the Euclidean integer dimensions. In the multifractal approach to data analysis, a noisy time series plot is "unraveled" into a large number of these fractals. It was hoped that fractal parameters (dimensions) obtained by unraveling the current and voltage data from an aluminum reduction cell would have characteristics sufficiently affected by alumina concentration to serve as the basis for a sensor.

The best way to display the fractal information for the noisy cell data was found to be an " $f-\alpha$ " curve of the type shown in Figure 9.8. The parameter $f$ is the "dimension" of one of the nested fractals and the $\alpha$ values are analogous to free energies as discussed in Williford and Windisch (1992). The intercepts of the curve in Figure 9.8 with the horizontal axis define two values of $\alpha$ and are called $\alpha_{\min }$ and $\alpha_{\max }$. These values describe certain high order moments of physical significance in the data base and are unique to the multifractal methods. Consequently, it was proposed that these $\alpha$ values or some function constructed from them might exhibit sensitivity to alumina concentration. The ratio $\alpha_{\max } / \alpha_{\min }$ was found to be the best function to use because it simplified the mathematical analysis.

Two ways to construct the f-alpha curve were tested in this work: the thermodynamic approach and the probabilistic approach. The probabilistic approach was found to give the most accurate results. Details on the probabilistic approach are given in Williford and Windisch (1992), but basically it involves an intermediate step of developing a "multiplier distribution curve" for the data. The multiplier distribution curve is a construct derived from probability arguments and increases the sensitivity of the calculated parameters to rare events, such as periods of extreme turbulence or extreme quiescence in the bath. This turns out to be especially important in the cases of $\alpha_{\min }$ and $\alpha_{\max }$. Given the resultant increase in accuracy in determining these intercepts, the probablistic 
(a)

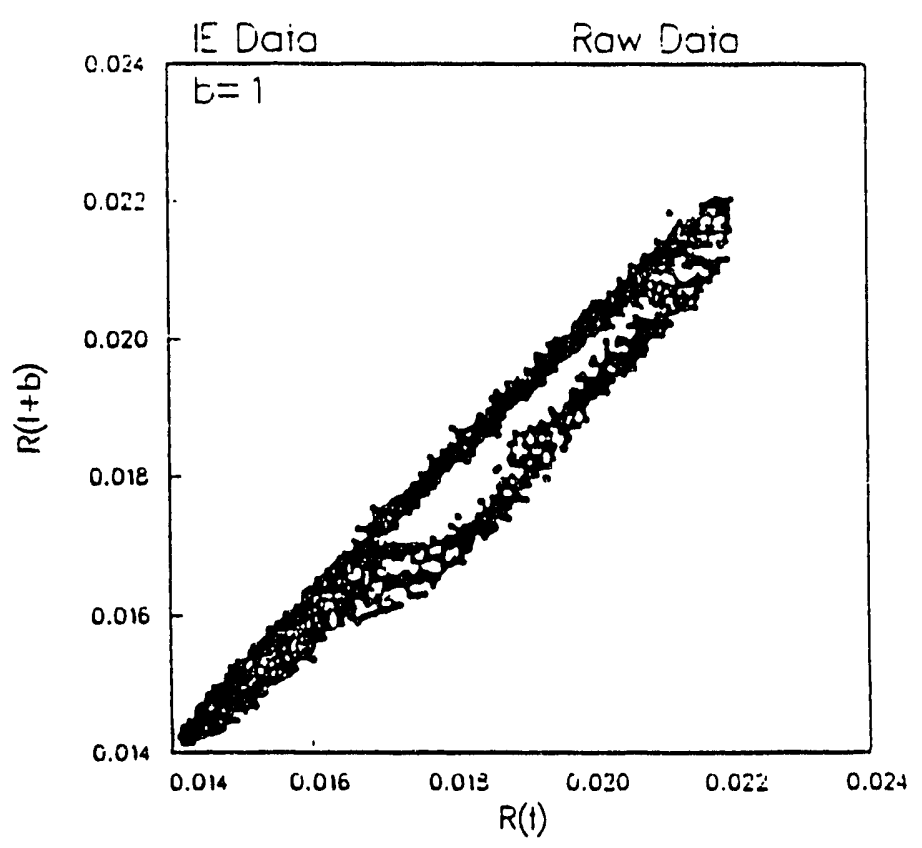

(b)

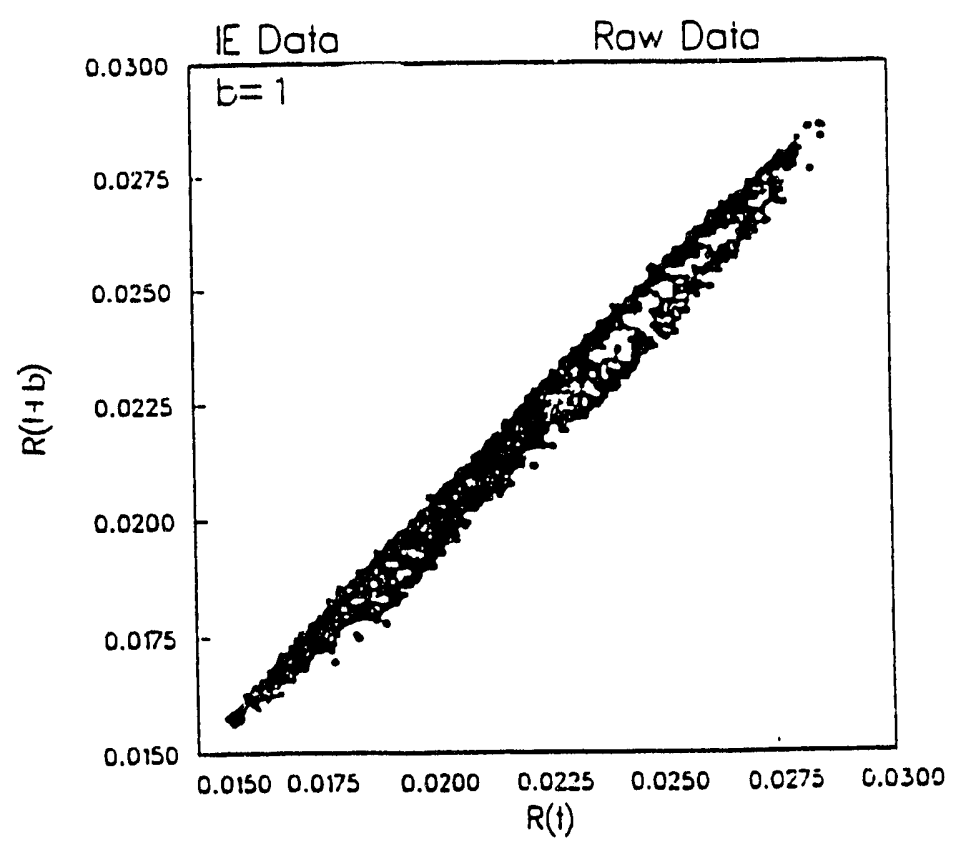

Figure 9.7. Phase Space Plots for Data from the Pilot Cell Test at Various Alumina Concentrations (\% Saturation): a) $85 \%$, b) $76 \%$, c) $48 \%$, and d) $23 \%$. 
(c)

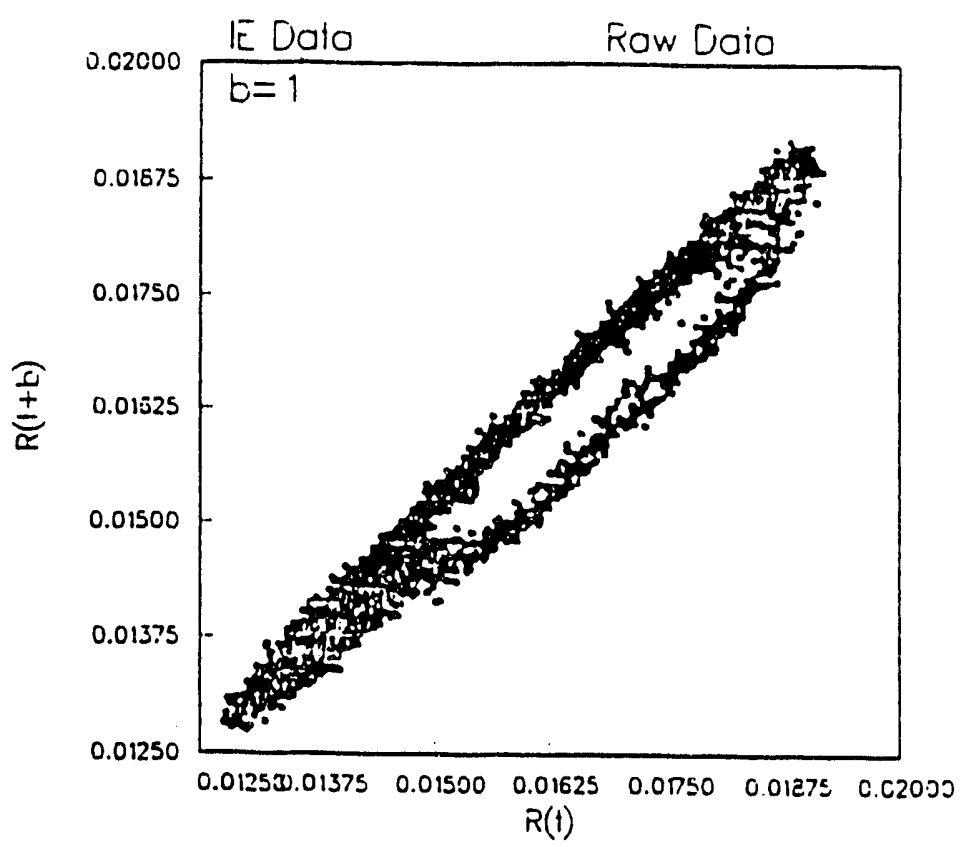

(d)

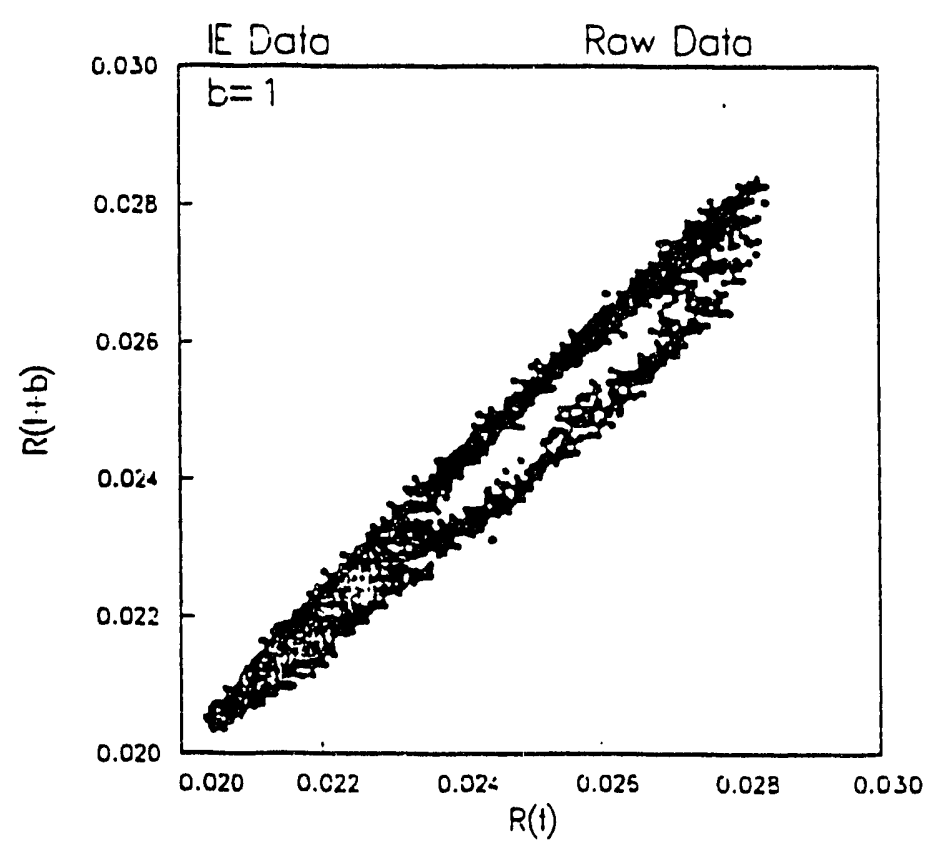

Figure 9.7. (contd) 


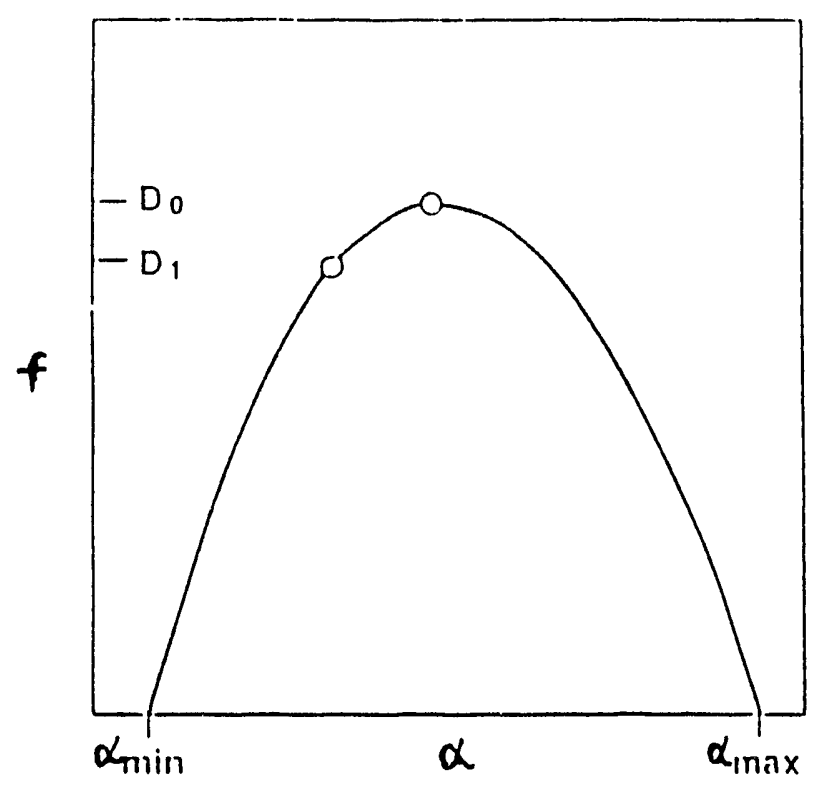

Figure 9.8. An Idealized $f-\alpha$ Curve

approach was given the best chance for success provided, of course, the $a_{\max } / a_{\min }$ ratio was sufficiently sensitive to alumina concentration, and sufficiently reliable for industrial applications.

The probabilistic multifractal approach was tested on both the laboratory data and the pilot cell data with similar results. Figure 9.9 shows the results of using the approach on the pilot cell data. The data were considered of good quality because the $f-\alpha$ curves were smooth and there appeared to be adequate sensitivity to changes in cell conditions. Unfortunately, as shown in Figure 9.9, there did not seem to be a consistent trend in the $\alpha_{\max } / \alpha_{\min }$ ratio versus alumina concentration. Each data point in the figure is an average computed from six files of 10,000 points each; the vertical bar shows the typical uncertainty at $95 \%$ confidence. The solid line is not a curve fit, but is a guide for the eye that indicates the trend in the $\alpha_{\max } / \alpha_{\min }$ ratio versus the alumina content. The scatter is comparable in magnitude to the change in the solid line versus alumina content, again indicating that the data contain noise factors that are not accounted for in the present analysis.

In conclusion, the multifractal approach appeared to suffer from some of the same shortcomings as the other DSA methods despite its sophistication and higher level of accuracy. This approach, like the others, did not appear to give a reliable correlation with alumina concentration. The approach may be sensitive to alumina concentration, but this has not yet been demonstrated with sufficient certainty to support using it as the basis for a sensor. It appears likely that the reason for the lack of any useful correlation is that too much extraneous noise has been present in all of the data analyzed to date, either from variation in other cell conditions or from instrumental sources. 


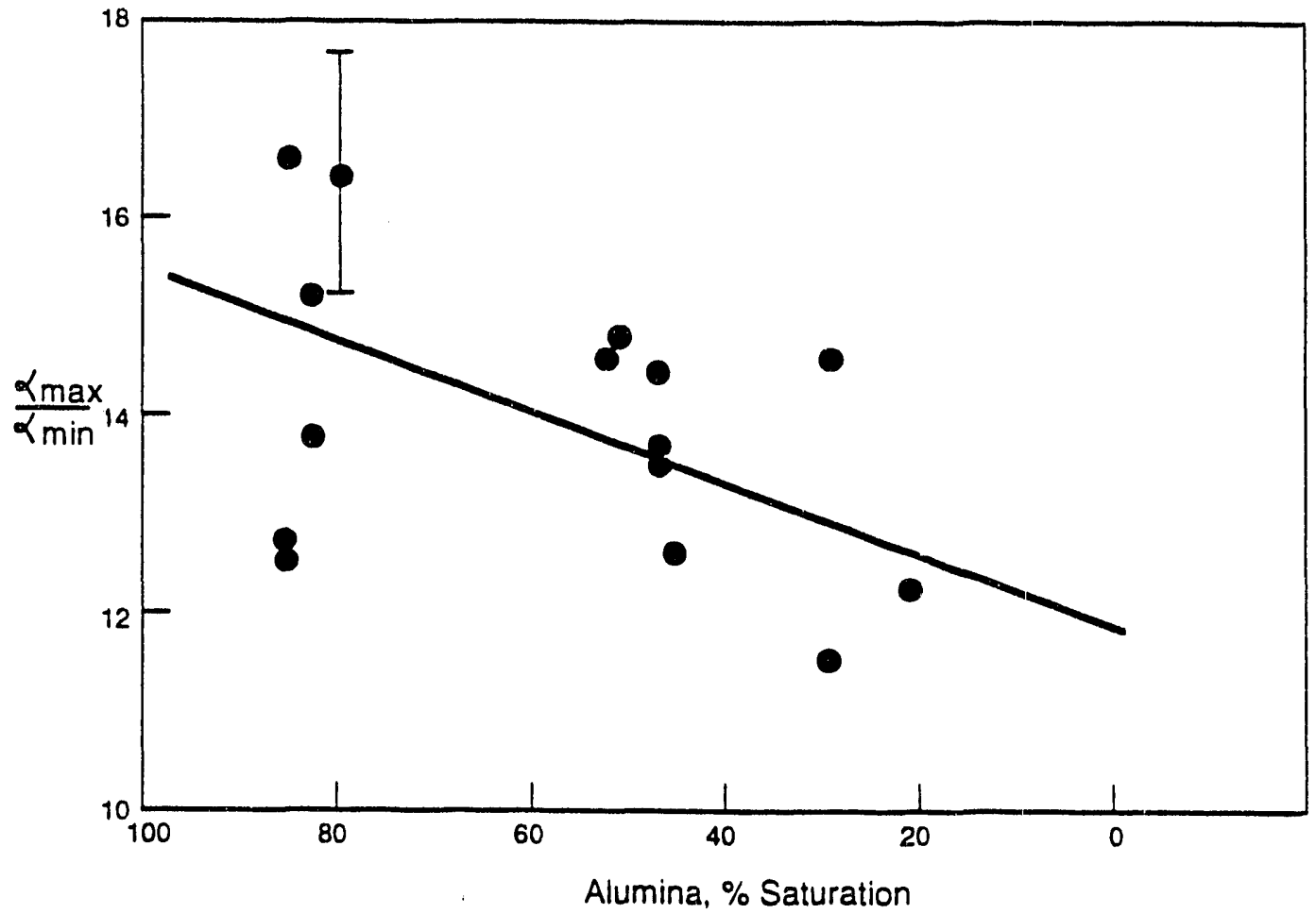

R9202038.1

Figure 9.9. $\alpha_{\max } / \alpha_{\min }$ Ratios Versus Alumina Concentration for the Pilot Cell Test

\subsection{Summary of Conclusions}

The principal conclusion from this work is that none of the DSA approaches demonstrated sufficient and consistent sensitivity to alumina concentration to serve as a basis for an alumina sensor. There are two possible explanations for the lack of correlation involving these methods: 1) there is no dependence, or a very weak one, on alumina concentration, and/or 2) there were overriding factors or extraneous noise that reduced the sensitivity or "overwhelmed" the signal components affected by alumina concentration. The latter possibility is most reasonable in light of the results from the pilot cell test that showed a dependence on anode current and other cell operating conditions.

Based on the results of this work, it was recommended that further study using DSA methods be suspended or postponed until another, less "noisy," pilot-scale test is performed with cermet anodes. Alternatively, a new strategy is required for applying the DSA approaches. For example, the methods could be applied to carbon anodes in commercial cells where a significantly greater volume of data can be collected over much longer times. A larger data base may facilitate the "factoring out" of the effects of fluctuations in other cell operating conditions. 


\subsection{Conclusions and Recommendations}

Eight different approaches to an alumina sensor were evaluated as part of the Sensors Development Program at PNL. To date, none of these approaches were found to satisfy the two primary requirements for an alumina sensor to be used in conjunction with cermet anodes: 1) adequate sensitivity to alumina concentration at concentrations close to saturation, and 2) ease of use in an industrial setting. The only approach that still shows promise is the use of DSA methods on current and voltage signals from the cermet anodes. This conclusion is based solely on its extremely easy and anticipated nonproblematic use in an industrial environment. After numerous laboratoryscale experiments and one pilot-scale evaluation, the DSA approach has not yet demonstrated adequate sensitivity to alumina concentration for use as the basis of a sensor. Despite this lack of success, however, it is recommended that further development work on the technique continue. The probabilistic multifractal methods seem especially advantageous because of the improvements in accuracy achieved in recent studies. Because of failures of the past correlation attempts, however, it is recommended that different data collection strategies be employed in any further development of the DSA methods. These strategies might include using a less "noisy" pilot-scale test with cermet anodes or applying the approach to carbon anodes in commercial cells where a significantly greater volume of data can be collected over much longer times allowing extraneous fluctuations to be more easily "factored out." 


\subsection{References}

Bonny, P., J. Gerphagnon, G. Laboure, M. Keinborg, P. Homsi, and B. Langon. 1984. "Process and Apparatus for Accurately Controlling the Rate of Introduction and the Content of Alumina in an Igneous Electrolysis Tank in the Production of Aluminum." U. S. Patent No. 4,431,491, February 14, 1984.

Brenden, B. B. 1988. Test of Dip Cup Instrumentation. PNL-6742, Pacific Northwest Laboratory, Richland, Washington.

Dewing, E. W., and E. Th. van der Kouwe. 1975. "Anodic Phenomena in Cryolite-Alumina Melts: I. Overpotentials at Graphite and Baked Carbon Electrodes." J, Electrochem. Soc, Vol. 122, No. 3, pp. 358-363.

Grjotheim, K., C. Krohn, M. Malinovsky, K. Matiasovsky, and J. Thonstad. $1982 . \quad$ Aluminum Electrolysis. Aluminum-Verlag, Dusseldorf, FRG.

Hart, P. E., B. B. Brenden, N. C. Davis, O. H. Koski, S. C. Marschman, K. H. Pool, C. H. Schilling, C. F. Windisch Jr., and B. J. Wrona. 1987. Inert Anode/Cathode Program Fiscal Year 1986 Annual Report. PNL-6247, Pacific Northwest Laboratory, Richland, Washington.

Koski, O. H., and S. C. Marschman. 1987. "Anode Film Formation and Control." U. S. Patent No. 4,921,584, November 3, 1987.

Lee, S. S., K. S. Lei, P. Xu, and J. J. Brown. 1984. "Determination of Melting Temperatures and $\mathrm{Al}_{2} \mathrm{O}_{3}$ Solubilities for Hall Cell Electrolyte Compositions." Light Metals 1984, The Metallurgical Society, Warrendale, Pennsylvania.

Marschman, S. C. 1989. Laboratory-Scale Testing of Non-Consumable Anode Materials. PNL-6805, Pacific Northwest Laboratory, Richland, Washington.

Skybakmoen, E., A. Solheim, and A. Sterten. 1990. "Phase Diagram Data in the System $\mathrm{Na}_{3} \mathrm{AlF}_{6}-\mathrm{Li}_{3} \mathrm{AlF}_{6}-\mathrm{AlF}_{3}-\mathrm{Al}_{2} \mathrm{O}_{3}$ Part II: Alumina Solubility." Light Metals 1990, The Minerals, Metals and Materials Society, Warrendale, PA, pp. 317-324.

D. M. Strachan, O. H. Koski, S. C. Marschman, C. H. Schilling, C. F. Windisch Jr., B. B. Brenden, N. C. Davis, and P. E. Hart. 1988. Fiscal Year 1987 Annual Report for the Inert Electrodes Program. PNL-6746, Pacific Northwest Laboratory, Richland, Washington.

Strachan, D. M., S. C. Marschman, N. C. Davis, J. R. Friley, and C. H. Schilling. 1989. Fiscal Year 1988 Annual Report for the Inert Electrodes Program. PNL-7106, Pacific Northwest Laboratory, Richland, Washington.

Strachan, D. M., C. F. Windisch Jr., O. H. Koski, L. G. Morgan, R. D. Pederson, N. E. Richards, and A. T. Tabereaux. 1990. Results from Electrolysis Test of a Prototype Inert Anode. PNL-7345, Pacific Northwest Laboratory, Richland, Washington. 
Tabereaux, A. T., and N. E. Richards. 1983. "An Improved Alumina Concentration Meter." Light Metals 1983, The Metallurgical Society, Warrendale, Pennsylvania, pp. 495-506.

Weyand, J. D., D. H. DeYoung, S. P. Ray, G. P. Tarcy, and F. W. Baker. 1986. Inert Anodes for Aluminum Smelting: Final Technical Report for the Period 1980 September 29 - 1985 September 30.

DOE-CONS-40158-20, Alcoa Laboratories, Alcoa Center, Pennsylvania.

Williford, R. E., and C. F. Windisch Jr. 1992. Final Report on the Application of Chaos Theory to an Alumina Sensor for Aluminum Reduction Cells. PNL-8042, Pacific Northwest Laboratory, Richland, Washington.

Windisch, C. F., Jr., O. H. Koski, N. D. Stice, C. L. Nikias, and L. G. Morgan. 1990. Fiscal Year 1989 Annual Report for the Sensors Development Program. PNL-7309. Pacific Northwest Laboratory, Richland, Washington.

Windisch, C. F., Jr., and N. D. Stice. 1990. Characterization of the Reaction Layer or Film on PNL Inert Anodes: Progress Report for April - December 1989. PNL-7326, Pacific Northwest Laboratory, Richland, Washington.

Windisch, C. F., Jr., and N. D. Stice. 1991a. Report on the Source of the Electrochemical Impedance on Cermet Inert Anodes. PNL-7629, Pacific Northwest Laboratory, Richland, Washington.

Windisch, C. F., Jr., and N. D. Stice. 1991b. Final Report on the Characterization of the Film on Inert Anodes. PNL-7589, Pacific Northwest Laboratory, Richland, Washington.

Windisch, C. F., Jr., D. M. Strachan, N. C. Davis, L. G. Morgan, J. W. Shade, N. D. Stice, and R. E. Westerman. 1991. Inert Electrodes Program Fiscal Year 1990 Annual Report. PNL-7777, Pacific Northwest Laboratory, Richland, Washington.

Windisch, C. F., Jr. 1991. "An Electrochemical Impedance Study on Cermet Anodes in AluminaSaturated Molten Cryolite." J. Electrochem. Soc., Vol. 138, No. 7, pp. 2027-2029.

Windisch, C. F., Jr. 1992. Final Report on DSA Methods for Monitoring Alumina in Aluminum Reduction Cells with Cermet Anodes. PNL-8076, Pacific Northwest Laboratory, Richland, Washington. 


\section{DISTRIBUTION}

No. of

Copies

\section{OFFSITE}

M. J. McMonigle

U.S. Department of Energy

Office of Industrial Programs

Forrestal Building

Washington, DC 20585

P. H. Salmon-Cox

U.S. Department of Energy

Office of Industrial Programs

Forrestal Building

Washington, DC 20585

12 DOE Office of Scientific and

Technical Information

T. Alcorn

Manufacturing Technology

Laboratory

Reynolds Metals Co.

3326 East 2nd Street

Muscle Shoals, AL 35661-1258

C. Anderson

Columbia Aluminum Co.

85 John Day Dam Road

Goldendale, WA 98620

J. V. Anderson

WCVE3

EG\&G Idaho, Inc.

Idaho Falls, ID 83415

D. Auburg

Bonneville Power Administration

P.O. Box 3621, PDX 97208

Portland, OR 97208
No. of

Copies

F. W. Baker

Ceramics Division

Alcoa Laboratories

Alcoa Center, PA 15069

M. Baltzell

Eastalco Aluminum Company

Alumax, Inc.

5601 Manor Woods

Frederick, MD 21701

J. A. Barclay

U.S. Bureau of Mines

2401 "E" Street N.W.

Washington, DC 20241

H. Robert Baumgartner

Ceramics Division

Alcoa Laboratories

Alcoa Center, PA 15069

T. R. Beck

Electrochemical Technology Corp.

1601 Dexter Avenue

Seattle, WA 98109

S. Berwagan

Bonneville Power Administration

P.O. Box $3621 \mathrm{~K}$

Portland, OR 97208

T. M. Besmann

Metals and Ceramics Division

Oak Ridge National Laboratory

P.O. Box X, Bldg. 4515

Oak Ridge, TN 37831-6063 
No. of

Copies

K. A. Blakely

President

Advanced Refractory

Technologies, Inc.

699 Hertel Ave.

Buffalo, NY 14207

M. H. Blenk

Du Pont

P.O. Box 787

Niagara Falls, NY 14302

L. G. Boxall

Martin Marietta Laboratories

1450 South Rolling

Baltimore, MD 21227

J. Bracher

Kaiser Aluminum and Chemical

Corp.

825 N.E. Multnomah St.,

Suite 960

Portland, OR 97232-2150

R. Brandt

Department of Materials

Science and Engineering

University of Washington FB-10

Seattle, WA 98195

J. J. Brown, Jr.

Materials Engineering

Virginia Polytechnic Institute

Blacksburg, VA 24061

A. Budner

Bonneville Power Administration

P.O. Box 3621--EPA

Portland, OR 97208
No. of

Copies
A. J. Caputo
Development Division
Oak Ridge Y-12 Plant
Building 9202 MS-8095
Oak Ridge, TN 37831-8095

N. Clark

Bonneville Power Administration

Industrial Conservation

P.O. Box 3621

Portland, OR 97208

A. Cooke

Martin Marietta Laboratories

1450 South Rolling

Baltimore, MD 21227

J. A. Coppola

Standard Oil Engineered

Materials Company

P.O. Box 156

Niagara Falls, NY 14302

R. Curtis

Materials Development

Corporation

81 Hicks Avenue

Medford, MA 02155

J. V. Day

Kaiser Aluminum and Chemical Corp.

E 2111 Hawthorne Road

Mead, WA 99021

D. H. DeYoung

Alcoa Technical Center

Alcoa Center, PA 15069

S. Diamond

Battelle Columbus Laboratories

505 King Avenue

Columbus, $\mathrm{OH}$ 43201-2693 
No. of

Copies

T. Dwonch

Snake River District BPA

101 W. Poplar

Walla Walla, WA 99362

G. L. Eitel

Stone \& Webster Engineering Corp

Greenwood Plaza Box 5406

Denver, CO 80217

R. Engdahl

Deposits and Composites, Inc.

318 Victory Drive

Herndon, VA 22070

J. F. Elliott

MIT

Room 4-138

77 Massachusetts Avenue

Cambridge, MA 02139

B. G. Epstein

A. D. Little, Inc.

955 Lenfant Plaza SW 4200

Washington, DC 20024-2119

J. W. Evans

University of California

Dept of Matl. Sci. and Mineral

Eng.

Berkeley, CA 94720

R. A. Fenimore

ICI Advanced Materials

Rollins Building, Eighth Floor

Wilmington, DE 19897

D. A. Figgins

ARCO Petroleum Products Co.

P.O. Box 61004

Anaheim, CA 92803-6104
No. of

Copies

P. Foster

Alcoa Laboratories

P.O. Box 772

New Kensington, PA 15068

J. Gee

Great Lakes Research Corp

P.O. Box 1031

Elizabethton, TN 37643

T. Gilligan

Eltech Systems Corp.

625 East Street

Fairport Harbor, OH 44077

W. M. Goldberger

Superior Graphite Co.

120 S. Riverside Plaza

Chicago, IL 60606

J. Goodwell

Center for Metals Production

Mellon Institute

4400 Fifth Avenue

Pittsburgh, PA 15213

J. Gregg

Eltech Research Corporation

625 East Street

Fairport Harbor, OH 44077

J. A. S. Green

Martin Marietta Laboratories

1450 South Rolling

Baltimore, MD 21227

C. Griffin

Ceramatec Inc.

2425 S. 900 West

Salt Lake City, UT 84119 
No. of

Copies

L. I. Grindstaff

Great Lakes Research Corp.

P.O. Box 1031

Elizabethton, TN 37643

J. Haggerty

MIT

Building 12, Room 009

77 Massachusetts Avenue

Cambridge, MA 02139

I. L. Harry

Electric Power Research

Institute

P.O. Box 10412

Palo Alto, CA 94303

W. E. Haupin

2820 7th Street Road

Lower Burrell, PA 15068

R. Hill

Union Carbide Corp.

P.O. Box 94637

Cleveland, OH 44101

H. F. Hillegass

Alcoa Wenatchee Works

P.O. Box 221

Wenatchee, WA 98807

D. G. Howitt

College of Engineering

University of California, Davis

Davis, CA 95616

F. R. Huettig

Advanced Magnetics, Inc.

45 Corey Lane

Medham, NJ 07945
No. of

Copies

G. R. Hyde

U.S. Bureau of Mines

2401 "E" Street N.W.

Washington, DC 20241

S. C. Jacobs

Primary Processing

Aluminum Company of America

Alcoa Technical Center

Alcoa Center, PA 15069

S. H. Jan

Tennessee Valley Authority

R\&D Division - MR 3A

Chattanooga, TN 37401

N. Jarrett

149 Jefferson Avenue

New Kinsington, PA 15068

J. Johnson

Intalco Aluminum Company

P.O. Box 937

Ferndale, WA 98248

L. Joo

Great Lakes Research Corp.

P.O. Box 1031

Elizabethton, TN 37643

M. Karmous

Oregon State Department of

Energy

625 Marion Street, N.E.

Salem, OR 97310

R. Keller

RD 3 Roundtop Road

Export, PA 15632 
No. of

Copies

C. W. Koerr

The Stackpole Corporation

Cermag Division

201 Stackpole Street

St. Marys, PA 15847

K. Krupinski

Aristech Research

1000 Tech Center Dr.

Monroeville, PA 15146

G. Y. Lai

Cabot Corporation

P.O. Box 9013

Kokomo, IN 46902-9013

R. A. Landy

Director of Research

North American Refractories Co.

3127 Research Dr.

State College, PA 16801

J. E. Lane

Ceramic Research and

Development Center

Westinghouse Electric Corp.

1310 Beulah Road

Pittsburgh, PA 15235

S. K. Lau

Standard Oil Engineered

Materials Company

Niagara Falls R\&D Center

P.O. Box 832

Niagara Falls, NY 14302

J. J. Leddy

Dow Chemical U.S.A.

1776 Building

Midland, MI 48640
No. of

Copies

W. W. Liang

Gas Research Institute

8600 West Bryne Mawr Avenue

Chicago, IL 60631

W. H. Link

Columbia Aluminum Corp.

85 John Day Dam Road

Goldendale, WA 98620

S. Loftness

Washington State Energy Office

400 E. Union

Olympia, WA 98504

W. Long

Building B815

Dow Chemical

Freeport, TX 77541

A. G. Longmuir

Kaiser Aluminum and Chemical Corp.

P.O. Box 877

Pleasanton, CA 94566

R. A. Lowden

Metals and Ceramics Division

Oak Ridge National Laboratory

P.O. Box X, Bldg, 4515

Oak Ridge, TN 37831-6063

W. N. Maclay

Koppers Company, Inc.

1005 William Pitt Way

Pittsburgh, PA 15238-1336

J. C. McCloskey

Ten Mile River Associates

296 Mt. Hope Street

North Attleboro, MA 02760 
No. of

Copies

G. Mamantov

University of Tennessee

Knoxville, TN 97996

S. C. Manaktala

Manager of Technology

Reduction Division

Kaiser Aluminum and Chemical

Corp.

300 Lakeside Drive

Oakland, CA 94643

V. H. Markant

Du Pont

P.O. Box 787

Niagara Falls, NY 14302

C. J. McMinn

Manufacturing Technology

Laboratory

Reynolds Metals Co.

3326 East 2nd Street

Muscle Shoals, AL 35661-1258

C. H. McMurtry

Standard Oil Engineered Materials Company

Niagara Falls R\&D Center

P.O. Box 832

Niagara Falls, NY 14302

M. A. Mitnick

Avco Specialty Materials

Subsidiary of Textron Inc.

2 Industrial Avenue

Lowell, MA 01851

H. Mortensen

R. Palika

Cercom, Inc.

P.O. Box 70

Vista, CA 92083
No of

Copies

P. Ness

Washington State Dept of Trade and Economic Development

2001 6th Avenue $\# 2600$

Seattle, WA 98121-2522

C. L. Nikias

30010 Via Borica

Rancho Palos Verdes, CA 90274

J. R. Payne

Kaiser Aluminum and Chemical Corp.

P.O. Box 877

Pleasanton, CA 94566

T. Payne

Columbia Falls Aluminum Co.

Columbia Falls, MT

W. Pebley

Oregon Freeze Dry Corp.

525 25th Avenue SW

P.O. Box 1048

Albany, OR 97321

R. D. Peterson

Manufacturing Technology

Laboratory

Reynolds Metals Co. 3326 East 2nd Street

Muscle Shoals, AL 35661-1258

T. R. Pritchett

Kaiser Aluminum and Chemical

Corp.

P.O. Box 877

Pleasanton, CA 94566

W. W. Pritsky

Aluminum Association

90019 th St. N.W.

Washington, DC 20006

Distr.6 
No. of

Copies

S. P. Ray

Alcoa Technical Center

Alcoa Center, PA 15069

Resource Center

Washington State Dept of Trade and Economic Development

20016 th Avenue \#2700

Seattle, WA 98121-2522

J. F. Rhodes

Advanced Composite Materials

Corp.

1525 S. Buncomb Rd.

Greer, SC 29651

N. E. Richards

Manufacturing Technology

Laboratory

Reynolds Metals Co.

3326 East 2nd Street

Muscle Shoals, AL 35661-1258

J. J. Ritter

Ceramics Division

National Bureau of Standards

Gaithersburg, MD 20899

R. C. Rohwedder

3028 Ohio Street Longview, WAD.

R. Sadoway MIT Room 8-109

77 Massachusetts Avenue

Cambridge, MA 02139

W. Scott

Department of Materials

Science \& Engineering

Wilcox Hall FB-10

University of Washington

Seattle, WA 98195
No. of

Copies

D. R. Secrist

Great Lakes Research Corp.

P.O. Box 1031

Elizabethton, TN 37643

A. B. Shah

Noranda Aluminum, Inc.

P.O. Box 70

New Madras, MO 36869

N. Shelton

Intalco

1300 S.W. 5th, Suite 3508

Portland, OR 97201

Brian Spector

Pace Consultants

4848 Loop Central Drive

Houston, TX 77081

F. W. Spillers

Dow Chemical U.S.A.

B-1210 Building

Freeport, TX 77541

R. M. Spriggs

Office of the Director

Center for Advanced

Ceramic Technology

Alfred University

Alfred, NY 14802

D. V. Stewart

Manufacturing Technology

Laboratory

Reynolds Metals Co.

3326 East 2nd St.

Muscle Shoals, AL 35661-1258

D. Strahan

Reynolds Metals Company

P.O. Box 27003

Richmond, VA 23261

Distr.7 
No. of

Copies

A. T. Tabereaux

Manufacturing Technology

Laboratory

Reynolds Metals Co.

3326 East 2nd Street

Muscle Shoals, AL 35661-1258

G. P. Tarcy

Aluminum Company of America

Alcoa Technical Center

Alcoa Center, PA 15069

P. Thaure

Alumax, Inc.

5655 Peachtree Parkway

Norcross, GA 30092

W. H. Thielbahr

Conservative Technology

Division

DOE-Idaho Operations Office

785 DOE Place

Idaho Falls, ID 83402

S. Thomson

General Manager

Klickitat PUD

1313 S. Columbus

Goldendale, WA 98620

R. Unger

Merner Research

P.O. Box 248

Ridgewood, NJ 07451
A. Vinnard
Bonneville Power
Administration (KWI)
P.O. Box 3621
Portland, OR 97208

No. of

Copies

T. Von Muller-KWI

Bonneville Power Administration

P.O. Box 3621

Portland, OR 97208

D. H. Weinblatt

AIMCOR

One Parkway North

Deerfield, IL 60015

J. D. Weyand

EG\&G Idaho, Inc.

Idaho Falls, ID 83415

B. Wilcox

Northwest Aluminum Co.

3313 W. Second St.

The Dalles, OR 97058

C. B. Wilson

Dow Chemical U.S.A.

Texas Operations

B-101 Building

Freeport, TX 77541

\section{FOREIGN}

D. Brodie

Comalco Ltd.

55 C.!llins St.

Melbourne,

AUSTRALIA

H. Connor

Group Licensing Controller

Johnson Matthey, plc

New Garden House

78 Hatton Garden

London EC1N 8JP

ENGLAND 
No. of

Copies

T. Kjar

Comalco Ltd.

55 Collins St.

Melbourne,

AUSTRALIA

E. W. Dewing

Alcan International

P.O. Box 8400

Kingston, Ontario

CANADA K7L 4Z4

D. N. MacMillan

Alcan International

C.P. 1250

Jonquieve, Quebec

CANADA G7S 4K8

\section{A. Oye \\ Institute of Inorganic \\ Chemistry \\ Norwegian Institute of \\ Technology \\ University of Trondheim \\ N-7034 Trondheim-NTH, \\ NORWAY}

\section{J. Thonstad \\ Laboratories of Industrial Electrochemistry \\ Norwegian Institute of Technology \\ University of Trondheim \\ N-7034 Trondheim-NTH, NORWAY}

K. O. Vee

ASV Ardal Verk

N-5875 Ardalstargen,

NORWAY
No. of

Copies

E. Frazer

CSIRO Australia

Division of Mineral Products

339 Williamstown Road

P.O. Box 124

Port Melbourne, Vic 3207

ONSITE

DOE Richland Field Office

D. R. Segna

24 Pacific Northwest Laboratory

M. Clement

D. K. Hilliard

G. L. McVay

N. L. Moore

L. G. Morgan

D. M. Strachan

R. W. Westerman

R. E. Williford

C. F. Windisch (10)

Publishing Coordination

Technical Report Files (5) 

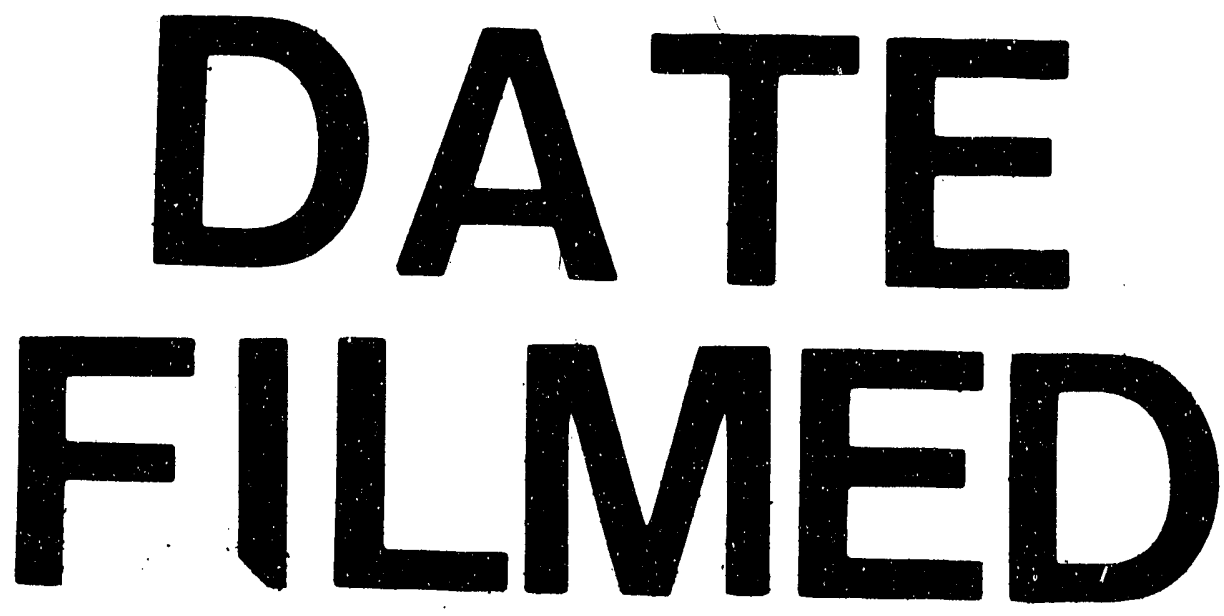

$12 / 21 / 92$ 


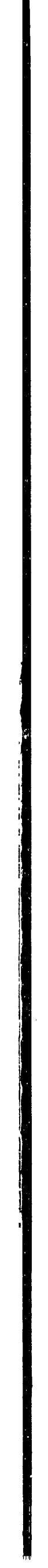

